\title{
WestVirginiaUniversity
}

THE RESEARCH REPOSITORY @ WVU

Graduate Theses, Dissertations, and Problem Reports

2006

\section{Efficacy of in-home Parent -Child Interaction Therapy}

Lisa M. Ware

West Virginia University

Follow this and additional works at: https://researchrepository.wvu.edu/etd

\section{Recommended Citation}

Ware, Lisa M., "Efficacy of in-home Parent -Child Interaction Therapy" (2006). Graduate Theses, Dissertations, and Problem Reports. 2425.

https://researchrepository.wvu.edu/etd/2425

This Dissertation is protected by copyright and/or related rights. It has been brought to you by the The Research Repository @ WVU with permission from the rights-holder(s). You are free to use this Dissertation in any way that is permitted by the copyright and related rights legislation that applies to your use. For other uses you must obtain permission from the rights-holder(s) directly, unless additional rights are indicated by a Creative Commons license in the record and/ or on the work itself. This Dissertation has been accepted for inclusion in WVU Graduate Theses, Dissertations, and Problem Reports collection by an authorized administrator of The Research Repository @ WVU.

For more information, please contact researchrepository@mail.wvu.edu. 
Efficacy of In-Home Parent-Child Interaction Therapy

Lisa M. Ware, M.A.

\author{
Dissertation submitted to the \\ Eberly College of Arts and Sciences \\ at West Virginia University \\ in partial fulfillment of the requirements \\ for the degree of
}
Doctor of Philosophy
in
Psychology
Cheryl B. McNeil, Ph.D., Chair Martin L. Boone, Ph.D. Barry Edelstein, Ph.D. Katherine H. Karraker, Ph.D. Tracy L. Morris, Ph.D.
Department of Psychology

\author{
Morgantown, West Virginia \\ 2006
}

Keywords: Parent-Child Interaction Therapy, Home-Based Interventions 


\section{ABSTRACT \\ Efficacy of In-Home Parent-Child Interaction Therapy}

Lisa M. Ware

In recent years, there has been much discussion of the efficacy and effectiveness of mental health interventions for children as well as the transportation of empirically-supported treatments (ESTs) to field settings. While there have been efforts to improve dissemination of ESTs, little research has examined the efficacy of treatments in settings other than the traditional clinic. A logical initial step in this line of research is to examine whether the efficacy of ESTs can be demonstrated in community settings such as in the home environment. There are many hypothesized benefits to providing services in the home setting. Based on the promise of this approach, there are a multitude of home-based programs focused on an array of child outcomes (e.g., child development, child health, child abuse prevention) with various levels of success. Despite the potential of this treatment modality, few ESTs have been evaluated in the home setting. One EST that has examined efficacy in the home setting is Behavioral Parent Training (BPT). Parent-Child Interaction Therapy (PCIT) is one such BPT program designed to help families of children with disruptive behavior problems. The purpose of the study was to examine the efficacy of an in-home PCIT program using a single-subject, A/B design across subjects with staggered baselines. Five caregiver-child dyads were recruited for the study, and three completed treatment. Decreases in caregiver use of negative behavior and caregiverreported child behavior problems were observed for completers. In addition, completers demonstrated increases in child compliance, caregiver use of positive behavior, and contingent praise. Data regarding caregivers' reported parenting stress and caregiver proportion of direct commands was less convincing. All three dyads completing treatment reported satisfaction with the intervention. Clinical implications and future research directions are discussed. 


\section{Acknowledgements}

First, and foremost, I would like to gratefully acknowledge my committee chair and advisor, Dr. Cheryl McNeil. She has been a source of support, encouragement, and guidance during this project as well as throughout my graduate school experience. I am proud to know her as a person, colleague, and friend. To my committee members, Drs. Martin Boone, Barry Edelstein, Katherine Karraker, and Tracy Morris, I extend my gratitude for their valuable input and helping to improve upon the study. I would like to thank Sarah Stevens and Maureen Conley for their dedication in executing this study in participants' homes during the hot summer months in Morgantown. In addition, I would like to thank the following colleagues for their support and assistance throughout the dissertation process: Dr. Beverly Fortson, Dr. Georganna Sedlar, Dr. Dawn Blacker, Heather Risk, Yi-Chuen Chen, and Jennifer Tiano.

Conducting a dissertation project from across the country is not without its unique challenges. Josh Masse served as the bridge between myself and this study and his tireless dedication and hard work were essential to the successful completion of this project.

I would like to thank the families who participated in this study. They invited therapists into their homes and subjected themselves to a considerable amount of scrutiny. Without their participation it can truly be said that the study could not have been completed.

Finally, I would like to thank my family. My husband, Todd Ware, has been selfless in his support of this project and my career and for that I am truly grateful. My mother, Maria Whitney, and my late father, Mark Whitney, have instilled in me the value of education. For their love and unconditional support I will be eternally grateful. 


\section{Table of Contents}

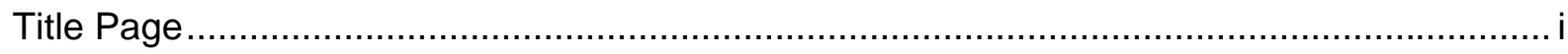

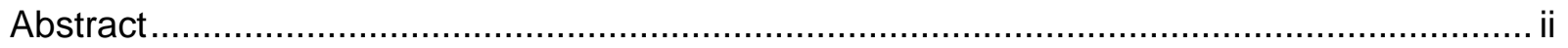

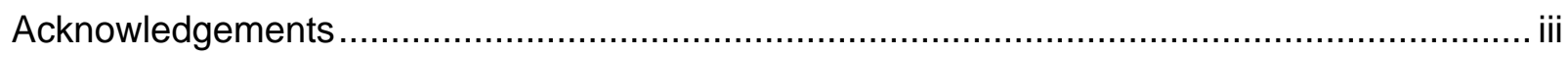

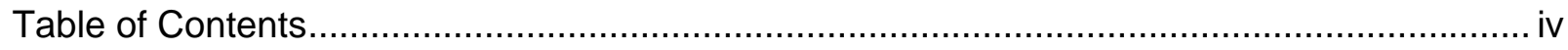

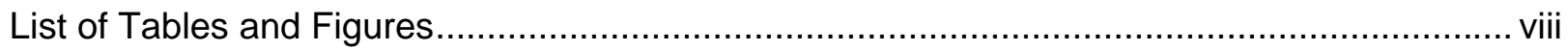

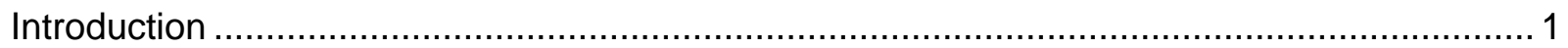

Transportability of Empirically-Supported Treatments to Field Settings .................... 2

Advantages of Home-based Interventions ..................................................... 2

Attrition within home-based interventions ............................................ 2

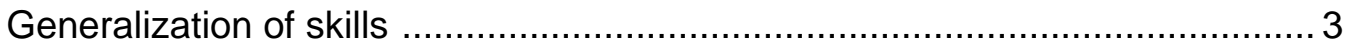

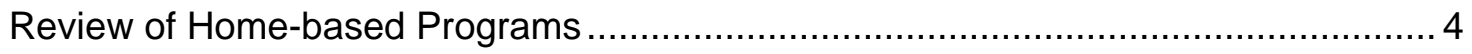

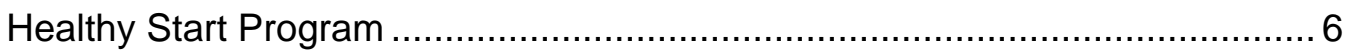

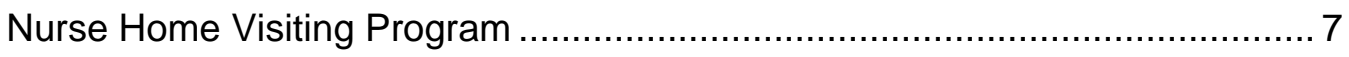

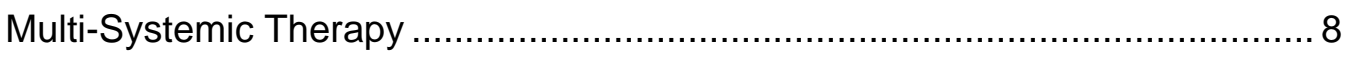

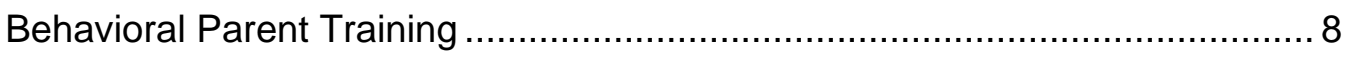

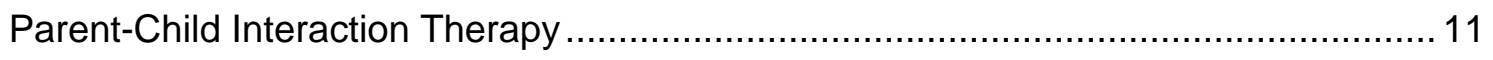

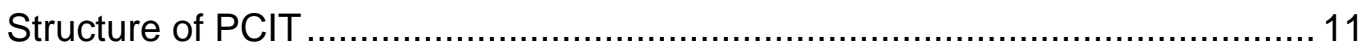

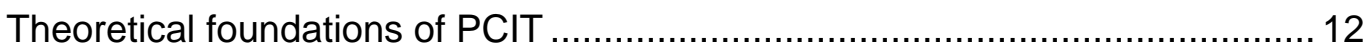

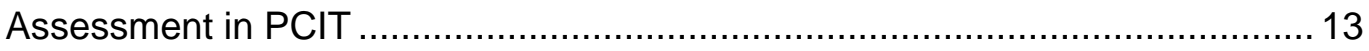

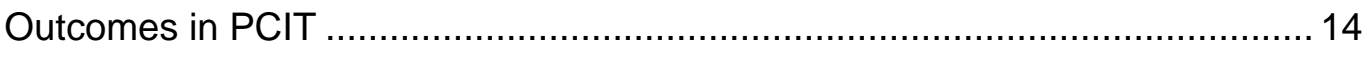

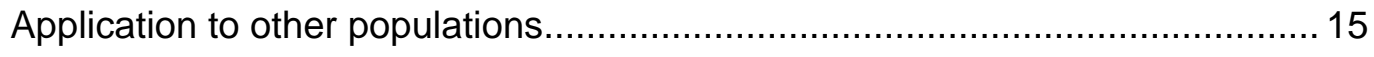

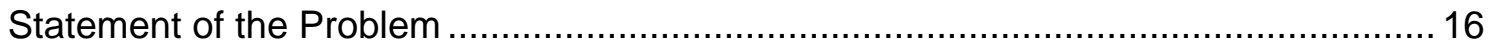

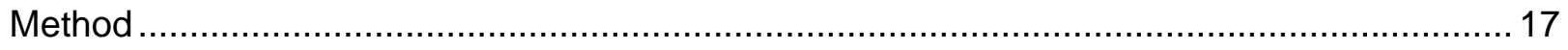

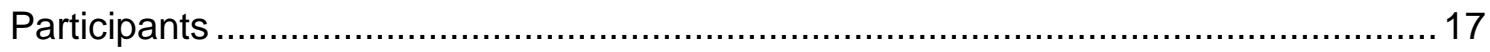

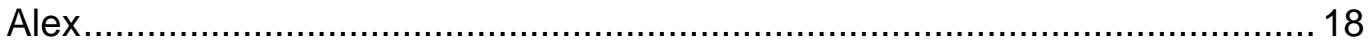




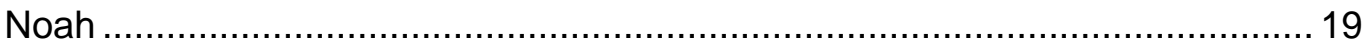

Tami

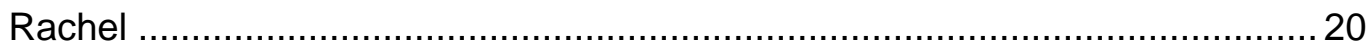

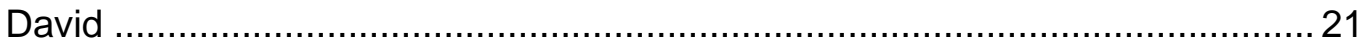

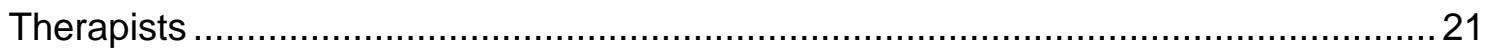

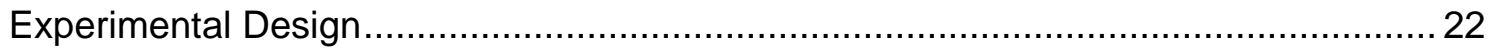

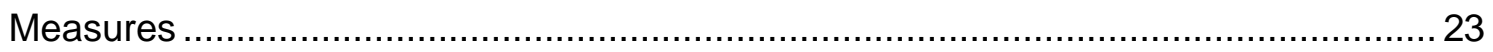

Child Behavior Checklist - Aggression subscale......................................... 23

Dyadic Parent-Child Interaction Coding System - II...................................... 24

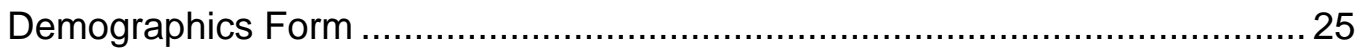

DSM-IV Structured Interview for Disruptive Behavior Disorders ...................... 25

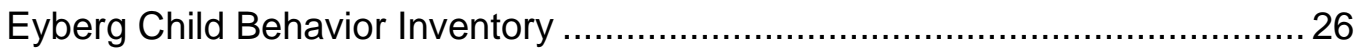

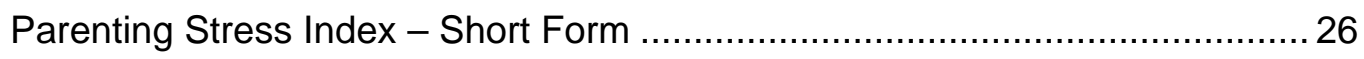

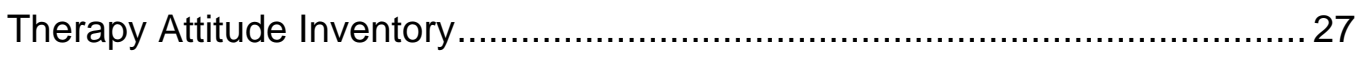

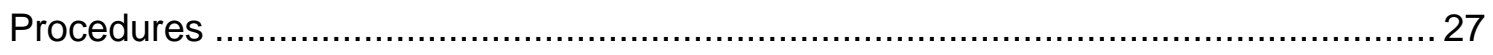

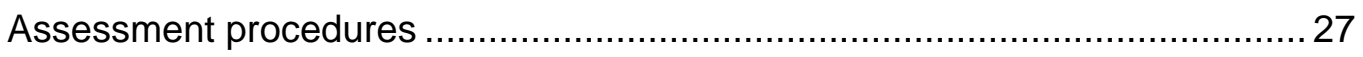

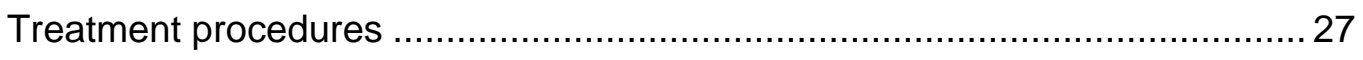

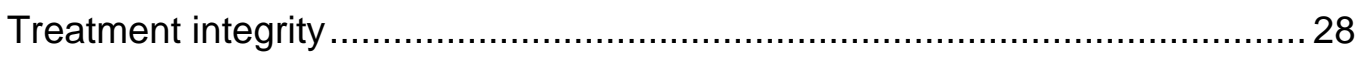

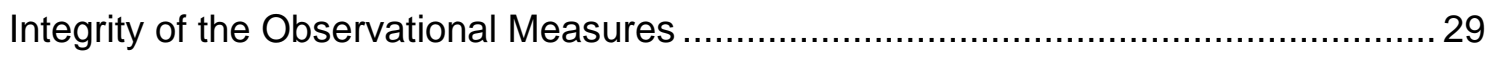

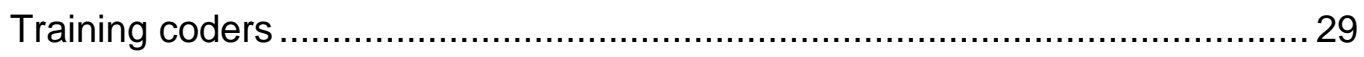

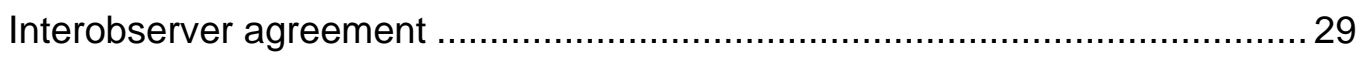

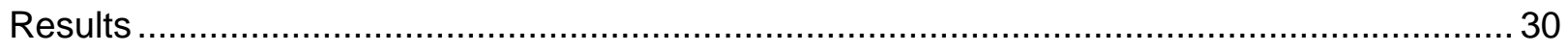

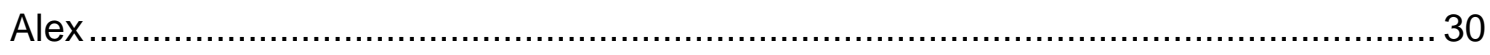

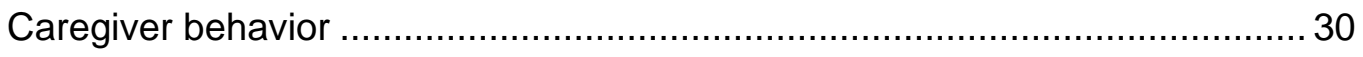

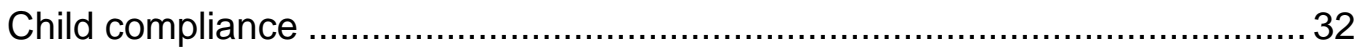

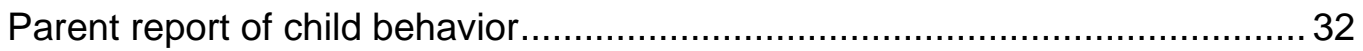




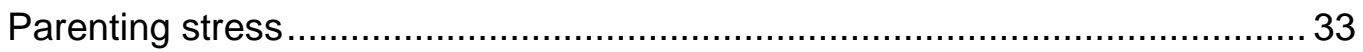

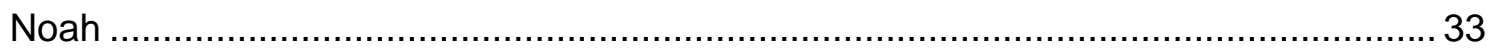

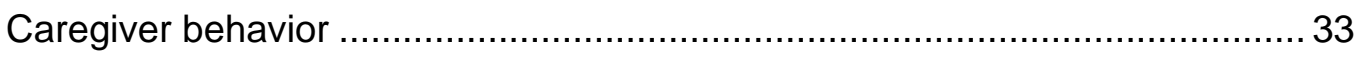

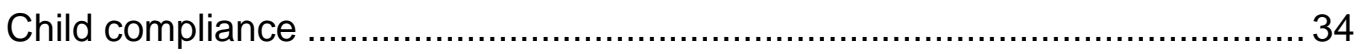

Parent report of child behavior.......................................................... 35

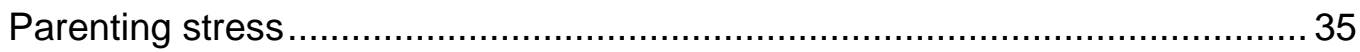

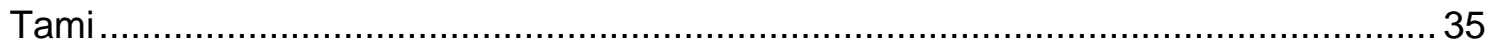

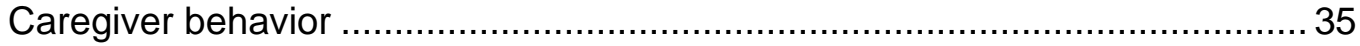

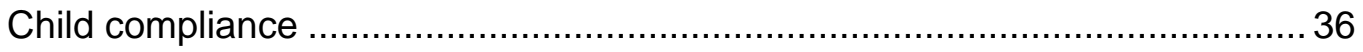

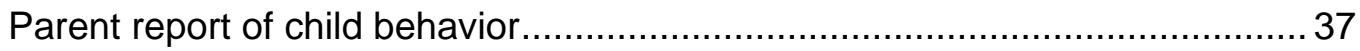

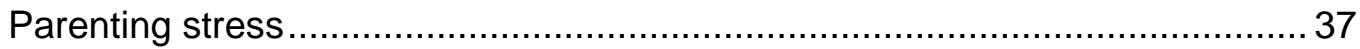

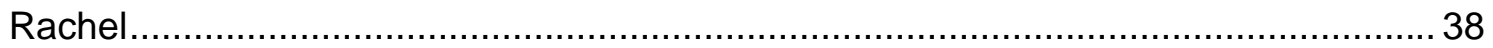

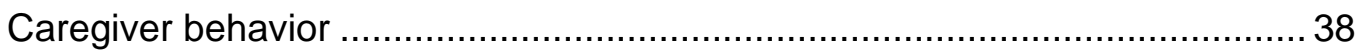

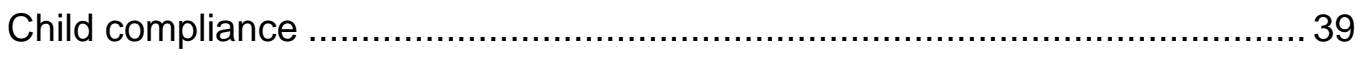

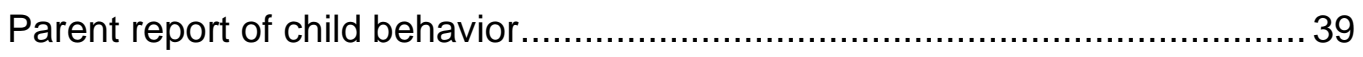

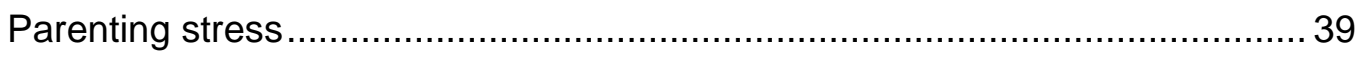

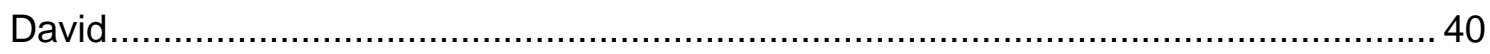

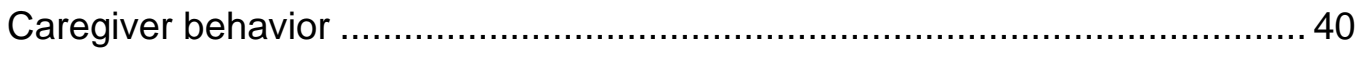

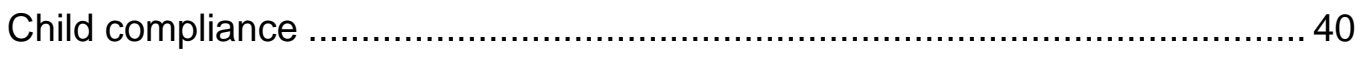

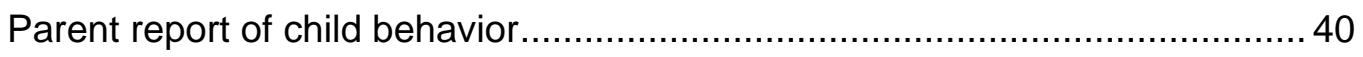

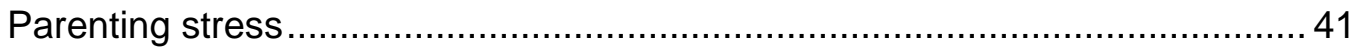

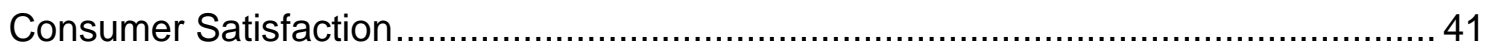

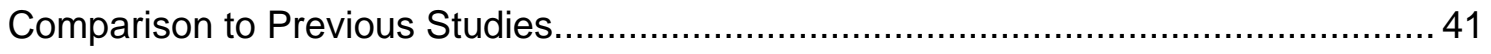

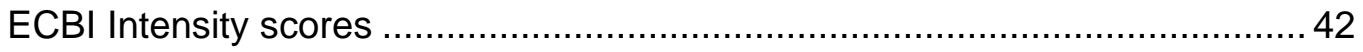

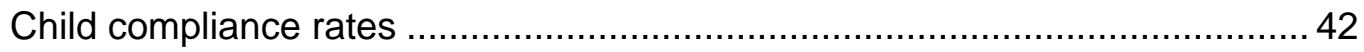

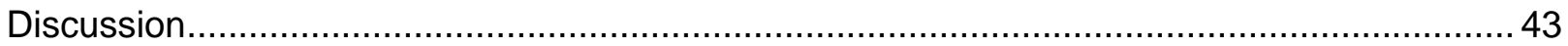




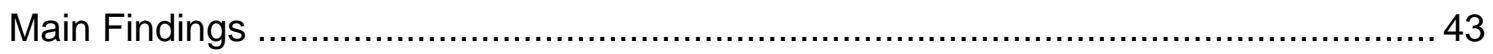

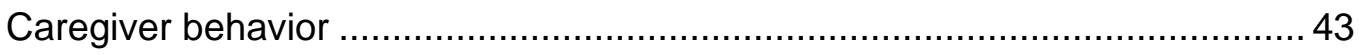

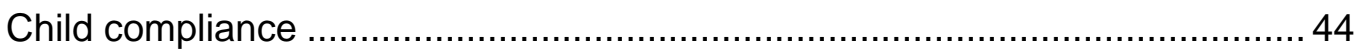

Parent report of child behavior ...................................................................... 44

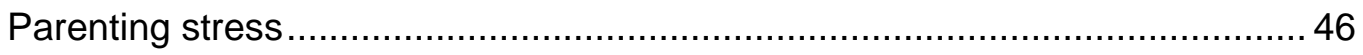

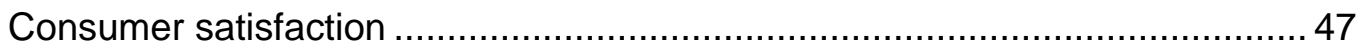

Additional Considerations and Future Directions................................................... 47

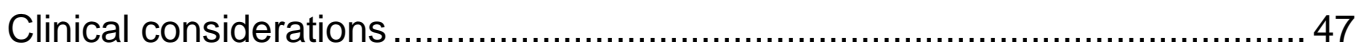

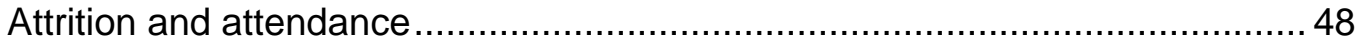

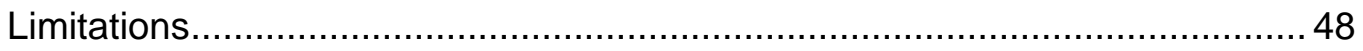

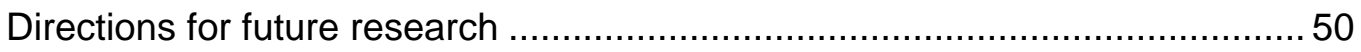

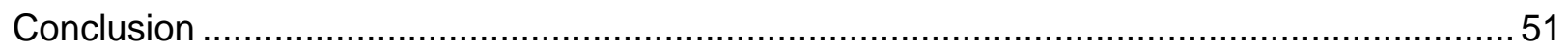

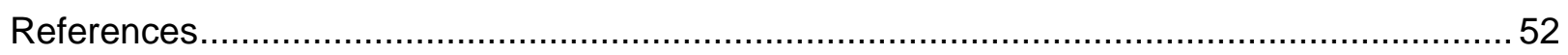

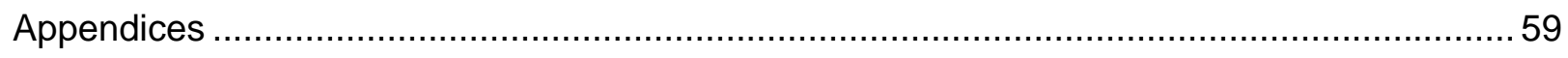

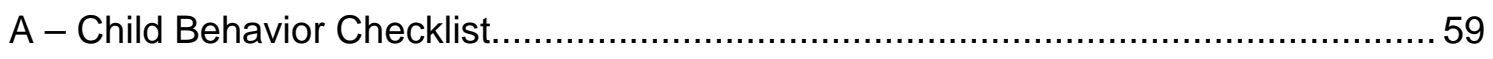

B - Dyadic Parent-Child Interaction Coding System Instructions for Caregivers ......... 60

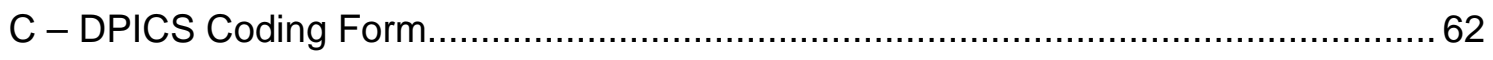

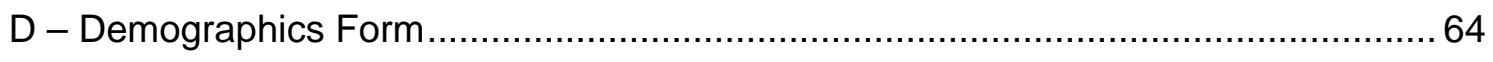

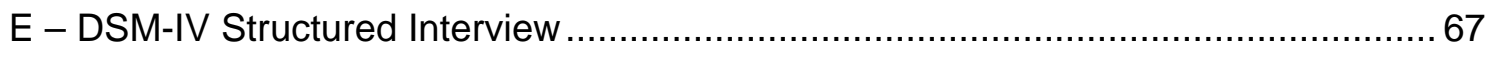

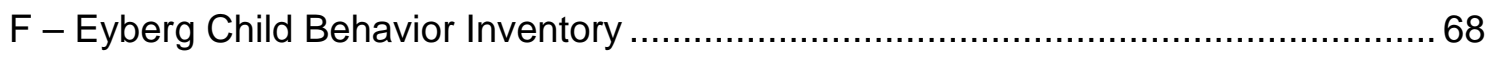

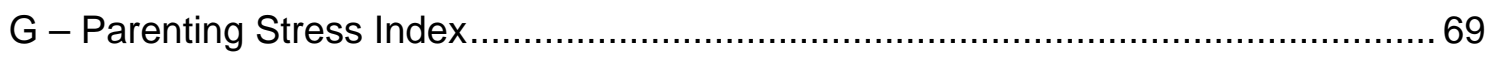

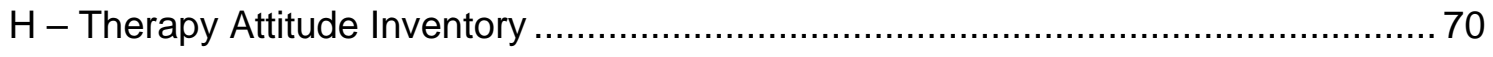

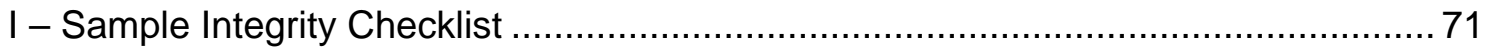




\section{List of Tables}

Table 1. Dependent Variables, Measures, and Assessment Points ................................... 75

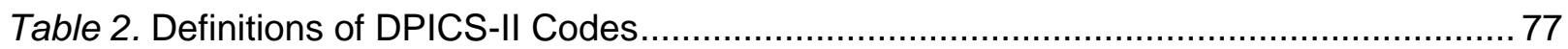

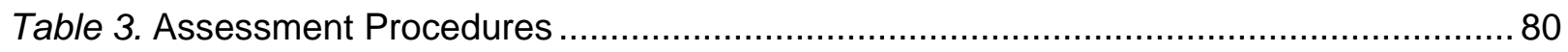

Table 4. Diagnoses of Participants Based on Caregiver Report on the DSM-IV Structured

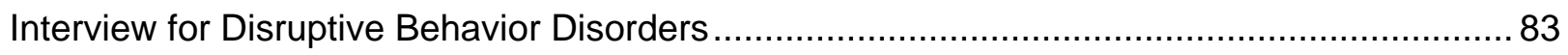

Table 5. ECBI Intensity Scores for the Present Study and Other PCIT Outcome Studies........ 84

Table 6. Child Compliance Rates for the Present Study and Other PCIT Outcome Studies.... 85 


\section{List of Figures}

Figure 1. Caregiver positive behavior exhibited by caregivers who completed treatment (i.e., Alex, Noah, Tami) with horizontal lines indicating means for each phase 86

Figure 2. Caregiver negative behavior exhibited by caregivers who completed treatment with horizontal lines indicating means for each phase

Figure 3. Proportion of direct commands exhibited by caregivers who completed treatment with horizontal lines indicating means for each phase..... 88

Figure 4. Contingent praise exhibited by caregivers who completed treatment with horizontal lines indicating means for each phase 89

Figure 5. Child compliance rates exhibited by children who completed treatment with horizontal lines indicating means for each phase 90

Figure 6. ECBI Intensity scores reported by caregivers who completed treatment with horizontal lines indicating means for each phase and dashed horizontal line indicating the cutoff for clinical significance

Figure 7. ECBI Problem scores reported by caregivers who completed treatment with horizontal lines indicating means for each phase and dashed horizontal line indicating the cutoff for clinical significance

Figure 8. Bar graph of PSI-SF scores reported by caregivers who completed treatment 93

Figure 9. Caregiver positive behavior exhibited by caregivers who terminated treatment prematurely (i.e., Rachel, David) with horizontal lines indicating means for each phase 94 Figure 10. Caregiver negative behavior exhibited by caregivers who terminated treatment prematurely with horizontal lines indicating means for each phase 95

Figure 11. Proportion of direct commands exhibited by caregivers who terminated treatment prematurely with horizontal lines indicating means for each phase..... 96

Figure 12. Contingent praise exhibited by caregivers who terminated treatment prematurely with horizontal lines indicating means for each phase 97 
Figure 13. Child compliance rates exhibited by children who terminated treatment prematurely

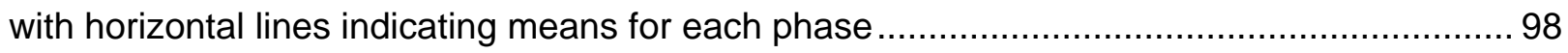
Figure 14. ECBI Intensity scores reported caregivers who terminated treatment prematurely with horizontal lines indicating means for each phase and dashed horizontal line indicating the cutoff for clinical significance 99

Figure 15. ECBI Problem scores reported by caregivers who terminated treatment prematurely with horizontal lines indicating means for each phase and dashed horizontal line indicating the cutoff for clinical significance 100

Figure 16. Bar graph of PSI-SF scores reported by caregivers who terminated treatment prematurely. 101 Figure 17. TAI scores reported by caregivers who completed treatment. 102 


\section{Efficacy of In-Home Parent-Child Interaction Therapy}

In recent years, there has been much discussion of the development and evaluation of empirically supported treatments (ESTs) for children as well as the transportability (e.g., Schoenwald \& Hoagwood, 2001) and dissemination (e.g., Herschell, McNeil, \& McNeil, 2004) of these interventions. Before the argument for widespread dissemination of these interventions can be made; however, transportability must be considered. Transportability refers to the effective implementation of an EST in a community setting. A logical first step in such a line of research would be to examine whether the efficacy of ESTs can be demonstrated in community settings such as in the home. There are many hypothesized benefits to providing services in the home (e.g., Sweet \& Applebaum, 2004). Based on the promise of this approach, there are a multitude of home-based programs focused on an array of child outcomes, with various levels of success (Gomby, Larson, Lewitt, \& Behrman, 1993; Sweet \& Applebaum). Despite the potential of this treatment modality, few ESTs have been evaluated in the home setting. One EST that has examined efficacy in the home setting is Behavioral Parent Training (BPT; e.g., Dadds, Sanders, \& James, 1987).

Parent-Child Interaction Therapy (PCIT; Hembree-Kigin \& McNeil, 1995) is a BPT program that has a solid evidence base demonstrating efficacy for families of children with disruptive behavior disorders (Eisenstadt, Eyberg, McNeil, Newcomb, \& Funderburk, 1993; McNeil, Eyberg, Eisenstadt, Newcomb, \& Funderburk, 1991; Schuhmann, Foote, Eyberg, Boggs, \& Algina, 1998). In addition, the Kaufman Report (Chadwick Center for Children and Families, 2004) recently designated PCIT as one of three intervention protocols considered to be best practices in child abuse treatment. While PCIT has demonstrated great success in the clinic with abusive and nonabusive families and has been implemented in the home as an adjunct service, the effects of in-home PCIT have not been evaluated to date. In the current study, the efficacy of an in-home PCIT program was evaluated using a single-subject, A/B design across subjects with staggered baselines. 
Transportability of Empirically-Supported Treatments to Field Settings

Herschell et al. (2004) provide a review of the dissemination of ESTs for children, an area that clearly is still in its infancy. The review describes the history of this movement and calls for dissemination research to ensure that children are receiving the best possible services the field has to offer. Herschell et al. and others (Shirk, 2004; Silverman, Kurtines, \& Hoagwood, 2004) note, however, that a critical first step in the dissemination of these interventions is the establishment of their transportability or effectiveness in "real-world" settings.

There are many questions that arise when beginning to examine whether a particular EST can be transported successfully into a community setting, including feasibility and acceptability by community mental health professionals; but, a logical first step is to examine whether their efficacy can be demonstrated in community settings such as in the home. The hypothesized benefits to providing services in the home have been reviewed in the literature. Advantages of Home-based Interventions

Sweet and Applebaum (2004) outlined several advantages of home-based service delivery in their meta-analysis of home visiting programs for families with young children. Homebased services may decrease some of the barriers to treatment such as lack of transportation and child care, and reduce the amount of time taken off from work by caregivers. Sweet and Applebaum further suggested that these services allow treatment providers to work with the whole family, provide personalized service, individual attention, and rapport building. Other proposed benefits of home visiting include the ability to link families with community referrals (Gomby et al., 1993) and reduce attrition (Gomby, 1999). While there is much discussion of these hypothesized benefits of home-based interventions, there is little empirical support for these claims. An area that has received the most attention in the home-based intervention literature is attrition and the retention of participants.

Attrition within home-based interventions. While one of the arguments for providing services in the home is reduced attrition rates, the research has yet to support this assumption. 
In fact, the literature indicates that retaining participants is a problem experienced in homebased programs as evidenced by various articles examining the phenomenon (Daro, McCurdy, Falconnier, \& Stojanovic, 2003; Olds, 2003). A review by Gomby (1999) reported that between $20 \%$ and $67 \%$ of families withdraw from services prior to their completion; however, some theoretical papers on home-based interventions have proposed that the flexibility of caregiver participation in such programs is one of their great advantages (e.g., Daro, 1988; Daro et al., 2003). Despite this argument, providers of in-home services are beginning to examine methods of engaging and maintaining participants (Daro et al.) in a similar way as clinic-based providers. Another potential advantage of home-based services is attenuated generalization of skills. While this area of research has received little attention in the home visiting literature, the technology of generalization has been addressed in the applied behavior analysis literature (e.g., Stokes \& Baer, 1977).

Generalization of skills. Stokes and Baer (1977) discussed the importance of generalization and reviewed various methods of training generalization. The method that appears to lend itself to discussion of generalization within home-based programs is the use of indiscriminable contingencies. Intermittent schedules of reinforcement have been demonstrated to be particularly resistant to extinction. Stokes and Baer note that resistance to extinction is a form of generalization over time. One of the reasons that intermittent schedules result in such strong behavior responses may be due to an inability to discriminate reinforcement and nonreinforcement opportunities. If this argument is extended to training settings, then generalization is more likely to occur if the respondent cannot discriminate between settings in which reinforcement is, or is not, provided. In clinic-based PCIT, for example, a child (or parent) may learn that reinforcement only occurs within the clinic setting and their behavior would likely reflect their ability to discriminate between the two settings (e.g., the child may behave well in the clinic setting and continue exhibiting disruptive behavior in the home environment); however, if parent training were provided within a home setting, the child would be less likely to 
discriminate in which setting reinforcement occurs, thereby increasing generalization (although one could argue that the child may discriminate between the presence or absence of the therapist).

A related article, by Stokes and Osnes (1989), stated that a conceptual flaw of the Stokes and Baer (1977) article was that generalization was characterized topographically rather than functionally. Stokes and Osnes expanded on the classification system presented by Stokes and Baer and categorized programming strategies for generalization into three categories: (1) Exploit current functional contingencies, (2) Train diversely, and (3) Incorporate functional mediators. The most relevant to the discussion of home-based services is the incorporation of functional mediators including the incorporation of common salient physical stimuli and common salient social stimuli. Clearly, by conducting the intervention in the home setting, the physical stimuli will be virtually identical between the training and generalization settings. Further, it is possible that social stimuli may be similar in the training and generalization environments. Given the hypothesized benefits reviewed above, many home-based interventions have been developed and implemented.

Review of Home-based Programs

There are estimated thousands of home visitation programs operating in the United States (Gomby, Culross, \& Behrman, 1999), and these programs appear to be more different than they are alike. While they share a common service modality (i.e., providing services in the home setting), they vary on a considerable number of variables including intervention goals (e.g., child health outcomes, child abuse prevention) and structure (e.g., time-limited intervention, assessment and referral), population served, and type of staff (i.e., professional, paraprofessional). Home-based programs also may differ in the degree to which they are "home-based." Some programs provide all services in the home setting, while other programs offer in-home services as an adjunct to other interventions. This level of variability has made comparisons across programs difficult, although investigators have attempted to provide 
analyses of such programs (e.g., Gomby et al., 1993; Sweet \& Applebaum, 2004).

The review by Gomby et al. (1993) limited its scope to those programs that utilized experimental designs for evaluation. Results suggested that the programs that achieved significant benefits were those that had a broad intervention scope. These programs have demonstrated success with child development outcomes and more limited success with child health outcomes. Areas in which the home visiting programs failed to demonstrate gains were prevention of poor birth outcomes and prevention of child abuse. Overall, programs that were augmented by other services (e.g., center-based services, medical services) fared better in the analysis.

Sweet and Applebaum (2004) conducted a meta-analysis of home visiting programs for families with young children. This review did not limit its scope based on research design as in the Gomby et al. (1993) review. Instead, this review included home visiting programs conducted after 1965 in the United States in which home visitation was the primary intervention. Programs targeting special populations such as chronically ill and physically challenged children were excluded as the authors believed these programs to be systematically different. The vast majority of programs reported that their primary goals were parent education and child development. Parent education included parent-child interaction skills, behaviors, parenting skills, and attitudes. Child development goals were broadly defined as any attempts to improve the child's well-being. Other primary goals reported by the reviewed programs included direct health care, child abuse prevention, parent social support (e.g., providing social resources), parent self-help (e.g., raising parents' self-competence), and parent self-sufficiency (e.g., job training).

Results of the meta-analysis by Sweet and Applebaum (2004) suggested that families benefited from home visiting programs in the following areas: parenting attitudes and behavior, parent education (i.e., parent's returning to school), child cognitive and socioemotional outcomes, and decreased actuality or possibility of abuse. Of note, however, is that while these 
results are statistically significant, the authors note that the majority of the outcomes had small effect sizes (i.e., less than .20). Based on the results of their meta-analysis, Sweet and Applebaum concluded that the utility of home visiting programs cannot be clearly stated, and although it appears that some families benefit from these services, further research is needed to clarify and specify what makes home visiting programs successful.

The broad scope of home-based programs makes a comprehensive review impossible; therefore, the home-based programs that have received the most attention in the literature and most relevant to working with families and children will be reviewed briefly. These include Healthy Start/Healthy Families, the Nurse Home Visitation Model, Multi-systemic Therapy, and Behavioral Parent Training Programs.

Healthy Start Program. The Healthy Start Program (HSP) is a statewide program in Hawaii supported by the Hawaii State Department of Health (Duggan et al., 2004). The Healthy Start Program model includes screening and assessment to identify families at risk for child abuse and provision of home visiting services for those families identified as being at risk (Duggan et al.). Assessments generally take place at the hospital when children are born and include a review of the mother's medical record and sometimes include a semi-structured interview (i.e., Kempe's Family Stress Checklist; Kempe, 1976) for further assessment of risk factors. The family is determined to be eligible for the program if they score 25 or higher on the Kempe Family Stress Checklist and are not currently involved with child protective services for the target child. Home visitors in the HSP are paraprofessionals with a minimum education of a high school diploma or equivalent. Home visitors work under the supervision of a professional at the bachelor's or master's level.

A wide array of services is provided by home visitors in the HSP including crisis management, modeling problem-solving, helping families access needed referrals (e.g., domestic violence support, parental substance abuse treatment), parenting education, and modeling effective parent-child interactions. The method of implementing these services is 
unclear as each program site determines its own curricula (Duggan et al., 2004).

At the time of the Duggan et al. (2004) randomized trial, approximately $70 \%$ of births in Hawaii were assessed with $20 \%$ of families determined to be at risk for child abuse. Of these families, the HSP was able to offer services to $40 \%$ of families based on funding availability. Duggan et al. conducted a randomized trial of the effectiveness of the HSP. Results suggested that the HSP was not successful in preventing child abuse. In addition, there were no differences between mothers participating in the HSP and mothers in the control group related to acceptance of their children's behavior, their use of nonviolent discipline, or in their observed emotional responsiveness to their children; however, HSP mothers were less likely to report neglectful behaviors. Overall, the authors concluded that the HSP failed to demonstrate effectiveness with regard to the proposed outcomes.

Nurse Home Visiting Program. In the Nurse Home Visiting Program (NHVP; Olds, Kitzman, Cole, \& Robinson, 1997) nurses provide low-income, first-time mothers with services aimed at improving pregnancy outcomes, child development and health, and promoting caregiver personal development (e.g., obtaining employment, returning to school). Visitation begins during pregnancy and continues until the child becomes 2 years of age. Visits are 75 to 90 minutes in length and are conducted once a week or every two weeks based upon the needs of the family. Assessments of caregiver, child, and family functioning are utilized to guide interventions. Other services provided by the home visitor include strengthening the caregiver's social support network (e.g., family, friends) and providing relevant community referrals.

Olds and colleagues (Olds et al., 2002) have subjected the NHVP to rigorous testing through the use of randomized clinical trials. Results suggest that the NHVP has been successful in the demonstration of targeted outcomes including increases in parental care of children (e.g., fewer injuries sustained, enhanced language development) and improvement of maternal life course (e.g., fewer pregnancies, gaining employment). Long-term outcome research of the NHVP suggests that children of mothers who participated in the program had 
fewer arrests and convictions, and were less likely to use substances or become sexually promiscuous when compared to children of mothers who did not participate in the program (Olds, 2006).

Multi-Systemic Therapy. Multi-systemic therapy (MST; Henggeler, Schoenwald, Borduin, Rowland, \& Cunningham, 1998) is an evidence-based intervention designed for antisocial youth. MST is theoretically based on Bronfenbrenner's ecological model in which the client is viewed within the context of his or her community. MST integrates a variety of empirically-based techniques including behavioral parent training and cognitive behavioral therapy. As MST is an ecologically-based program, a home-based method of service delivery was deemed to be the most logical by MST developers. However, developers note that while MST is similar to other home visiting programs due to the method of service delivery, there are significant differences including the purpose of intervention, treatment provided, and outcomes (Schoenwald \& Henggeler, 1997). Another way in which MST varies from typical home-based interventions is that MST providers are trained to conceptualize each case and take part in hypothesis testing regarding reasons for client improvement, barriers to change, and potential causes of problem behavior and related factors.

The efficacy of MST has been demonstrated in several rigorous randomized clinical trials (see Henggeler, 1999 for review). Outcomes examined include improved parent-child relations (Brunk, Henngeler, \& Wheelan, 1987), recidivism reduction among violent and chronic juvenile offenders (Borduin et al., 1995; Henggeler, Melton, \& Smith, 1992, Henggeler, Melton, Brondino, Scherer, \& Hanley, 1997), and reduction of drug and alcohol-related outcomes (e.g., self-reported substance use, substance-related arrests; Henngeler et al., 1991).

Behavioral Parent Training. Behavioral parent training to address child disruptive behavior disorders is an intervention that has been designated as a "well-supported" intervention in reviews conducted by the Section on Clinical Child Psychology (see the Journal of Clinical Child Psychology Volume 27) and Chorpita and colleagues (2002). This designation 
indicates that the intervention is supported by at least two group design studies that were conducted by different researchers or by a large series of single case design studies. There are a multitude of different parent training programs with research in this area beginning in the 1960s. One exemplar of this work is a single-subject design conducted by Wahler, Winkel, Peterson, \& Morrison (1965) in which they demonstrated that modification of mothers' reactions to their children's behavior resulted in child behavior change. Similarly, Hawkins, Peterson, \& Schweid (1966) trained the mother of a 4-year-old boy to provide behavior management for her child resulting in reduction of disruptive behaviors. Commonly used parent training programs include Forehand and McMahon's (1981) Helping the Noncompliant Child, Webster-Stratton's (1981) The Incredible Years, Patterson's (Patterson, Reid, Jones, \& Conger, 1975) parent training program, Sanders's (1999) Triple-P Program, and Eyberg's (1988) PCIT. These programs are similar in their view of the parent as the agent of change in child disruptive behaviors and they are based on Hanf's (1969) two-phase model of parent training. In the first phase, parents are taught positive behavior skills and the use of selective attention while the second phase targets noncompliance more directly. With regard to home-based BPT programs, some have evaluated programs completed only in the home (Sanders \& Dadds, 1982), while others have examined the use of BPT programs in the home as an adjunct to clinic-based services (e.g., Worland, Carney, Milich, \& Grame, 1980).

Sanders and Dadds (1982) utilized a single-subject design to analyze the generalization of skills from an in-home BPT program plus Planned Activities Training (PAT). The training setting was the home and generalization settings included additional home and community settings. The home was considered a generalization setting if it differed substantially from the training setting (e.g., family activity, time of day). PAT consisted of teaching the parents skills to prevent child misbehavior such as explaining the rules to their child prior to a given situation and providing activities for their children (e.g., quiet games for children to play while traveling in the car). Based on in-home training, parents were able to demonstrate behavior modification skills 
in both training and generalization settings. However, the authors noted that generalization of increases in positive parent behaviors were less likely than generalization in reductions in aversive parent behaviors.

Worland et al. (1980) examined whether training conducted in the home setting added to the effectiveness of an established group parent-training program. Twenty families participated in the study and were referred for a variety of problems including noncompliance, temper tantrums, and fighting. Families were randomly assigned to one of three groups: (1) group training only, (2) group training plus weekly in-home observations, or (3) group training plus weekly in-home observations plus home training that occurred along with group training. Group training consisted of 2-hour meetings conducted every week for eight consecutive weeks. Parents were taught a variety of behavior management skills including the use of positive reinforcement, differential attention, time-out, and a token economy. Results indicated increases in parent skills and decreases in child disruptive behavior across all three groups with no between group differences. The authors hypothesized that in-home training or the presence of an observer in the home would lead to increased generalization of parent skills and child behavior from the clinic to the home. As no group or group-by-treatment effects were detected on any of the outcome measures, the authors concluded that, "clinic-based treatment need not require additional in-home training to be effective" (p. 23). While it is valid that the authors obtained statistically significant reductions in problem behavior with clinic-based training only, it is possible that the in-home training provided (i.e., four sessions lasting 30 to 45 minutes) was not sufficient to produce hypothesized outcomes with regard to generalization of skills.

In sum, results of the findings from the home-based intervention literature suggest that a variety of programs have been implemented with varying degrees of success. In order to improve upon this literature it is recommended that research making the progression from efficacy to effectiveness be continued as has been done with the NHVP, MST and Behavioral Parent Training Programs. In the proposed study an evaluation of an empirically supported 
treatment (i.e., PCIT) implemented completely within the home setting will be conducted. While this is an efficacy study with many controls in place, it is an important initial step in a line of research to establish the effectiveness of in-home PCIT.

\section{Parent-Child Interaction Therapy (PCIT)}

Structure of PCIT. PCIT is a two-stage Hanf-based (Hanf, 1969) intervention including a relationship enhancement phase (Child Directed Interaction [CDI]) and a discipline phase (Parent Directed Interaction [PDI]). Throughout PCIT skills are taught by coaching the parents while they are interacting with their child in a play situation. During CDI, parents are taught to manage child behavior through use of strategic attention and selective ignoring. In providing appropriate attention, parents are taught to avoid questions, commands, and criticism, which may lead the play or set a negative tone during the interaction. Instead, parents are asked to use a set of skills aimed at relationship enhancement or PRIDE skills when attending to child appropriate behavior. PRIDE skills include Praise (preferably labeled praise), Reflection, Imitation, Description (preferably behavioral description), and Enthusiasm. At the same time, parents are taught to avoid questions, criticisms, and commands during the play. When the child misbehaves (e.g., playing roughly with the toys), parents are taught to ignore by turning their back away from the child and avoiding eye contact.

During PDI, the target behavior is child compliance and parents are taught to use a consistent, predictable discipline program utilizing a time-out procedure still within the context of a play situation. Within the PDI phase of treatment, parents are taught how to give an effective command, determine compliance, and follow through with appropriate consequences for compliance and noncompliance. Child compliance is reinforced by parent use of labeled praise (e.g., "Thank you for listening"). When the child does not comply, the parent is taught to use a highly structured time-out procedure. In this model, time-out does not provide an escape from the original command. The procedure ends only when the child complies with the original command. 
The family proceeds from CDI to PDI only when the parent demonstrates mastery of the CDI skills. CDI mastery criteria is defined as the caregiver's use of the following skills during a 5-minute DPICS-II CDI observation: (a) 10 labeled praises, 10 reflections, and 10 behavioral descriptions; (b) no more than 3 questions, commands, or criticisms; and (c) ignoring of nonharmful inappropriate behaviors. Similarly, treatment is not complete until the parent obtains mastery of the PDI skills and the child's behavior is within normal limits. To meet PDI mastery criteria, during the 5-minute DPICS-II PDI observation the parent must give at least 4 commands, of which $75 \%$ must be effective and the parent must show at least $75 \%$ correct follow-through after effective commands. Each phase of treatment is preceded by a didactic session during which the therapist uses lecture, modeling, role-playing, and handouts to explain the skills to the parent. During subsequent sessions, the parent is coached directly in their use of the skills while interacting with their child. At least 30 minutes of each coaching session is devoted to coaching. In clinic-based PCIT, coaching sessions take place with the parent and child in the therapy room while the therapist observes from behind a one-way mirror. As the parent and child are engaged in play, the therapist coaches the parent by use of a bug-in-theear device. In this way the parent is provided with direct feedback on their behavior during the session. Throughout treatment, parents are assigned homework that generally involves practicing at home the skills they have learned in the clinic. The average number of weekly 1-hr sessions is 13, with a range of 9 to 16 (Schuhmann et al., 1998).

Theoretical foundations of PCIT. Social learning theory maintains that the development and maintenance of child behavior problems takes place within dysfunctional interactions between the parent and child. Patterson and colleagues have described the coercive cycle as a pattern of parent-child interaction among families of children exhibiting behavior problems (Patterson, 1976, 1982). This interaction style is maintained by negative reinforcement. For example, a parent may issue a command to their child to which the child responds by arguing and noncompliance. The parent may withdraw the command (i.e., give up) therefore increasing 
the likelihood that the child will respond to commands with defiance in the future. On some occasions the parent may persist in their attempts to get their child to comply and may escalate to yelling. If the child responds to the escalation (i.e., complies with the command), the chances of the parent using power-assertive techniques to obtain compliance will increase. One way that PCIT uses behavioral principles to alter such aversive interactions is by teaching parents to use a consistent discipline program including a time-out procedure. The behavioral basis of PCIT is further evidenced by the use of operant procedures (e.g., positive reinforcement, extinction, punishment). Indeed, Greco, Sorrell, and McNeil (2001) suggested that a comprehensive understanding of the contingencies of reinforcement is important for success as a PCIT therapist.

In addition to the social learning foundation, Baumrind's $(1967 ; 1991)$ research describing parenting style and child outcomes fits well within the PCIT framework. Research suggests that the authoritative parenting style, characterized by a balance of responsiveness and demandingness, is associated with positive child behavior (Azar \& Wolfe, 1989; Olson, Bates, \& Bayles, 1990; Querido \& Eyberg, 2001). The development of authoritative parenting is encouraged throughout PCIT by maintaining a dual focus on enhancing the parent-child relationship and providing predictable, consistent limit setting.

Assessment in PCIT. Assessment is conducted continuously throughout treatment during PCIT. A comprehensive initial pre-treatment assessment is conducted that typically includes a thorough clinical interview with the caregiver, completion of parent rating questionnaires (i.e., Eyberg Child Behavior Inventory [ECBI; Eyberg \& Pincus, 1999; Eyberg \& Ross, 1978], Child Behavior Checklist [Achenbach \& Edelbrock, 1981], Parenting Stress Index [Abidin, 1995]), and direct observation of parent-child interactions using the Dyadic Parent-child Interaction Coding System - II (DPICS-II; Eyberg, Bessmer, Newcomb, Edwards, \& Robinson, 1994). Assessment continues throughout PCIT by monitoring parent skill at the beginning of each session. This ongoing assessment is essential because change in parental behavior 
determines the course of progress through PCIT. Finally, at post-treatment, the same pretreatment measures are completed again along with a consumer satisfaction measure (i.e., Therapy Attitude Inventory; Eyberg, 1974).

Outcomes in PCIT. Outcome research evaluating the clinic-based model of PCIT has demonstrated statistically and clinically significant changes in child behavior in the home and school settings based on parent and teacher ratings as well as direct observation (Eisenstadt et al., 1993; McNeil et al., 1991; Schuhmann et al., 1998). Outcome research also has demonstrated change in parent behavior including increases in positive verbalizations (e.g., reflection) and decreases in critical and sarcastic statements (Eisenstadt et al.; Schuhmann et al.). These studies have utilized a number of comparison groups including wait-list controls (McNeil, Capage, Bahl, \& Blanc, 1999; Querido \& Eyberg, 2001; Schuhmann et al.), normal and untreated classroom controls (McNeil et al., 1991), modified treatment groups (Nixon, Sweeney, Erickson, \& Touyz, 2003), treatment dropouts (Edwards et al., 2002), and control groups presenting with various levels of disruptive behaviors (Funderburk, Eyberg, Newcomb, McNeil, Hembree-Kigin, \& Capage, 1998). Generalization research on PCIT outcomes indicates that the behavior of untreated siblings of referred children improves during PCIT (Brestan, Eyberg, Boggs, \& Algina, 1997; Eyberg \& Robinson, 1982). In addition, parents report lower levels of personal distress, increased parenting self-efficacy, and a reduction in psychopathology after treatment (Eyberg, Boggs, \& Algina, 1995; Eyberg \& Robinson).

Maintenance of the effects of PCIT has been demonstrated in both short-term and longterm studies. Short-term follow up studies (under 1 year) have found maintenance on a number of variables including observed parent behavior (e.g., praise, criticism) and child behavior (i.e., compliance), parent report of disruptive behaviors, and parent self-report of stress, competence, and control (Eisenstadt et al., 1993; Nixon et al., 2003; Querido \& Eyberg, 2001). One - and 2year maintenance studies have stability in observed parent behavior, child compliance, and parent report of disruptive behaviors (Eyberg, Funderburk, Hembree-Kigin, McNeil, Querido, \& 
Hood, 1991). In addition, these longer-term studies have found maintenance in teacher report of disruptive behavior as well as classroom observation of child compliance (Funderburk et al., 1998). Boggs et al. (2004) conducted a controlled 1- to 3- year follow up study of PCIT comparing 23 treatment completers to 23 treatment noncompleters. Results indicated that parents who completed treatment reported less disruptive behaviors than those who dropped out of treatment prematurely. Hood and Eyberg (2003) found that parent report of child disruptive behavior was maintained or demonstrated behavioral gains at 3- to 6-year follow up. In addition, parent perception of their control over child behavior maintained over time.

Application to other populations. While PCIT was clearly developed for use with families of children with disruptive behavior problems, it has been applied to other populations with some success. PCIT has been applied to diverse populations including developmental disorders (Eyberg \& Matarazzo, 1980), chronic pediatric illness (Miller \& Eyberg, 1991), childhood internalizing disorders (Choate, Pincus, Eyberg, \& Barlow, 2005), and child physical abuse populations (Urquiza \& McNeil, 1996). Recent research has emerged providing preliminary evidence of the effectiveness of PCIT with abusive populations (Chaffin et al., 2004; Timmer, Urquiza, Zebell, \& McGrath, 2005; Urquiza, Timmer, McGrath, Zebell, \& Herschell, 2006).

Chaffin et al. (2004) conducted an efficacy study examining the effects of PCIT on recidivism in a sample of maltreating families. The study compared three treatment groups: (1) PCIT, (2) Enhanced PCIT, and (3) a community-based parenting group. Enhanced PCIT consisted of traditional PCIT in the clinic plus individualized services for a variety of issues including parental depression, substance abuse, and domestic violence. In addition, families in the Enhanced PCIT condition did receive home visits that included helping the parent implement PCIT skills; however, only 55\% of participants received this service. Chaffin et al. reported that Enhanced PCIT (including some PCIT conducted in the home) was not comparable to the classic PCIT coaching sessions that occur in the clinic. Recidivism data revealed that $19 \%$ of participants in the PCIT condition had a re-report compared to 36\% in the Enhanced PCIT 
group and $49 \%$ in the community-based group. Chaffin and colleagues found that adding services to PCIT did not improve outcome and may have actually attenuated outcome. Sufficient data were not collected on the in-home PCIT component of this program to reach any definitive conclusions as to its efficacy. To date there have been no studies of the efficacy of inhome PCIT.

\section{Statement of the Problem}

While the child treatment outcome literature has made great strides in the development, evaluation, and dissemination of ESTs, few of these interventions have laid the foundation for transportability research by demonstrating efficacy in community settings such as the home. The purpose of this study was to contribute to this emerging literature by examining the efficacy of an in-home PCIT program using a single-subject, A/B design across subjects with staggered baselines. Specific hypotheses tested included:

1. Caregiver behavior. It was hypothesized that implementation of in-home PCIT would result in observable changes in caregiver behavior across treatment phases.

(a) Caregiver use of positive behavior (i.e., labeled praise, behavioral description, reflection) will increase across the CDI phase of treatment as measured by the Dyadic ParentChild Interaction Coding System - II (Eyberg et al., 1994). Definitions and examples of these behaviors can be found in Table 2 .

(b) Caregiver use of negative behavior (i.e., questions, commands, criticism) will decrease across the CDI phase of treatment as measured by the Dyadic Parent-Child Interaction Coding System - II (Eyberg et al.). Definitions and examples of these behaviors can be found in Table 2.

(c) Caregiver proportion of direct commands will increase during PDI as measured by the Dyadic Parent-Child Interaction Coding System - II (Eyberg et al.).

(d) Caregiver use of contingent praise will increase during PDI as measured by the Dyadic Parent-Child Interaction Coding System - II (Eyberg et al.). 
2. Child compliance. It was hypothesized that observed child compliance would increase during PDI training as measured by the Dyadic Parent-Child Interaction Coding System - II (Eyberg et al., 1994).

3. Parent report of child behavior. It was expected that the severity of child disruptive behavior as measured by caregiver report on the Eyberg Child Behavior Inventory (Eyberg \& Pincus, 1999; Eyberg \& Ross, 1978) and DSM-IV Structured Interview for Disruptive Behavior Disorders (McNeil et al., 1991) would decrease throughout both CDI and PDI phases of treatment.

4. Parenting stress. Implementation of an in-home PCIT program was hypothesized to be associated with reductions in parenting stress as measured by caregiver report on the Parenting Stress Index - Short Form (Abidin, 1995).

5. Consumer satisfaction. It was hypothesized that in-home PCIT would be an appropriate and acceptable intervention for children with externalizing behavior problems and their families as measured by caregiver report on the Therapy Attitude Inventory (Eyberg, 1974).

Method

\section{Participants}

Participants were recruited from local schools and preschools in a small, university town in West Virginia. Inclusion criteria for the study were as follows: (a) child was between the ages of 2 and 7 (due to PCIT prerequisites), (b) child was exhibiting significant behavior problems as evidenced by a CBCL Aggression subscale score at the 95th percentile or higher and presence of symptoms consistent with a diagnosis of a disruptive behavior disorder as measured by parent report on the Diagnostic and Statistical Manual - Fourth Edition (DSM-IV; American Psychiatric Association, 1994) Structured Interview for Disruptive Behavior Disorders (McNeil et al., 1991), (c) participating caregiver was the primary caregiver and legal guardian of the child, and (d) caregiver agreed to the constraints of the research design (i.e., treatment being conducted in the home, completing assessment questionnaires, possible delay in treatment due 
to the staggered baseline). The first five participants met the selection criteria and were admitted into the study; no families were excluded from the study. Participants were given incentives for their involvement in the study (i.e., \$100 for pre-treatment assessment, \$75 for obtaining mastery criteria during the first phase of treatment, $\$ 75$ for post-treatment assessment, and $\$ 50$ for follow-up assessment). Two participants terminated treatment prematurely, while the remaining three participants completed the entire course of treatment. The children and families are described below using pseudonyms to protect their confidentiality.

Alex. Alex is a 5-year-old Caucasian male who participated in the study with his 30 -yearold biological mother. Alex was recruited for participation from a local Head Start preschool. Alex lives with his 9-year-old sister, biological parents, and paternal grandparents. Alex's father has an associate's degree and is employed as a foreman; his mother is a homemaker and has a bachelor's degree. The household combined annual income was $\$ 20,000-30,000$.

At intake, Alex's mother reported that Alex had difficulty listening, was very active, and was often physically aggressive with his sister and peers at Head Start. Alex's mother was diagnosed with generalized anxiety disorder and depression. When Alex's father was 13 years old, he witnessed his brother (i.e., Alex's uncle) being struck and killed by a car. Alex's father reportedly never received any mental health services following the incident, and it is unclear whether he has existing trauma symptoms. Alex's sister is currently receiving mental health services for anxiety symptoms. Alex has an unremarkable medical history and all of his developmental milestones were met on time.

One chronic stressor for Alex's family was the fact that they lived in the grandparent's home. Throughout the course of treatment, Alex's mother reported distress related to a custom home she and Alex's father were having built. In addition, Alex's mother was involuntarily unemployed for a great portion of the treatment but eventually began a job she enjoyed. Lastly, Alex's mother had a difficult time balancing her schedule between her job, her children, and her own schooling. Overall, the family appeared to be experiencing elevated levels of stress. Alex 
and his mother completed treatment after having participated in three baseline sessions, a CDI didactic session, five CDI coaching sessions, two PDI didactic sessions, six PDI coaching sessions, a post-treatment assessment session, and a follow-up assessment session.

Noah. Noah is a 5-year-old Caucasian male who lived at home with his parents, two older sisters, and older brother. At the time of the study, Noah's mother was unemployed and his father worked as a laborer. Noah's mother had a high school education and his father went to a professional trade school. They reported an annual family income of $\$ 10,000-20,000$. Noah was in Head Start when the study began. Noah's mother reported that he often did not listen, frequently threw objects, and had trouble getting along with his siblings. Noah's mother disclosed that she had a learning disability and mental health concerns (i.e., depression). In addition, Noah's mother reported that Noah's father and all of his siblings have been diagnosed with learning disabilities.

During the course of the study, Noah's family was experiencing a number of stressors. Most significant was the fact that Noah's mother exhibited depressive symptoms and endorsed suicidal ideation with a history of suicide attempts. During the study, Noah's mother was receiving intensive individual counseling and was prescribed anti-depressants. She stated that her greatest source of stress was her children. Noah's family also experienced financial stress during the study, including being limited to the use of one vehicle. Noah and his mother attended four baseline sessions, a CDI didactic session, seven CDI coaching sessions, two PDI didactic sessions, eight PDI coaching sessions, a post-treatment assessment session, and a follow-up assessment session.

Tami. Tami is a 7-year-old Caucasian female who lived at home with her adoptive parents and younger brother at the time of intake. The family sought services through the university clinic after hearing about PCIT during a local seminar. The family reported a combined annual income of $\$ 70,000$. Tami was in the second grade during the study. Tami was characterized by her mother as a "strong-willed and determined" girl who "often wants her way." 
Specifically, Tami's mother reported that she often exhibited aggressive behaviors (e.g., kicking, hitting) that would frequently escalate in intensity until caregivers gave in to her demands. Tami's mother initially reported that she and Tami's father often disagreed regarding parenting issues. As a child, Tami experienced medical complications that included a loss of hearing in one ear. Follow-up on this condition was not attained. Psychiatric family history is unknown. In regard to current familial stressors, Tami's mother reported being overwhelmed with her schedule, which involved balancing her nursing job and law school. Tami's mother often did not complete her therapeutic homework assignments and occasionally seemed disorganized and overwhelmed. During the course of treatment, Tami's maternal grandfather passed away which caused additional distress in the family. Between the post-treatment assessment session and follow-up, Tami's parents separated and have since filed for divorce. In the initial phase of treatment, Tami's mother spoke with the therapists about her anxiety regarding certain aspects of the PCIT program (i.e., being observed and coached). Therapists reported that this anxiety subsided as treatment progressed and rapport was more firmly established. Tami and her mother attended six baseline sessions, the CDI didactic session, four CDI coaching sessions, two PDI didactic sessions, nine PDI coaching sessions, a post-treatment assessment session, and a follow-up assessment session.

Rachel. Rachel is a 4-year-old Caucasian female who lives at home with her biological parents and her 13-year-old brother. Rachel was referred for the study by a local community mental health agency. Rachel's father is a high school graduate who was employed as a facilities engineer. Her mother was 36 years old at the time of the study, was unemployed, and had attended some college courses. The family chose not to report their income level. Rachel's mother reported that her daughter's behavior was a great source of stress for the family. Rachel had a history of frequent urinary tract infections and had occasionally been incontinent. Rachel's father has been diagnosed with a mood disorder and was prescribed Lexapro to target associated symptoms. 
Rachel's mother reported significant distress with regard to her relationship with Rachel's father. Specifically, she reported feeling unsupported by her husband and indicated that they often disagreed in their parenting styles. At one point during treatment, Rachel's mother unexpectedly left the home and stayed with a friend for two days. The rest of the family was unaware of her whereabouts during that time. Rachel missed a number of consecutive treatment appointments due to painful headaches, fever, and stomach pains. Rachel's mother ultimately terminated therapy prematurely stating "she just couldn't take it anymore." She expressed that the therapy caused her anxiety, and she was unable to keep up with the homework assignments. Rachel and her mother participated in four baseline sessions, the CDI didactic session, five CDI coaching sessions, two PDI didactic sessions, and three PDI coaching sessions. She reported feeling overwhelmed with life stressors (e.g., the dissolution of her marriage) and felt that she could not devote the time necessary to the treatment.

David. David is a multi-racial 2-year-old male who lived at home with his 25-year-old biological mother. David's family was referred through an Early Head Start program. During intake, David's mother reported that David had difficulty listening and was often noncompliant. David's mother also reported concern over the safety of her son due to his reckless behavior (e.g., being destructive with toys). David's mother reported stress related to her inability to locate or maintain employment. She reported having a good relationship with her parents who were a major source of financial assistance. She reported an annual income of less than $\$ 10,000$. During the first week of treatment, David's mother attained employment but quickly stated that her new schedule was a cause of distress to her. David and his caregiver were inconsistent in their attendance. The family had two "no-shows" (i.e., family was not home or did not come to the door when therapists arrived), one cancellation, and was chronically late for their appointments. David's mother was terminated from the study after multiple attempts to contact her with no response. David and his mother attended three baseline sessions, a CDI didactic session, and three CDI coaching sessions. 


\section{Therapists}

Two graduate students from the Child Clinical Psychology Program at West Virginia University served as therapists in the study. Both therapists had previous PCIT experience (i.e., served as a therapist on a minimum of three PCIT cases with extensive supervision and participated on a clinical team devoted to PCIT for one year) and were provided with a detailed treatment manual outlining procedures for each session. They also received weekly one-hour group supervision throughout the study from a licensed clinical psychologist with extensive experience in providing and supervising PCIT. Participants were randomly assigned to therapists.

\section{Experimental Design}

A single-subject $A B$ design across subjects with staggered baselines was used to assess caregiver behavior, child compliance, and child behavior problems. Dyads began treatment after meeting baseline criteria (i.e., minimum of three sessions and no notable upward trend). Baseline data were collected once prior to the CDI phase of treatment and again before the PDI phase of treatment. Baseline data for CDI were obtained by assessing caregiver positive behaviors (i.e., labeled praise, reflection, behavioral description). The first baseline data point was obtained during the 5-minute DPICS-II CDI observation at the pre-treatment assessment session. A minimum of three consecutive data points were collected during baseline with data demonstrating no notable upward trend before treatment began. No more than one baseline data point per day and no fewer than one per week were collected. One week after the initial dyad began treatment, the next dyad whose DPICS data met the baseline criteria began treatment. Each subsequent week, another dyad began treatment.

Two criteria were used to determine when to change from CDI to PDI conditions. First, participants' caregivers had to meet mastery of the CDI skills. Mastery of the CDI skills was defined as the caregiver's use of the following skills during a 5-minute DPICS-II CDI observation: (a) 10 labeled praises, 10 reflections, and 10 behavioral descriptions; (b) no more 
than three questions, commands, or criticisms; and (c) ignoring of non-harmful inappropriate behaviors. As different target behaviors were hypothesized to change during the PDI intervention, the second criterion for changing to PDI was the establishment of PDI baseline data based on caregiver behavior (i.e., proportion of direct commands during the DPICS-II PDI observation). These data had to be consistent for three consecutive sessions, with no notable upward trend. The first baseline data point for PDI was obtained during a 5-minute pretreatment DPICS-II PDI observation. Subsequent baseline data points were collected throughout the CDI phase of treatment using a 5-minute DPICS-II PDI observation. Missed appointments were scheduled for later in the same week or the following week. Follow-up data were collected for each dyad 1 month after the post-treatment session.

A total of nine dependent variables were examined in the study and were assessed at various points in treatment (i.e., pre-treatment, each session, post-treatment, follow up; see Table 1). Five dependent variables were based on the DPICS-II observations. The first two dependent variables (i.e., caregiver positive behavior, caregiver negative behavior) were related to the goals of the CDI phase of treatment and were coded during the 5-minute DPICS-II CDI observation. Caregiver positive behavior was calculated by totaling the frequencies of labeled praise, reflection, and behavioral description. Caregiver negative behavior was calculated by totaling the frequencies of questions, criticisms, and commands. Three dependent variables that related to PDI goals were measured during the 5-minute DPICS-II PDI observation: proportion of direct commands, contingent praise, and child compliance. Proportion of direct commands was calculated by dividing the frequency of direct commands by the total of direct commands plus indirect commands. Contingent praise was assessed using a frequency count. Child compliance was calculated by dividing the number of commands complied with by the total number of commands. Other dependent variables included scores on the Eyberg Child Behavior Inventory, Parenting Stress Index Short Form, Therapy Attitude Inventory, and the DSM-IV Structured Interview for Disruptive Behavior Disorders. 


\section{Measures}

Child Behavior Checklist (CBCL; Achenbach \& Edelbrock, 1981; Achenbach \& Rescorla, 2000, 2001). The CBCL is a standardized parent report measure used to assess general child psychopathology (Appendix A). The Preschool (ages $1 \frac{1 / 2}{2}$ to 5) and School Age (ages 6-18) forms were used in the current study. For each item, parents indicated on a 3-point scale the extent to which each item described their child's behavior within the past 2 months. It yields a Total Problems score, two broadband scores (Internalizing Problems, Externalizing Problems) and narrowband subscale scores (e.g., Aggressive Behaviors, Attention Problems). Psychometric properties of the CBCL have been demonstrated in numerous studies (e.g., see Achenbach \& Rescorla, 2000, 2001 for reviews). In addition, the CBCL has been able to discriminate between referred and non-referred samples (Achenbach, 1991). Norms are based on age and gender of the child. Only the Aggression subscale was used in the current study for screening purposes. Items from the Aggression subscale include, "hits others," "defiant," and "disobedient." This subscale was used as a screening device as the behavioral items are consistent with disruptive behavior disorders which are targeted in PCIT.

Dyadic Parent-Child Interaction Coding System - II (DPICS-II; Eyberg et al., 1994). The DPICS-II was developed to code parent and child behaviors during their interactions. Normative data for the DPICS-II are available (Eyberg et al.). Reliability and validity of the DPICS-II during live coding situations has yielded adequate results (Bessmer, 1993; Bessmer \& Eyberg, 1993). More specifically, the DPICS-II manual (Eyberg et al.) lists live coding agreement scores averaging $64 \%$ (range $=25 \%$ to $93 \%$ ) for the twelve codes included in the current study. The definitions for the twelve codes are included in Table 2.

Seven of the 12 DPICS-II codes were used to create two composite codes for caregiver behavior that are related to the goals of CDI (i.e., caregiver positive behavior [CPB] and caregiver negative behavior [CNB]). CPB consisted of Labeled Praise, Reflection, and Behavioral Description assessed during the DPICS-II CDI observation. CNB consisted of 
Question, Criticism, Direct Command, and Indirect Command.

The DPICS-II was used to code caregiver and child behavior during two 5-minute structured observations at pre-treatment, post-treatment, prior to each session, and at follow up. During these interactions, the extent of parental control required varies (Hembree-Kigin \& McNeil, 1995). The therapist gave the parent specific instructions for each of the interactions (Appendix B). The first structured observation was the DPICS-II Child Directed Interaction (CDI) observation where the caregiver was instructed to let the child lead the play and simply follow the child's lead. The second structured observation was the DPICS-II Parent Directed Interaction (PDI) observation in which the caregiver informed the child that the caregiver chooses (and leads) the activity. The DPICS-II CDI and PDI situations were used to observe caregiver and child behavior. All observations were coded live during session. Coders used a standardized form developed for the present study to record all observational data (Appendix C).

Demographics form. A demographics form was developed for use in the current study (Appendix D). This form included the following information: (a) child age, (b) child gender, (c) child ethnicity, (d) caregiver age, (e) caregiver gender, (f) caregiver ethnicity, (g) number and ages of siblings in the home, (h) primary caregiver's relationship to the child, (i) marital status, (j) employment status, (k) occupation, (l) caregiver education level, and (m) family income.

Diagnostic and Statistical Manual - IV (DSM-IV) Structured Interview for Disruptive Behavior Disorders (McNeil et al., 1991). The DSM-IV Structured Interview (Appendix E) was created to assess the severity and duration of child disruptive behaviors based on diagnostic criteria for oppositional defiant disorder, conduct disorder, and attention deficit/hyperactivity disorder. The measure utilizes DSM-IV criteria in assigning diagnoses. Respondents are asked to rate each item on a four-point scale from 1 (i.e., rarely) to 4 (i.e., very often). Items are considered symptomatic if they are endorsed as occurring pretty often or very often. Reliability and validity of this measure have been demonstrated in various PCIT outcome studies (Eyberg 
et al., 2001; McNeil et al.; Schuhmann et al., 1998). The DSM-IV Structured Interview was administered at pre treatment, post treatment, and follow up.

Eyberg Child Behavior Inventory (ECBI; Eyberg \& Pincus, 1999; Eyberg \& Ross, 1978). The ECBI is a parent report form used to assess disruptive behavior problems of children between the ages of 2 and 16 (Appendix F). This measure consists of 36 items that were designated as typical problem behaviors by parents of children with conduct problems. Parents indicate the frequency of these behaviors by rating each item on a scale of 1 (never) to 7 (always), yielding an Intensity Score. Parents also indicate whether the behavior is problematic for them (i.e., yes or no), generating a Problem Score. The clinical cutoff scores are 131 for the Intensity Score and 15 for the Problem Score (Eyberg \& Pincus). There have been a number of studies demonstrating the reliability of the ECBI as well as its validity and sensitivity to change following treatment (e.g., Boggs, Eyberg, \& Reynolds, 1990; Eyberg \& Ross). In addition, research demonstrates the sensitivity of the ECBI to weekly change in the intensity of child behavior problems (Perez, Bell, Adams, Garzarella, \& Eyberg, 2002). The ECBI was completed by the caregiver at pre- and post treatment, follow up, and prior to each treatment session.

Parenting Stress Index - Short Form (PSI-SF; Abidin, 1995). The PSI-SF is a 36-item parent self-report derived from the 120 -item full scale PSI. The PSI-SF was designed to assess stress within the parent-child relationship (Appendix G). Parents are asked to endorse items using a Likert scale ranging from strongly agree to strongly disagree. For the purposes of the current study, only the Parental Distress, Difficult Child, and Parent-Child Dysfunctional Interaction subscales were analyzed. A number of studies have demonstrated adequate reliability and validity for the PSI-SF (see Abidin for review). Although findings from many of the original PSI-SF studies were restricted to high functioning Caucasian parents (Abidin), more recent literature has been conducted with minorities, single parents, and parents with lower socioeconomic status and support the use of the PSI-SF with these populations (e.g., Bhavnagri, 1999; Kelley, 1998; Reitman, Currier, \& Stickle, 2002). In addition, the full-scale PSI 
has demonstrated sensitivity to PCIT treatment (e.g., Eisenstadt et al., 1993). The PSI-SF was administered at pre- and post treatment, and at follow up.

Therapy Attitude Inventory (TAl; Eyberg, 1974). The original TAI was developed by Eyberg and Johnson (1974) as a consumer satisfaction measure for behavioral parent training programs. Eyberg revised the questionnaire (Appendix $\mathrm{H}$ ) to assess parental satisfaction with $\mathrm{PCIT}$. The TAI is a 10-question measure containing items on a 5-point Likert scale, which vary depending on the specific item, but with a higher score indicating higher satisfaction. Items explore parents' perceptions of techniques learned, quality of the parent-child relationship, changes in the severity of behavior problems, and overall impressions of PCIT. Psychometric evaluations of the TAI have demonstrated adequate reliability (Brestan, Jacobs, Rayfield, \& Eyberg, 1999; Eisenstadt et al., 1993) and validity (Brestan et al.; Eisenstadt et al.; Eyberg \& Matarazzo, 1980). The TAI was administered at post treatment and at follow up.

Procedures

Assessment procedures. An outline of the assessment procedures is provided in Table 3. Families interested in participating in the study contacted the investigator at the university clinic. Using a standardized referral form designed for use in the current study, the primary investigator or a graduate student therapist involved in the study called referred families to discuss the referral question, provide an overview of PCIT, and describe the purpose and logistics of the study. During this phone contact, the purpose of the phone call was explained and verbal consent regarding information collected during the phone call was obtained. Study eligibility was determined by administering two brief screeners (i.e., aggression subscale of the CBCL and DSM-IV Structured Interview for Disruptive Behavior Disorders) to the caregiver over the phone. The first five families contacted met inclusion criteria and were admitted into the study. A pre-treatment assessment session (to be conducted in the home) was then scheduled. Pre-treatment assessment began by obtaining written informed consent to participate in the study. The pre-treatment assessment procedures were conducted in the following order: (1) 
caregiver completion of two self-report questionnaires (i.e., ECBI, PSI-SF), (2) completion of a thorough clinical interview (including Demographics Form), and (3) coding of the two 5-minute DPICS-II observations (i.e., CDI, PDI).

Throughout treatment, the ECBI and two behavior observations (i.e., CDI, PDI) were collected prior to each session. Post-treatment assessment was conducted on the session following the family's completion of treatment and was administered in the same order as pretreatment: (1) caregiver completion of three self-report questionnaires (i.e., ECBI, PSI-SF, TAI), (2) administration of the DSM-IV Structured Interview, and (3) coding of the 5-minute DPICS-II CDI and PDI observations. At follow up, the post-treatment assessment was replicated.

Treatment procedures. Therapists met with families in their home for twice-weekly 1hour treatment sessions. One therapist served as the primary clinician for the family and two therapists were present at $42.8 \%$ of sessions overall. There were two reasons for conducting inhome PCIT in pairs. First, for the initial sessions, two therapists were sent to the home to address any potential safety concerns. Second, the second therapist conducted reliability coding for the study. Treatment followed standard practice of clinic-based PCIT with the exception that all sessions were conducted in the home. Modifications from the clinic-based protocol were necessary in order to implement this treatment in the home setting. For example, during clinic-based PCIT, therapists coach parents through use of a bug-in-the-ear device from behind a one-way mirror. As this technology is not available in the home setting, therapists provided "in-room" coaching. During coaching sessions in the home, the therapist sat behind the caregiver and provided feedback discretely. Preliminary research suggests that coaching in the room is an effective alternative to the bug-in-the-ear technology (Rayfield \& Sobel, 2000).

A brief summary of sessions is provided here. A more detailed treatment manual adapted for in-home PCIT was provided to therapists to ensure adherence to the treatment protocol (see Appendix I for a sample integrity checklist that was used by the therapists during the session). Session 1 was the first face-to-face meeting with the participants during which 
written informed consent was obtained and the pre-treatment assessment was conducted. During this first appointment, therapists explained to participants that distractions should be kept at a minimum during treatment sessions. Participants were asked to refrain from having visitors, accepting telephone calls, or having the television on during treatment sessions. During subsequent sessions, baseline data were obtained until criteria (i.e., a minimum of three data points with no notable upward trend) were met. At the session following baseline criteria, the therapist conducted the CDI didactic session. CDI coaching began at the session following the didactic session and continued until the caregiver met mastery criteria for the CDI phase of treatment. Once the dyad met baseline criteria for changing conditions to the PDI phase of treatment, the PDI didactic session was conducted at the next session. The PDI didactic session was followed by PDI coaching sessions until the caregiver met mastery criteria (i.e., caregiver must give at least four commands, of which at least $75 \%$ must be direct and caregiver must show at least $75 \%$ correct follow-through after giving an effective command) and the child's behavior is within normal limits as indicated by the ECBI. After mastery criteria for PDI was reached, the post-treatment assessment was conducted. A follow-up session was conducted one month after the post-treatment assessment session.

Treatment integrity. Therapists met weekly with a licensed clinical psychologist with extensive experience in PCIT for supervision of the treatment cases. During supervision sessions, therapists reviewed and discussed treatment session content and the supervisor provided feedback on correct therapy implementation to enhance treatment integrity. Therapists were required to use self-monitoring by bringing integrity checklists to each therapy session and checking off items as they were completed (see Appendix I for a sample). In addition, a graduate student or an advanced undergraduate psychology student performed treatment integrity checks for at least $30 \%$ of the therapy sessions. The reviewers observed the treatment sessions in the home and completed the integrity checklists independently. Integrity percentages were calculated for each session by dividing the number of session components 
appropriately completed by the total number of session components possible and multiplying by 100. Treatment integrity scores were averaged for each participant and ranged from $99.5 \%$ to $100 \%$. Treatment integrity dropped to $86 \%$ during one of Tami's sessions as the therapists were unable to conduct coding during that session.

Integrity of the Observational Measures

Training coders. The two graduate students serving as therapists in the study were trained to code parent-child interactions using the DPICS-II. Training included a series of lessons, homework, and quizzes that were designed for the purpose of training DPICS-II coders. After coders completed the DPICS-II training, they worked toward attaining acceptable reliability by coding live, analog interactions. A 15-second interval system was used to calculate kappa agreement for the following DPICS-II codes: labeled praise, reflection, behavioral description, question, indirect command, direct command, criticism, contingent praise, and child compliance. Coders were designated reliable after they attained an agreement of .75 kappa for three consecutive observations. The primary investigator maintained contact with the coders via email and regularly scheduled phone conferences to discuss progress and allowed the opportunity to raise any issues or concerns regarding the coding system.

Interobserver agreement. All DPICS-II observations were coded live. Agreement was evaluated for $42.80 \%$ of the observations with agreement being assessed comparably across all phases of treatment (i.e., baseline, CDI, PDI, follow up). Kappas were calculated for each DPICS-II code used as a dependent variable or part of a dependent variable (i.e., labeled praise [LP], reflection [RF], behavioral description [BD], Question [Q], Criticism [CR], Direct Command [DC], Indirect Command [IC], Contingent Praise [CP], and Child Compliance [CCO]). Kappas were averaged across participants for each of the nine DPICS-II codes and ranged from .87 (Question) to 1.0 (Contingent Praise). Overall kappas for each DPICS-II code and their ranges were as follows: $\operatorname{LP}(M=.97$, range $=.90-1.0), \operatorname{RF}(M=.94$, range $=.90-.97), \mathrm{BD}(M=.95$, range $=.85-.99), \mathrm{Q}(M=.87$, range $=.82-.94), \mathrm{CR}(M=.95$, range $=.88-.99), \mathrm{DC}(M=.92$, 
range $=.80-.98), \mathrm{IC}(M=.89$, range $=.83-.95), \mathrm{CP}(M=1.0$, range $=1.0)$, and $\mathrm{CCO}(M=.93$, range $=.91-.96)$. Kappas for coder agreement at each observation were high and were generally above .60. Kappa dropped below .60 on three different codes (LP, Q, IC) on three different observations for the same participant (Tami).

Results

PDI observations were suspended during the two PDI didactic sessions while caregivers were instructed on the discipline procedure. In addition, observations were suspended during the first two PDI coaching sessions until the caregiver could demonstrate competence in the discipline procedure. Caregivers had to demonstrate competence either directly during a coaching session or within a role-play situation if the child did not have a timeout during one of the first two PDI coaching sessions. Thus, data were not collected for those variables examined during the PDI observations (i.e., proportion of direct commands, contingent praise, and child compliance) until the third PDI coaching session. The purpose of not conducting observations during those sessions was to ensure that the caregiver would not implement the discipline procedure incorrectly in the absence of adequate coaching.

Alex

Caregiver behavior. CPB data for Alex and his mother are illustrated in Figure 1. During baseline, no notable upward trend was observed and caregiver positive behavior was at an overall low level with a mean of 1.25. A notable increase in caregiver positive behavior was observed when the family transitioned into the CDI phase of treatment. Of note, CPB increased from 0 to 16 after only having received the didactic session (i.e., the caregiver had not yet received any coaching). CPB steadily increased across CDI with the caregiver obtaining mastery after four coaching sessions. The mean level of CPB during CDI was 29.00. The PDI didactic session took place over sessions 10 and 11. Observations resumed during session 13. The level of CPB maintained throughout PDI with a mean of 28.20. At follow-up, 26 CPBs were observed. 
CNB data for Alex and his mother are displayed in Figure 2. During baseline, no notable trend was detected and the mean equaled 9.25. During CDI, there was a notable decrease in CNB with the mean decreasing to 2.20. During PDI, CNB continued to decrease with a mean level of 0.20 . At follow-up, there were no CNBs during the observation.

Data for the proportion of direct commands for Alex and his mother are displayed in Figure 3. Data were variable throughout baseline ranging from $0 \%$ to $100 \%$ use of direct commands, with an overall phase mean of $52.50 \%$. Only two data points were obtained from the CDI phase of treatment. While data were collected for three additional CDI sessions, no commands (indirect or direct) were given during the observation, thus, no data were available for plotting. During CDI, Alex's caregiver obtained a 0\% proportion of direct commands during the first CDI session and $33.33 \%$ in the following session, for an average of $16.67 \%$. Data were collected during the PDI phase beginning with session 14 (due to the PDI didactic). Proportion of direct commands was $100 \%$ throughout PDI during all four observed sessions and remained at $100 \%$ during the follow-up observation.

Contingent praise (CP) data for Alex and his mother are reflected in Figure 4. CP only occurred once throughout baseline and never occurred during the CDI phase of treatment. During PDI, CP increased with a mean equaling 6.00. At follow up, the level of CP maintained with seven CPs observed.

Child compliance. Alex's compliance data are displayed in Figure 5. Low levels of compliance were exhibited during baseline with a mean of $16.17 \%$. Only two data points were obtained during CDI with child compliance increasing from 0 at session 5 to $66.67 \%$ at session 6. Child compliance data for sessions 8 through 10 could not be plotted as there were no commands given during those observations. When observations resumed during PDI, child compliance increased to $100 \%$ and remained at $100 \%$ throughout PDI. Child compliance maintained at $100 \%$ at the follow-up assessment.

Parent report of child behavior. ECBI Intensity score data are displayed in Figure 6. 
ECBI Intensity scores during baseline were well above the cutoff for clinical significance (i.e., 131) with no notable trend and an average of 208.00. During CDI, ECBI Intensity scores began to decrease with a mean equaling 188.50. During PDI, scores continued to decrease and dropped below clinical significance at session 17; however, the overall mean remained above clinical significance at 138.75 . At follow up, the ECBI Intensity score was 81 . As shown in Figure 7, ECBI Problem scores followed the same pattern for this dyad. At baseline, scores were above clinical significance (i.e., 15) and stable with no notable trend and an average of 28.00. During CDI, there was a notable downward trend and a mean of 27.83. After transitioning to PDI, the problem score increased slightly and remained elevated until session 16 when the scores began to decrease. ECBI Problem scores were below clinical significance during sessions 17 and 18. The overall mean for ECBI Problem scores during PDI was 20.50. At follow up, ECBI Problem scores had decreased to a score of three.

Results from the DSM-IV Structured Interview for Disruptive Behavior Disorders for all participants are displayed in Table 4. At pre-treatment, Alex met diagnostic criteria for Oppositional Defiant Disorder (ODD) and Attention-Deficit Hyperactivity Disorder (ADHD) Combined Type. At post-treatment assessment, Alex met criteria for ADHD - Impulsive Type. At follow up, Alex continued to meet criteria for ADHD - Impulsive Type.

Parenting stress. The PSI-SF was administered at pre- and post-treatment assessment as well as at follow up. PSI-SF data for Alex's family are displayed in Figure 8. All subscales of the PSI-SF follow roughly the same pattern. Specifically, scores are elevated at pre-treatment, decrease to within normal limits at post-treatment, and are elevated again at follow up. Noah

Caregiver behavior. CPB data for Noah and his mother are depicted in Figure 1. CPB during baseline was low and demonstrated a slight downward trend with a mean equaling 2.6. CPB increased consistently across the CDI phase of treatment with a mean of 20.14. Data were not collected during sessions 13 and 14 due to the PDI didactic session. CPB maintained 
throughout PDI although the data were slightly more variable with a mean of 25.13 . This skill maintained at follow-up assessment with 23 CPBs coded during the observation.

CNB frequencies are displayed in Figure 2. CNB during baseline was variable, with an average of 20.60 . There was a notable drop in CNB once CDI commenced and there was a downward trend throughout CDI with an average of 3.43. CNB remained low and stable throughout PDI with a mean of 1.38. CNB increased at follow up with six CNBs coded during the observation.

Proportion of direct commands data are displayed in Figure 3. Baseline data were variable ranging from $36.00 \%$ to $100 \%$ and an average of $60.70 \%$. No commands were observed during the first two observations of the CDI phase. For the remaining five sessions, proportion of direct commands ranged from $0 \%$ to $50.00 \%$, with an average of $18.15 \%$. Data collection during PDI began at session 17. Data were variable throughout this phase ranging from $0 \%$ to $100 \%$, with an overall phase mean of $70.56 \%$. During the follow-up observation, proportion of direct commands dropped to $33.33 \%$.

$\mathrm{CP}$ data for Noah and his mother are reflected in Figure 4. Only one CP occurred during baseline with a mean of .25 . There was no notable change in $\mathrm{CP}$ with the implementation of CDI. There were three CPs throughout this phase of treatment with a mean equaling .43 . When PDI observations resumed, there was a notable increase in CP - an upward trend was noted during PDI and resulted in an overall mean equaling 2.83. There were six CPs observed during follow-up assessment.

Child compliance. Noah's compliance rates are displayed in Figure 5. Noah's compliance ranged from $16 \%$ to $50 \%$ throughout baseline, with a mean of $36.00 \%$. Compliance rates remained variable during $\mathrm{CDI}$ with a range from $0 \%$ to $100 \%$ and a mean equaling 30.40\%. There was $0 \%$ compliance during the first PDI session. After this session, compliance increased with a mean of $70.33 \%$ for the PDI phase of treatment. Sessions 21 and 22 yielded 100\% compliance, with 100\% compliance at follow up. 
Parent report of child behavior. ECBI Intensity score data are displayed in Figure 6. ECBI Intensity scores during baseline were above clinical significance with no notable trend and an average of 144.8. During CDI, ECBI Intensity scores remained stable at approximately the same level, with a mean equaling 149.5. After the implementation of PDI, ECBI Intensity scores began to decrease and dropped below clinical significance at session 17 , with an overall mean of 103.5. At follow up, the ECBI Intensity score was 66. As shown in Figure 7, ECBI Problem scores did not follow the same pattern. At baseline, four out of five data points were above clinical significance and were variable with no notable trend and a mean of 18.2. At the beginning of $\mathrm{CDI}$, there was a notable upward trend for sessions 6 through 8 and a downward trend for sessions 9 through 12. The mean during CDI was 26.63. The ECBI Problem score remained elevated after transitioning to PDI for the first three sessions, after which a notable downward trend was observed with scores dropping below clinical significance. ECBI Problem scores were below clinical significance during sessions 17 and 19 through 23. At follow up, ECBI Problem scores maintained, with a score of 2.

At pre-treatment, Noah met diagnostic criteria for ODD and ADHD - Impulsive Type based on his mother's responses to the DSM-IV Structured Interview for Disruptive Behavior Disorders. At post-treatment and follow-up assessment, Noah did not meet diagnostic criteria for any of the disruptive behavior disorders.

Parenting stress. PSI-SF data obtained from Noah's mother are displayed in Figure 8. All subscales of the PSI-SF follow roughly the same pattern, with decreases from pre- to postand post- to follow-up assessment. The most notable decreases occurred in the Difficult Child subscale with scores decreasing from the 95th percentile at pre treatment to the 60th percentile at post treatment and dropping to the 30th percentile at follow up.

Tami

Caregiver behavior. CPB data for Tami and her mother are depicted in Figure 1. CPB during baseline was low, with no notable upward trend and a mean equaling 1.17. CPB 
increased across the first three CDI coaching sessions with a slight decrease in session 11 with a mean of 25.00. Data were not collected during sessions 12 and 13 due to the PDI didactic session. CPB increased at the beginning of the PDI phase of treatment to 51 and then decreased to 27 at session 17. CPB then became stable with an overall phase mean of 35.22 . CPB maintained at follow up; 36 CPBs were coded during the follow-up observation. CNB frequencies are displayed in Figure 2. CNB during baseline was variable with a slight upward trend and an average of 38.5. CNB decreased immediately and became stable after CDI began, with a mean of 3.0. CNB remained low and stable throughout PDI, with a mean of 2.44. One CNB was observed at follow up.

Data for proportion of direct commands for Tami and her mother are displayed in Figure 3. During baseline, proportion of direct commands increased steadily over the first four sessions from $23.08 \%$ to $68.75 \%$, followed by a decrease to $20.0 \%$ at session 5 and $0 \%$ at session 6 . The baseline average was $35.25 \%$. During CDI, data remained variable ranging from $8.33 \%$ to $83.30 \%$ and an average of $31.67 \%$. PDI data collection began during session 16 . Data were variable and ranged from $12.5 \%$ to $100 \%$, with an overall increasing trend across the phase. The average proportion of direct commands during PDI was $66.27 \%$. At follow up, this level maintained, with direct commands being observed $75.00 \%$ of the time.

CP data for Tami and her mother are reflected in Figure 4. No instances of CP occurred during baseline or CDI. When PDI observations resumed after the didactic session, there was a notable increase in $\mathrm{CP}$, with a mean equaling 6.57. At follow up, CP increased further, with 14 CPs coded during the observation.

Child compliance. Tami's compliance rates are displayed in Figure 5. Her compliance was quite variable during baseline and ranged from $15.15 \%$ to $55.25 \%$ with a mean of $35.67 \%$. Compliance data were collected only during four CDI sessions with $0 \%$ compliance at sessions 8 and 10, 40.00\% compliance at session 9, and 58.33\% compliance at session 10. Overall, compliance during CDI equaled 24.58\%. PDI data collection resumed at session 16. 
Compliance increased from $75.00 \%$ at session 16 to $100 \%$ at session 18 . Compliance remained at $100 \%$ for the remainder of PDI, with an overall phase mean of $94.86 \%$. At follow up, Tami exhibited 93.75\% compliance.

Parent report of child behavior. ECBI Intensity scores are displayed in Figure 6. During baseline, Tami's ECBI Intensity scores were stable, with no notable trend and a mean just above clinical significance at 133.29. During CDI, ECBI Intensity scores decreased across the first two coaching sessions, increased during session 10, and rose above clinical significance at session 11. The overall ECBI Intensity score mean for CDI was 120.00 . No notable change was noted immediately after implementation of PDI, but an overall downward trend across the phase was observed. The ECBI Intensity score mean for PDI was below clinical significance at 125.80. At follow up, the ECBI Intensity score was 68. As shown in Figure 7, ECBI Problem scores followed roughly the same pattern for this dyad. At baseline, scores were well above clinical significance $(M=22.29)$, but a downward trend was noted. ECBI Problem data collected during CDI were variable with an upward trend at the end of the phase and a mean of 18.60. There was a slow downward trend observed across the first four sessions of PDI. After session 16, the downward slope was more distinct (with the exception of session 19 where the score increased to 17), dropping to 3 at session 22. At follow up, ECBI Problem scores remained low, with one problem reported.

Based on caregiver report using the DSM-IV Structured Interview for Disruptive Behavior Disorders, Tami met diagnostic criteria for ODD at pre-treatment. At post-treatment assessment and follow-up, Tami did not meet criteria for any disruptive behavior disorders.

Parenting stress. The PSI-SF data for Tami's family are displayed in Figure 8. There was no clear pattern in the PSI-SF data. The Difficult Child subscale scores decreased across each assessment phase from the 95th percentile at pre-treatment assessment to the 50th percentile at follow-up assessment. The Parental Distress subscale data revealed an opposite pattern increasing across all phases of assessment from the 65th percentile at pre-treatment 
assessment to the 90th percentile at follow-up assessment. For the Parent-Child Dysfunctional Interaction subscale, the scores increased slightly from the 60th percentile at pre-treatment to the 65th percentile at post-treatment. This subscale score then dropped to the 45th percentile at follow-up assessment. The Total Stress subscale decreased from pre-treatment (i.e., 90th percentile) to post-treatment (i.e., 75th percentile), but a slight increase was noted at the followup assessment (i.e., 80th percentile).

Rachel

Caregiver behavior. As shown in Figure 9, CPB data during baseline were low, with no notable upward trend and a mean equaling 0.40. CPB increased immediately after CDI was implemented. There was an upward trend across the phase, with a phase mean of 27.00. Data were not collected during sessions 11 and 12 due to the PDI didactic session. The overall level of CPB dropped slightly during PDI, with a mean equaling 24.67. Data were collected for three PDI sessions before the family withdrew from treatment.

CNB frequencies are displayed in Figure 10. CNB during baseline was stable with no notable trend and an average of 17.6. Upon implementation of CDI, CNB decreased gradually throughout this phase $(M=2.6)$. CNB remained low during the three sessions of PDI, with a mean of 1.67 .

Proportion of direct commands data for Rachel and her caregiver are displayed in Figure 11. Baseline data were variable and ranged from $42.86 \%$ to $100 \%$, with a notable downward trend for the last three sessions. The overall mean for baseline was 69.11\%. During CDI, proportion of direct command data ranged from $0 \%$ to $100 \%$, with a notable downward trend throughout the phase and an overall phase mean of $52.00 \%$. Data were collected on proportion of direct commands for one session of PDI prior to the family's termination from treatment. Proportion of direct commands was $100 \%$ during the last session.

CP data for Rachel and her mother are reflected in Figure 12. Only one instance of CP was observed during baseline (session 2), for an overall mean of 0.2. No CPs were observed 
during CDI. CP data were collected only once during PDI (session 15), during which two CPs were observed.

Child compliance. As shown in Figure 13, Rachel's compliance rates during baseline were generally low (i.e., below 30\%), with the exception of session 3 during which a compliance rate of $75.0 \%$ was observed. Overall compliance during baseline was $28.80 \%$. During CDI, compliance was quite variable ranging from $0 \%$ to $100 \%$ with an average of $50 \%$. Compliance was 80\% during session 15 (the only PDI session in which observation data were collected).

Parent report of child behavior. ECBI Intensity score data are displayed in Figure 14. During baseline, Rachel's ECBI Intensity scores were stable, with no notable trend and a mean well above clinical significance at 172.4 . There was no notable change upon implementation of CDI. ECBI Intensity scores remained stable with a slight downward trend and a phase mean of 147.83. During the last CDI session, ECBI Intensity scores dropped to just below clinical significance (i.e., 130). Scores increased slightly upon phase change to PDI. Data were stable throughout PDI and remained above clinical significance with an overall phase mean of 140.75 . As shown in Figure 15, ECBI Problem score data followed roughly the same pattern for this dyad. At baseline, scores were above clinical significance and stable, with a baseline mean of 21.00. There was no notable change upon commencement of CDI. ECBI Problem data remained stable throughout CDI with no notable trend and a phase mean of 19.33. Again, when PDI began, there was no notable change in ECBI Problem scores. Data remained stable across the four sessions of PDI with a phase mean above clinical significance at 19.50 .

At pre-treatment, Rachel met diagnostic criteria for ODD and ADHD - Impulsive type based on the DSM-IV Structured Interview for Disruptive Behavior Disorders administered to her mother. No post-treatment or follow-up data were available as the family terminated treatment prematurely.

Parenting stress. PSI-SF data for Rachel's family are displayed in Figure 16. Rachel's caregiver reported clinically significant distress across all domains. Only pre-treatment data 
were obtained as Rachel and her caregiver withdrew from treatment prior to completion. Scores were in the 99th percentile on the Parent Domain, Difficult Child Domain, and Total Stress. The Parent-Child Dysfunctional Interaction subscale score was in the 95th percentile.

David

Caregiver behavior. CPB frequencies are displayed in Figure 9. During baseline, CPB was low, with no notable upward trend and a mean equaling 1.0. CPB increased after the implementation of CDI, with a phase mean of 17.33 and no notable trend. As shown in Figure 10, there was a slight downward trend in CNB during baseline, with a baseline mean of 34.75. Upon implementation of CDI, CNB decreased further with a slight downward trend throughout CDI and a phase mean equaling 8.67.

Proportion of direct commands for David and his caregiver are reflected in Figure 11. Data were stable throughout baseline, with an average of $85.78 \%$. A notable decrease in proportion of direct commands was observed upon commencement of CDI. The CDI phase mean for proportion of direct commands was $24.75 \%$ and ranged from $0 \%$ to $40.91 \%$. CP for David and his mother are reflected in Figure 12. No CPs were observed during baseline or CDI. The family terminated treatment after three sessions of CDI.

Child compliance. As shown in Figure 13, David's compliance rates during baseline were very low (i.e., below 20\%) and stable, with no notable trend and a baseline mean of 9.25\%. CDI data were variable, with a phase mean of $22.33 \%$.

Parent report of child behavior. As illustrated in Figure 14, ECBI Intensity score data for David were stable across baseline with no notable trend and a baseline mean of 132.75 . There was no notable change when CDI was implemented; however, by the last session of CDI, ECBI Intensity scores had dropped to 116. The CDI phase mean was 128.67. As shown in Figure 15, ECBI Problem scores followed roughly the same pattern for this dyad. At baseline, scores were stable and above clinical significance with no notable trend and an average of 19.75. Again, there was no notable change upon implementation of CDI. There was a slight downward trend 
across the three sessions of CDI, with a phase mean of 18.00 .

At pre-treatment, David met diagnostic criteria for ODD based on his mother's responses to the DSM-IV Structured Interview for Disruptive Behavior Disorders. No post-treatment or follow-up data are available as the family terminated treatment prematurely.

Parenting stress. PSI-SF data obtained from David's caregiver are displayed in Figure 16. David's caregiver reported clinically significant distress on the Difficult Child, Parent-Child Dysfunctional Interaction, and Total Stress subscales. The Parent Domain was within normal limits at the 65th percentile. Only pre-treatment data were obtained as David and his caregiver terminated treatment prematurely. Scores were in the 99th percentile on the Parent Domain, Difficult Child Domain, and Total Stress. The Parent-Child Dysfunctional Interaction subscale score was in the 95th percentile.

\section{Consumer Satisfaction}

TAI results are displayed for all participants in Figure 17. Among treatment completers, responses from Alex and Tami's caregivers resulted in the highest possible score on the TAI (i.e., 50) at post-treatment and follow-up assessments. Responses from Noah's caregiver yielded a score of 44 at post-treatment assessment and 45 at follow-up assessment. Noah's caregiver rated the following items as slightly lower (i.e., 4) than an optimal score (i.e., 5): learning techniques for teaching my child new skills, getting along with their child, feeling confident in ability to discipline, child compliance, the degree to which the program helped with other general personal problems not directly related to your child, and general feeling about the program. Consumer satisfaction measures were not obtained from Rachel's or David's caregivers due to their premature termination from treatment. It is unclear whether the families' reasons for terminating treatment prematurely were related to the intervention or service modality.

\section{Comparison to Previous Studies}

In order to provide a context for the data obtained in the present study, data will be 
compared to previous PCIT outcome studies. The studies used for comparison include Nixon et al. (2003), Schuhmann et al. (1998), Eisenstadt et al. (1993), and McNeil et al. (1991). Only data from the three families completing treatment were used for comparison.

ECBI intensity scores. Table 5 displays means and standard deviations for ECBI Intensity pre-treatment scores of the present study as well as the aforementioned PCIT outcome studies. The mean from the present study was $157.67(S D=34.82)$. This was lower than all means from previous PCIT outcome studies, which ranged from $166.59(S D=18.93$; Nixon et al., 2003) to 180.70 (SD = 28.20; McNeil et al., 1991). The mean ECBI Intensity post-treatment scores for the three families participating in the present study was lower than the comparison means at $89.33(S D=12.90)$. Means from the other outcomes studies ranged from 105.9 (SD = 29.20; McNeil et al.) to 131.60 (SD = 40.60; Schuhmann et al., 1998). The mean ECBI Intensity score at follow-up assessment for the present study was $71.67(S D=8.14)$. Follow-up assessment data were only available from two of the outcome studies. Nixon et al. used a 6month follow up and Schuhmann et al. used a 4-month follow up. At the 1-month follow up for the present study, the mean for ECBI Intensity scores was $71.67(S D=8.14)$. The means for the Nixon et al. and Schuhmann et al. studies were $117.47(S D=31.69)$ and $126.30(S D=$ 42.10), respectively.

Child compliance rates. Means and standard deviations for child compliance rates for the present study and comparison studies are displayed in Table 6. Compliance rates were used from the Nixon et al. (2003), Schuhmann et al. (1998), Eisenstadt et al. (1993), and McNeil et al. (1991) studies. The present study resulted in pre-treatment compliance rates of $21.79 \%$ $(S D=25.61)$. The Schuhmann et al. study reported similar pre-treatment compliance rates at 23\%. Pre-treatment compliance rates for the other outcome studies were higher, with $64 \%$ (SD $=24)$ in the Nixon et al. study, $47.0 \%(S D=15.9)$ in the Eisenstadt et al. study, and $40.7 \%$ (SD $=18.2$ ) in the McNeil et al. study. At post-treatment, compliance rates for the present study were $100 \%$ for all three families. In the Nixon et al. study, compliance rates increased to $81 \%$ (SD = 
22). Similarly, compliance rates increased at post-treatment for the Schumann et al., Eisenstadt et al., and McNeil et al. studies to $47 \%, 73.1 \%(S D=19.9)$, and 70.4\% (SD = 16.3), respectively. Compliance rates maintained at follow up in the present study at $97.92 \%$ (SD = .03). Nixon et al. was the only other study to report follow-up compliance rates. Maintenance of treatment gains was observed at follow up, with a rate of $83 \%(S D=21)$.

\section{Discussion}

\section{Main Findings}

Caregiver behavior. The three families who completed treatment demonstrated similar rates of skill acquisition for caregiver positive behavior (CPB). At baseline, caregivers demonstrated very low levels of this behavior. As hypothesized, upon commencement of CDI, all caregivers demonstrated a gradual increase in use of these skills across this phase. Once families transitioned to PDI, their skills maintained at near mastery level. These results maintained at follow-up assessment for all three families. Rachel's caregiver demonstrated a similar pattern of CPB skill acquisition prior to withdrawing from treatment. In contrast, while David's caregiver demonstrated an increase in CPB after transitioning to CDI, the overall level of CPB maintained at the same level across the first three sessions of CDI, but did not increase in the same way as the other participants.

The families completing treatment exhibited varying levels of caregiver negative behavior (CNB) during baseline with Tami's caregiver exhibiting the highest level of $\mathrm{CNB}(\mathrm{M}=$ 38.5). All families demonstrated the same response upon implementation of CDI; CNB frequencies decreased and appeared more stable, which was consistent with the proposed hypothesis. During PDI, these scores remained low. The same pattern was observed for Rachel and David's caregivers although the decline in David's caregiver's use of CNB appeared more gradual when compared to the other families.

The data for proportion of direct commands were somewhat consistent with the proposed hypothesis that the proportion of direct commands would increase during PDI. 
Baseline data for Alex, Noah, Tami, and Rachel were highly variable. Proportion of direct commands remained variable during CDI. There was an overall increase in the proportion of direct commands for Alex, Noah, and Tami during PDI although data remained variable for Noah and Tami. Rachel's data followed a similar trend although data were only collected for one PDI session. David's data were not examined for this variable as he terminated treatment prior to PDI.

All families demonstrated the same pattern of skill acquisition for contingent praise (CP). Levels of CP were low and almost nonexistent during baseline and CDI. During PDI, CP increased for Alex, Noah, and Tami. These results are consistent with the proposed hypothesis that CP would increase during PDI. While it appears as though Noah's caregiver exhibited lower levels of CP across PDI, it is important to note that his caregiver utilized CP for all but two times Noah complied during PDI. Therefore, a better measure of CP might have been a percentage with number of CPs divided by number of times the child complied (or number of parent opportunities). As data were only collected for one PDI session for Rachel, it is unclear whether her data would have followed the same pattern during PDI. David's caregiver exhibited no CPs during baseline or CDI.

Child compliance. It was proposed that child compliance would increase during the PDI phase of treatment. For the three families that completed treatment, compliance rates varied during baseline and CDI, but made notable increases during the PDI phase of treatment. In addition, child compliance rates maintained at one-month follow up for all three families. Rachel's compliance data were variable during baseline and CDI. It is unclear whether her compliance would have increased during PDI, although her compliance rate was $80.0 \%$ during her last and only session of PDI. David showed slight improvement from baseline to CDI although his data were limited and variable.

Parent report of child behavior. All participants presented with significant levels of child behavior problems as indicated by parent report. It was hypothesized that parent report of child 
behavior problems would decrease across both CDI and PDI phases of treatment. ECBI Intensity scores for Alex and Noah were relatively consistent throughout baseline. Adam's ECBI Intensity scores gradually decreased across CDI and PDI. This pattern is consistent with previous research using the ECBI to monitor treatment progress during PCIT (Perez et al., 2002). Noah's data remained relatively stable through CDI and decreased throughout PDI. Rachel's data demonstrated a similar pattern, although after a stable baseline, data decreased slightly throughout CDI, but then remained stable at the same level throughout PDI. Tami's data showed a more unique pattern in which the scores were variable during baseline and began to decline in CDI, but then increased throughout the end of CDI and beginning of PDI. Her scores then decreased throughout the rest of PDI. One hypothesis for this pattern was the amount of caregiver contact with the child. Therapists from the study explained that Tami participated in a day camp during the study and that the decline in ECBI scores appeared to coincide with the amount of daily contact the caregiver had with Tami. When day camp was over, the ECBI scores increased before making a decline to within normal limits. ECBI Intensity scores maintained at follow up for the three completers. Finally, David's limited data showed stable ECBI scores at the level of clinical significance throughout baseline and CDI.

Patterns for the ECBI Problem scores were slightly different. For Alex and Noah, the pattern was roughly the same as the ECBI Intensity scores. Scores were variable during baseline and then began to gradually decrease during CDI. Both Alex and Noah demonstrated a slight increase after PDI was implemented. This phenomenon has been noted anecdotally among PCIT clinicians. It is hypothesized that after the discipline procedure is implemented, children attempt to "test the limits." Once the children experience this procedure consistently, their problem behavior decreases. For Tami, there was a downward trend during baseline followed by an increase in ECBI Problem scores across CDI. Scores then gradually decreased across PDI. Follow-up ECBI Problem scores for the three completers were equal to or less than their lowest score obtained during treatment. In contrast, no notable change was detected in 
ECBI Problem scores for Rachel across baseline, CDI, and PDI. One possible explanation for this lack of change is the level of participation in the program. Specifically, therapists noted that Rachel's caregiver was experiencing a significant amount of distress at this time and reported to therapists that she was inconsistent in her completion of therapeutic homework due to these additional stressors. This overall level of distress is reflected in her PSI-SF scores in which the Parent Domain was significantly elevated (99th percentile). It has been suggested that one explanation for a profile in which there are high Problem scores and low Intensity scores on the ECBI is a low level of parental tolerance perhaps caused by distress (Eyberg \& Pincus, 1999). Finally, David's data followed the same pattern as his ECBI Intensity data remaining stable across baseline and CDI although well above the cutoff for clinical significance.

All of the participants met criteria for a disruptive behavior disorder based on their caregiver's responses to the DSM-IV Structured Interview for Disruptive Behavior Disorders with all participants meeting criteria for oppositional defiant disorder. Rachel no longer met criteria for ODD at post-treatment or follow up. Alex and Noah met criteria for an additional disorder at pretreatment. Alex met criteria for ADHD - Combined Type and Noah met criteria for ADHD Impulsive Type. Alex met criteria for ADHD - Impulsive Type at post-treatment assessment and again at the follow-up assessment while Noah no longer met criteria for any disruptive behavior disorder at post-treatment or follow-up assessment.

Parenting stress. Results suggested that all caregivers reported significant levels of distress on at least one domain (e.g., Difficult Child). It is possible that parenting distress may have impacted progress in treatment. Of the treatment completers, Noah needed the greatest number of CDI coaching sessions (i.e., 7) to reach CDI mastery with Alex and Tami needing five and four sessions, respectively. In addition, Noah's caregiver was the only one to report a significant amount of distress on the Parent Domain of the PSI-SF, which assesses stressors independent of the child's behaviors including depression and self-confidence in the parenting role. One theory is that these additional stressors may have impacted Noah's caregiver's ability 
to learn the skills effectively. This is supported to some degree by the fact that the only other participant (i.e., Rachel) to report such an elevated level of distress on the Parent Domain withdrew from treatment prematurely. This suggests that parents participating in PCIT who are experiencing additional stressors beyond those presented by parenting a difficult child or difficulties within the parent-child relationship may benefit from adjunct services directly targeted at reducing caregiver distress. However, caution should be used in implementing such adjunct interventions based on the Chaffin et al. (2004) study which suggested that additional services may attenuate therapeutic outcomes.

Consumer satisfaction. Overall, caregiver responses suggested a high degree of satisfaction with in-home PCIT with two of the caregivers giving the highest possible ratings at post-treatment assessment and follow-up assessment. However, these results should be interpreted with caution. First, although measures were taken to ensure that the participants' responses were kept confidential from the therapists (i.e., providing the participants with sealed envelopes for their completed TAIs), it is possible that the participants' responses were biased by their desire to please the experimenters (i.e., therapists). In addition, consumer satisfaction measures were not obtained from Rachel and David's caregivers, so it is unclear whether their termination may have been influenced by dissatisfaction with the intervention. Finally, the TAI was designed to assess consumer satisfaction for the clinic-based PCIT program and no items address the home-based nature of the current intervention.

\section{Additional Considerations and Future Directions}

Clinical considerations. Clinicians providing treatment during this study were able to provide a wealth of information regarding the clinical challenges presented by in-home PCIT. All of the challenges reported by the clinicians could be generally categorized as related to having less environmental control in comparison to clinic-based PCIT. When conducting PCIT in the clinic the clinician has great control over the environment. For example, the clinic therapy room is typically bare except for a table for special playtime, two chairs for the caregiver and child to 
sit in, and a limited number of toys to use during the session. In contrast, when providing treatment in the home, there are many other physical distractions to contend with during session. One reported problem was the distraction of other family members being present in the home and coming and going during session. While clinicians reported that the in-room coaching was initially awkward for families, they felt that generally, providing treatment in the home setting helped facilitate rapport building with the families. These challenges should be explored in future research as they could impact treatment acceptability by treatment providers.

Attrition and attendance. While there were no proposed hypotheses related to attrition and treatment attendance, we had hoped that providing treatment in the home would reduce the likelihood of premature termination and client "no-shows." As reported earlier, there was a 40\% attrition rate in the present study with two out of five families terminating prematurely. Although based on a very small sample, this rate is consistent with research on attrition in child psychotherapy outcome studies estimating that approximately half of families terminate from treatment prematurely (Baekeland \& Lundwall, 1975; Pekarik \& Stephenson, 1988). While consistent with previous research, these results were surprising given that families were offered $\$ 300$ in incentives for their participation. An attempt was made to collect exit interviews from the two families who withdrew from treatment in order to ascertain possible reasons for termination. Several attempts were made to contact David's caregiver, but were met with no response. As indicated previously, Rachel's caregiver reported feeling as though the intervention was too overwhelming for her given the additional stressors she was experiencing at the time (e.g., marital discord). With regard to attendance, participants were present for every session with the exception of David's family who missed two sessions. In other words, the family was not home when the clinicians arrived for the scheduled appointment. Further research is needed to examine attrition and attendance for in-home PCIT in comparison to clinic-based PCIT.

Limitations. Most of the limitations of the present study can be subsumed under concerns with generalization. First, this study was conducted with a number of sources of 
support. Clinicians conducted sessions in pairs $42.80 \%$ of the time. This is important to note because PCIT can be a very demanding therapy to implement as it is so directive due to the demands of live coaching and coding. Clinicians also had the support of an advanced undergraduate student who engaged in a number of tasks including keeping siblings occupied during the session. Second, the clinicians who participated in this study were graduate students in a doctoral program for clinical psychology and received intensive supervision throughout the study. Third, the participants in this study were not clinic-referred. While participants met inclusion criteria for the study based on presence of child behavior problems, their average ECBI Intensity scores were lower than those reported in clinic-based PCIT outcome studies, suggesting that these children may not have exhibited behavior problems comparable to a clinic-referred population. Finally, this study was conducted in a small, university town. Should in-home PCIT be conducted in more urban settings, it is likely that clinicians would encounter unique barriers to treatment (e.g., concerns for safety of the therapist when working in areas with high crime, poverty).

Other limitations were noted regarding the current study including the use of participant incentives, use of self-report measures, and limited follow up. Specifically, participants were paid up to $\$ 300$ for their participation in this study. It is possible that this financial incentive influenced participants' responses on self-report measures. In addition, the anticipation of reaching discipline phase (PDI) was used clinically as an incentive for caregivers to obtain CDI mastery as many caregivers are interested in learning discipline strategies to manage their children's disruptive behavior. Participants also may have been influenced to please the experimenters who came to their homes by responding favorably on the self-report measures. It is hoped that use of behavioral observations provided additional evidence of therapeutic changes and reduced the likelihood that caregiver responses were heavily influenced by experimenter effects. Finally, the follow up used in the present study was at one month, which is a relatively limited period of time in which to assess whether gains maintained. Also, only one 
data point was collected at follow up. A more comprehensive follow up would have included more data points and be collected at a more distant time (e.g., one year) after post-treatment assessment.

Directions for future research. The promising results of this study open the door for many future research studies. First, future research should confirm and expand on the present study. As the present study examined the efficacy of in-home PCIT using an experimental, singlesubject design, a logical next step would be to confirm these results using a randomized design to directly compare in-home and clinic-based PCIT. Another area for future research is effectiveness of in-home PCIT to determine whether this intervention can be successful when implemented by community mental health agencies.

While not addressed directly in this study, one of the arguments for using home-based interventions is increased generalization of skills. Further research should address whether gains made by children and caregivers in in-home PCIT differ from those participating in clinicbased PCIT. Consumer satisfaction ratings for in-home PCIT suggested that families were satisfied with the intervention; however, for the reasons outlined earlier, more research is needed to clarify whether families like home-based services better than clinic-based services. A related area of research could include an analysis of treatment matching to determine which families would be best suited for in-home PCIT. Given that the implementation of PCIT will likely be costly based on the time and travel demands placed on the therapist, use of a decision tree may be helpful in establishing which families would benefit most from this modality.

Finally, clinic-based PCIT has demonstrated a multitude of effects in addition to increasing parent skills and decreasing child disruptive behavior (e.g., generalization of effects to school setting, generalization to nontreated siblings, reduction in recidivism for physical abuse). Future research is needed to examine whether these same effects hold true for in-home PCIT. 


\section{Conclusion}

This study provided an initial evaluation of the efficacy of in-home PCIT, or PCIT conducted completely within the home setting. While there are limitations to the present study, results of this study provide preliminary evidence supporting the use of in-home PCIT to affect change in caregiver behavior, caregiver report of child behavior, and child compliance. The results of this study provide a foundation for many future research areas including examination of the effectiveness of in-home PCIT and whether provision of an EST such as PCIT in the home setting can alleviate barriers to treatment, which ultimately lead to attrition. 


\section{References}

Abidin, R. R. (1995). Parenting Stress Index (3rd ed.). Odessa, FL: Psychological Assessment Resources.

Achenbach, T. M. (1991). Manual for the Child Behavior Checklist/4-18 and 1991 profile. Burlington: University of Vermont, Department of Psychiatry.

Achenbach, T. M., \& Edelbrock, C. S. (1981). Behavioral problems and competencies reported by parents of normal and disturbed children aged 4 through 16. Monographs of the Society for Research in Child Development, 46(1, Serial No. 188).

Achenbach, T. M., \& Rescorla, L. A. (2000). Manual for ASEBA Preschool Forms \& Profiles. Burlington, VT: University of Vermont, Research Center for Children, Youth, \& Families.

Achenbach, T. M., \& Rescorla, L. A. (2001). Manual for ASEBA School-Age Forms \& Profiles. Burlington, VT: University of Vermont, Research Center for Children, Youth, \& Families.

American Psychiatric Association (1994). Diagnostic and Statistical Manual of Mental Disorders (4th ed.). Washington, DC: Author.

Azar, S. T., \& Wolfe, D. A. (1989). Child abuse and neglect. In E. J. Mash \& R. A. Barkley (Eds.), Treatment of Childhood Disorders (pp. 451-489). New York: Guilford.

Baekeland, F., \& Lundwall, L. (1975). Dropping out of treatment: A critical review. Psychological Bulletin, 82, 738-783.

Baumrind, D. (1967). Child care practices anteceding three patterns of preschool behavior. Genetic Psychology Monographs, 75, 43-88.

Baumrind, D. (1991). The influence of parenting style on adolescent competence and substance use. Journal of Early Adolescence, 11, 56-95.

Bessmer, J. L. (1993). The reliability of live coding of the dyadic parent-child interaction coding system-II (clinical version). Unpublished master's thesis, University of Florida, Gainesville.

Bessmer, J., and Eyberg, S. (1993, November). Dyadic Parent-child Interaction coding system-II (DPICS-II): Initial reliability and validity of the clinical version. Paper presented at the AABT Preconference on Social Learning and the Family, Atlanta, Georgia.

Bhavnagri, N. P. (1999). Low income African American mothers' parenting stress and instructional strategies to promote peer relationships in preschool children. Early Education and Development, 10, 551-571.

Boggs, S. R., Eyberg, S. M., Edwards, D., Rayfield, A., Jacobs, J., Bagner, D., et al. (2004). Outcomes of parent-child interaction therapy: A comparison of dropouts and treatment completers one to three years after treatment. Child \& Family Behavior Therapy, 26(4), $1-22$. 
Boggs, S. R., Eyberg, S. M., \& Reynolds, N. A. (1990). Concurrent validity of the Eyberg Child Behavior Inventory. Journal of Clinical Child Psychology, 19, 75-78.

Borduin, C. M., Mann. B. J., Cone, L. T., Henngeler, S. W., Fucci, B. R., Blaske, D. M., et al. (1995). Multisystemic treatment of serious juvenile offenders: Long-term prevention of criminality and violence. Journal of Consulting and Clinical Psychology, 63, 569-578.

Brestan, E. V., Eyberg, S. M., Boggs, S. R., \& Algina, J. (1997). Parent-child interaction therapy: Parents' perceptions of untreated siblings. Child and Family Behavior Therapy, 19, 1328.

Brestan, E. V., Jacobs, J. R., Rayfield, A. D., \& Eyberg, S. M. (1999). A consumer satisfaction measure for parent-child treatments and its relation to measures of child behavior change. Behavior Therapy, 30(1), 17-30.

Brunk, M. A., Henngeler, S. W., \& Wheelan, J. P. (1987). Comparison of multisystemic therapy and parent training in the brief treatment of child abuse and neglect. Journal of consulting and clinical psychology, 55, 171-178.

Chadwick Center for Children and Families. (2004). Closing the quality chasm in child abuse treatment: Identifying and disseminating best practices. San Diego, CA: Author.

Chaffin, M., Silovsky, J. F., Funderburk, B., Valle, L. A., Brestan, E. V., Balachova, T., et al. (2004). Parent-Child Interaction Therapy with physically abusive parents: Efficacy for reducing future abuse reports. Journal of Consulting and Clinical Psychology, 72, 500510.

Choate, M. L., Pincus, D. B., Eyberg, S. M., \& Barlow, D. H. (2005). Treatment of young children with separation anxiety disorder using Parent-Child Interaction Therapy. Cognitive and Behavioral Therapy, 12,125-135.

Chorpita, B. F., Yim, L. M., Donkervoet, J. C., Arensdorf, A., Amundsen, M. J., McGee, C., et al. (2002). Toward large-scale implementation of empirically supported treatments for children" A review and observations by the Hawaii Empirical Basis to Services Task Force. Clinical Psychology: Science and Practice, 9, 165-190.

Dadds, M. R., Sanders, M. R., \& James, J. E. (1987). The generalization of treatment effects in parent training with multidistressed parents. Behavioural Psychotherapy, 15, 289-313.

Daro, D. (1988). Confronting child abuse. New York: The Free Press.

Daro, D., McCurdy, K., Falconnier, L., \& Stojanovic, D. (2003). Sustaining new parents in home visitation services: key participant and program factors. Child Abuse and Neglect, 10, 1101-1125.

Duggan, A., McFarlane, E., Fuddy, L., Burrell, L., Higman, S. M., Windham, A., et al. (2004). Randomized trial of a statewide home visiting program: Impact in preventing child abuse and neglect. Child Abuse and Neglect, 28, 597-622.

Edwards, D. L., Eyberg, S. M., Rayfield, A., Jacobs, J., \& Hood, K. K. (2002). Outcomes of Parent-Child Interaction Therapy: A comparison of treatment completers and treatment 
dropouts one to three years later. Manuscript submitted for publication.

Eisenstadt, T. H., Eyberg, S., McNeil, C. Newcomb, K., \& Funderburk, B. (1993). Parent-child interaction therapy with behavior problem children: Relative effectiveness of two stages and overall treatment outcome. Journal of Clinical Child Psychology, 22, 42-51.

Eyberg, S. M. (1974). Therapy Attitude Inventory. (Available from Sheila Eyberg, PhD, Department of Clinical and Health Psychology, Box 100165 Health Science Center, University of Florida, Gainesville, FL 32610-0165).

Eyberg, S. (1988). Parent-child interaction therapy: Integration of traditional and behavioral concerns. Child and Family Behavior Therapy, 10, 33-45.

Eyberg, S. M., Bessmer, J., Newcomb, K., Edwards, D., \& Robinson, E. (1994). Dyadic Parentchild Interaction Coding System-II: A manual. Social and Behavioral Sciences Documents (Ms. No. 2897).

Eyberg, S. M., Boggs, S. R., \& Algina, J. (1995). Parent-Child Interaction Therapy: A psychosocial model for the treatment of young children with conduct problem behavior and their families. Psychopharmacology Bulletin, 31, 83-91.

Eyberg, S. M., Funderburk, B. W., Hembree-Kigin, T. L., McNeil, C. B., Querido, J. G., \& Hood, K. K. (2001). Parent-Child Interaction Therapy with behavior problem children: One and two year maintenance of treatment effects in the family. Child and Family Behavior Therapy, 23(4), 1-20.

Eyberg, S. M., \& Johnson, S. M. (1974). Multiple assessment of behavior modification with families: Effects of contingency contrasting and order of treated problems. Journal of Consulting and Clinical Psychology, 42, 594-606.

Eyberg, S. M., \& Matarazzo, R. G. (1980). Training parents as therapists: A comparison between individual parent child interactions training and parent group didactic training. Journal of Clinical Psychology, 36, 492-499.

Eyberg, S. M., \& Pincus, D. (1999). Eyberg Child Behavior Inventory Sutter Student Behavior Inventory - Revised professional manual. Psychological Assessment Resources.

Eyberg, S. M., \& Robinson, E. A. (1982). Parent-child interaction training: Effects on family functioning. Journal of Clinical Child Psychology, 11, 130-137.

Eyberg, S. M. \& Ross, A. W. (1978). Assessment of child behavior problems: The validation of a new inventory. Journal of Clinical Child Psychology, 7, 113-116.

Forehand, R., \& McMahon, R. (1981). Helping the noncompliant child: A clinician's guide to parent training. New York: Guilford Press.

Funderburk, B. W., Eyberg, S. M., Newcomb, K., McNeil, C. B., Hembree-Kigin, T., \& Capage, L. (1998). Parent-Child Interaction Therapy with behavior problem children: Maintenance of treatment effects in the school setting. Child and Family Behavior Therapy, 20, 17-38.

Gomby, D. (1999). Understanding evaluations of home visitation programs. The Future of 
Children, 9, 27-43.

Gomby, D., Culross, P., \& Behrman, R. (1999). Home visiting: Recent program evaluations Analysis and Recommendations. The Future of Children, 9, 4-26.

Gomby, D. S., Larson, C. S., Lewit, E. M., \& Behrman, R. E. (1993). Home visiting: Analysis and Recommendations. The Future of Children, 3(3), 6-22.

Greco, L. A., Sorrell, J. T., \& McNeil, C. B. (2001). Understanding manual-based behavior therapy: Some theoretical foundations for Parent-Child Interaction Therapy. Child and Family Behavior Therapy, 23(4), 21-36.

Hanf, M. (1969). A Two Stage Program for Modifying Maternal Controlling During Mother-Child $(M-C)$ Interaction. Paper presented at the meeting of the Western Psychological Association, Vancouver, BC.

Hawkins, R. P., Peterson, R. F., \& Scweid, E. (1966). Behavior therapy in the home: Amelioration of problem parent-child relations with the parent in a therapeutic role. Journal of Experimental Child Psychology, 4, 99-107.

Hembree-Kigin, T. L., \& McNeil, C. (1995). Parent-child interaction therapy. New York: Plenum.

Henggeler, S. W. (1999). Multisystemic therapy: An overview of clinical procedures, outcomes, and policy implications. Child Psychology \& Psychiatry Review, 4(1), 2-10.

Henngeler, S. W., Borduin, C. M., Melton, G. B., Mann, B. J., Smith, L., Hall, J. A., et al. (1991). Effects of multisystemic therapy on drug use and abuse in serious juvenile offenders: $A$ progress report from two outcome studies. Family Dynamics of Addiction Quarterly, 1, 40-51.

Henggeler, S. W., Melton, G. B., \& Smith, L. A. (1992). Family preservation using multisystemic therapy: An effective alternative to incarcerating serious juvenile offenders. Journal of Consulting and Clinical Psychology, 60, 953-961.

Henggeler, S. W., Melton, G. B., Brondino, M. J., Scherer, D. G., \& Hanley, J. H. (1997). Multisystemic therapy with violent and chronic juvenile offenders and their families: The role of treatment fidelity in successful dissemination. Journal of Consulting and Clinical Psychology, 65, 821-833.

Henggeler, S. W., Schoenwald, S. K., Borduin, C. M., Rowland, M. D., \& Cunningham, P. B. (1998). Multisystemic treatment of antisocial behavior in children and adolescents. New York: Guilford.

Herschell, A. D., McNeil, C. B., \& McNeil, D. W. (2004). Clinical child psychology's progress in disseminating empirically supported treatments. Clinical Psychology: Science and Practice, 11, 267-288.

Hood, K. K., \& Eyberg, S. M. (2003). Outcomes of Parent-Child Interaction Therapy: Mothers' reports of maintenance three to six years after treatment. Journal of Clinical Child and Adolescent Psychology, 32, 419-429. 
Kelley, S. J. (1998). Stress and coping behaviors of substance abusing mothers. Journal of the Society of Pediatric Nurses, 3, 103-110.

Kempe, H. (1976). Child abuse and neglect: The family and the community. Cambridge, MA: Ballinger.

McNeil, C. B., Capage, L. C., Bahl, A., \& Blanc, H. (1999). Importance of early intervention for disruptive behavior problems: Comparisons of treatment and wait-list control groups. Early Education and Development, 10, 445-454.

McNeil, C. B., Eyberg, S. M., Eisenstadt, T. H., Newcomb, K., \& Funderburk, B. W. (1991). Parent-Child Interaction Therapy with behavior problem children: Generalization of treatment effects to the school setting. Journal of Clinical Child Psychology, 20, 140-151.

Miller, E. M., \& Eyberg, S. M. (1991). Parent-Child Interaction Therapy with a diabetic child. Advances in Child Health Psychology: Abstracts. Gainesville, FL: Clinical and Health Psychology Publishing.

Nixon, R. D. V., Sweeney, L., Erickson, D. B., \& Touyz, S. W. (2003). Parent-Child Interaction Therapy: A comparison of standard and abbreviated treatments for oppositional defiant preschoolers. Journal of Consulting and Clinical Psychology, 71, 251-260.

Olds, D. (2003). Reducing program attrition in home visiting: What do we need to know? Child abuse \& neglect, 27(4), 359-361.

Olds, D. (2006). The Nurse-Family Partnership: An evidence-based preventive intervention. Infant Mental Health Journal, 27(1), 5-25.

Olds, D., Kitzman, H., Cole, R., \& Robinson, J. (1997). Theoretical foundations of a program of home visitation for pregnant women and parents of young children. Journal of community psychology, 25(1), 9-25.

Olson, S. L., Bates, J. E., \& Bayles, K. (1990). Early antecedents of child hyperactivity: The role of parent-child interaction, cognitive competence, and temperament. Journal of Abnormal Child Psychology, 18, 317-334.

Patterson, G. R. (1976). The aggressive child: Victim and architect of a coercive system. In E. J. Mash, L. A. Hamerlynck, \& L. C. Handy (Eds.), Behavior modification and families (pp. 267-316). New York: Brunner/Mazel.

Patterson, G. R. (1982). Coercive family process. Eugene, OR: Castalia.

Patterson, G. R., Reid, J. G., Jones, R. R., \& Conger, R. E. (1975). A social learning approach to family intervention: Families with aggressive children. Eugene, OR: Castalia.

Pekarik, G., \& Stephenson, L. A. (1988). Adult and child client differences in therapy dropout research. Journal of Clinical Child Psychology, 17, 316-321.

Perez, J. C., Bell, S., Adams, R. W., Garzarella, L., \& Eyberg, S. M. (2002). Tracking treatment progress of families with oppositional preschoolers. Paper presented at the Third Annual Parent-Child Interaction Therapy Conference, Sacramento, CA. 
Querido, J. G., \& Eyberg, S. M. (2001, June). Parent-Child Interaction Therapy with Head Start families. Poster session presented at the second annual PCIT meeting, Sacramento, CA.

Rayfield, A., \& Sobel, A. (2000). Effectiveness of "in-room" coaching of Parent-Child Interaction Therapy. Paper presented at the First Annual Parent-Child Interaction Therapy Conference, Sacramento, CA.

Reitman, D., Currier, R. O., \& Stickle, T. R. (2002). A critical evaluation of the Parenting Stress Index - Short Form (PSI-SF) in a Head Start population. Journal of Clinical Child and Adolescent Psychology, 31, 384-392.

Sanders, M. R. (1999). Triple P-positive parenting program: Towards an empirically validated multilevel parenting and family support strategy for the prevention of behavior and emotional problems in children. Clinical Child and Family Psychology Review, 2(2), 7190 .

Sanders, M. R., \& Dadds, M. R. (1982). The effects of planned activities and child management procedures in parent training: An analysis of setting generality. Behavior Therapy, 13, 452-461.

Schoenwald, S. K., \& Henggeler, S. W. (1997). Combining effective treatment strategies with family-preservation models of service delivery. In R. J. Illback, C. T. Cobb \& H. M. J. Joseph (Eds.), Integrated services for children and families: Opportunities for psychological practice (pp. 121-136). Washington, DC: American Psychological Association.

Schoenwald, S. K., \& Hoagwood, K. (2001). Effectiveness, transportability, and dissemination of interventions: What matters when? Psychiatric Services, 52, 1190-1197.

Schuhmann, E., Foote, R., Eyberg, S. M., Boggs, S., \& Algina, J. (1998). Parent-Child Interaction Therapy: Interim report of a randomized trial with short-term maintenance. Journal of Clinical Child Psychology, 27, 34-45.

Shirk, S. R. (2004). Dissemination of youth ESTs: Ready for prime time? Clinical Psychology: Science and Practice, 11(3), 308-312.

Silverman, W. K., Kurtines, W. M., \& Hoagwood, K. (2004). Research progress on effectiveness, transportability, and dissemination of empirically supported treatments: Integrating theory and research. Clinical Psychology: Science and Practice, 11, 295299.

Stokes, T. F., \& Baer, D. M. (1977). An implicit technology of generalization. Journal of Applied Behavior Analysis, 10, 349-367.

Stokes, T. F., \& Osnes, P. G. (1989). An operant pursuit of generalization. Behavior Therapy, 20, 337-355.

Sweet, M. A., \& Applebaum, M. I. (2004). Is home visiting an effective strategy? A meta-analytic review of home visiting programs for families with young children. Child Development, 5, 
1435-1456.

Timmer, S. G., Urquiza, A. J., Zebell, N. M., \& McGrath, J. M. (2005). Parent-Child Interaction Therapy: Application to physically abusive and high-risk parent-child dyads. Child Abuse \& Neglect, 29, 825-842.

Urquiza, A. J., \& McNeil, C. B. (1996). Parent-Child Interaction Therapy: Potential applications for physically abusive families. Child Maltreatment, 1, 134-144.

Urquiza, A. J., Timmer, S. G., Herschell, A. D., McGrath, J. M., Zebell, N. M., Porter, A. L., et al. (in press). Parent-Child Interaction Therapy: Application of an empirically supported treatment to maltreated children in foster care. Child Maltreatment.

Wahler, R. G., Winkel, G. H., Peterson, R. F., \& Morrison, D. C. (1965). Mothers as behavior therapists for their own children. Behaviour Research and Therapy, 3, 113-124.

Webster-Stratton, C. (1981). Modification of mothers' behaviors and attitudes through a videotape modeling group discussion program. Behavior Therapy, 12, 634-642.

Worland, J., Carney, R., Milich, R., \& Grame, C. (1980). Does in-home training add to the effectiveness of operant group parent training? A two-year evaluation. Child Behavior Therapy, 2(1), 11-24. 
Appendix A

Child Behavior Checklist (Achenbach \& Rescorla, 2000, 2001) 
Appendix B

Dyadic Parent-Child Interaction Coding System Instructions for Caregivers 


\section{Dyadic Parent-Child Interaction Coding System Instructions for Caregivers}

\section{Child Directed Interaction (CDI)}

"In this situation, tell (child's name) that he/she may play with whatever he/she chooses. Let

him/her pick any activity he/she wants. You just follow his/her lead and play along with him/her."

Parent Directed Interaction (PDI)

"That was fine. Now we'll switch to another situation. Tell (child's name) that it's your turn to pick the game. You can pick any activity. Keep him/her playing with you according to your rules." 
Appendix C

DPICS Coding Form 


\begin{tabular}{|l|l|l|l|l|l|l|l|l|l|l|l|l|l|l|l|l|}
\hline & 1 & 2 & 3 & 4 & 5 & 6 & 7 & 8 & 9 & 10 & 11 & 12 & 13 & 14 & 15 & \\
\hline LP & & & & & & & & & & & & & & & & LP \\
\hline BD & & & & & & & & & & & & & & & & BD \\
\hline RF & & & & & & & & & & & & & & & & RF \\
\hline QU & & & & & & & & & & & & & & & & QU \\
\hline CR & & & & & & & & & & & & & & & & CR \\
\hline DC & & & & & & & & & & & & & & & & DC \\
\hline IC & & & & & & & & & & & & & & & & IC \\
\hline CP & & & & & & & & & & & & & & & & CP \\
\hline CCO & & & & & & & & & & & & & & & & CCO \\
\hline Other & & & & & & & & & & & & & & & & Other \\
\hline & 16 & 17 & 18 & 19 & 20 & 21 & 22 & 23 & 24 & 25 & 26 & 27 & 28 & 29 & 30 & \\
\hline LP & & & & & & & & & & & & & & & & LP \\
\hline BD & & & & & & & & & & & & & & & & BD \\
\hline RF & & & & & & & & & & & & & & & & RF \\
\hline QU & & & & & & & & & & & & & & & & QU \\
\hline CR & & & & & & & & & & & & & & & & CR \\
\hline DC & & & & & & & & & & & & & & & & DC \\
\hline IC & & & & & & & & & & & & & & & & IC \\
\hline CP & & & & & & & & & & & & & & & & CP \\
\hline CCO & & & & & & & & & & & & & & & & CCO \\
\hline Other & & & & & & & & & & & & & & & & Other \\
\hline
\end{tabular}


Appendix D

Demographics Form 


\section{Demographics Form}

Please complete the following information. Place an X next to the appropriate responses.

Child's Name Date

Child's Birth Date

Child's Gender: __ Male

— Female

Child's Ethnicity: __ Caucasian

African American

Asian/Pacific Islander

Hispanic

Multi-Ethnic

Other

Caregiver's Birth Date

Caregiver's Gender: __ Male

_ Female

Caregiver's Ethnicity: ___ Caucasian

African American

Asian/Pacific islander

Hispanic

Multi-Ethnic

Other

Please list your child's siblings and their ages below:

\begin{tabular}{|l|l|}
\hline Name & Age \\
\hline & \\
\hline & \\
\hline & \\
\hline & \\
\hline
\end{tabular}


Which best describes your relationship with your child:

Biological parent

Step-parent

Foster parent

Adoptive parent

Other relative guardian

Other

The child's primary caregivers are:

Married

_ Separated
Divorced
Single
Living Together
Widow/er

The following describes the child's primary caregivers employment status:

Caregiver:

Working part-time

Unemployed

Retired

Full-time foster parent

Job Title:
Caregiver:

W_ Working full time

Unemployed

Retired

Full-time foster parent

Job Title:

The highest education level of the child's primary caregivers are:

Caregiver:

Some High School

GED

High School Degree

Professional/Trade School Degree

Associate's Degree

Bachelor's Degree

Master's Degree

Advanced Degree (ex: Ph.D., M.D.)

Other

Approximate family income per year:
Caregiver:

Some High School

GED

High School Degree

Professional/Trade School Degree

Associate's Degree

Bachelor's Degree

Master's Degree

Advanced Degree (ex: Ph.D., M.D.)

Other

$\$ 10,000$ or below

$\$ 10,001$ to $\$ 20,000$

$\$ 20,001$ to $\$ 30,000$

$\$ 30,001$ to $\$ 40,000$

$\$ 40,001$ to $\$ 50,000$

$\$ 50,001$ to $\$ 60,000$

$\$ 60,001$ or above 
Appendix $\mathrm{E}$

DSM-IV Structured Interview for Disruptive Behavior Disorders (McNeil et al., 1991) 
Appendix F

Eyberg Child Behavior Inventory (Eyberg \& Pincus, 1999) 
Appendix G

Parenting Stress Index - Short Form (Abidin, 1995) 
Appendix $\mathrm{H}$

Therapy Attitude Inventory (Eyberg, 1974) 
Appendix I

Sample Integrity Checklist 


\section{FIRST CDI COACHING SESSION OUTLINE/INTEGRITY CHECKLIST}

Date:

Therapist:

Child:

Integrity Check? Y I N Rater:

\section{Before this session}

1. Bring toy box containing legos, Mr. Potato Head, and art supplies

2. Bring DPICS coding sheet and homework sheets

3. Bring timer for DPICS-II coding

4. Bring $\mathrm{ECBI}$ for caregiver to complete

\section{TREATMENT SESSION}

\section{Check-in \& set-up}

(1) Have caregiver complete the ECBI

(2) Talk with child briefly about therapy

- Why they are in therapy

- What therapy will be like

- The room and the toys

- The in-room coaching rules (e.g., "I cannot look at you or talk with you when you are playing with your mom. You should pretend like I'm invisible. I will be whispering ideas to your mom to maker her play with you even more fun. When our coaching time is over, then I can talk with you and play with you again.")

(3) Set-up PCIT area - place the legos, Mr. Potato Head, and art supplies on the table

(4) Let the child play at the table; sit with caregiver

(5) Remind caregiver of the "Do" (i.e., PRIDE) and "Avoid" (i.e., commands, questions, criticisms) skills of CDI.

Review briefly, longer only if it seems you need to establish more credibility with the caregiver (i.e., if caregiver seems skeptical of treatment or of you as an expert). In this case, present this as a leading theory/approach in the area of child behavior problems, and emphasize how effective it is. 


\section{FIRST CDI COACHING SESSION OUTLINE/INTEGRITY CHECKLIST (Continued)}

(6) Ask for homework sheets. Review homework for about 10 minutes.

Issues might include:

a) Praising caregivers for doing homework (however often they completed it);

b) Any comment caregiver wrote on homework sheet;

c) Any activity on sheet that is likely to be problematic;

d) Asking how child liked CDI;

e) Asking what CDI skill caregiver found hardest to do; in this case, offer reassurance.

(7) Discuss one issue unrelated to the child's behavior or the caregiver's use of treatment skills or child management.

\section{Coding and Coaching}

(8) Get into your coaching position next to the caregiver (away from the child).

(9) Explain DPICS-II CDI observation to caregiver:

OK, IN THIS SITUATION, TELL (CHILD'S NAME) THAT HEISHE MAY PLAY WITH WHATEVER HE/SHE CHOOSES. LET HIM/HER PICK ANY ACTIVITY HE/SHE WANTS. YOU JUST FOLLOW HIS/HER LEAD AND PLAY ALONG WITH HIM/HER.

(10) Code caregiver and child in CDI for 5 minutes.

(11) Explain DPICS-II PDI observation to caregiver:

THAT WAS FINE. NOW WE'LL SWITCH TO ANOTHER SITUATION. TELL (CHILD'S NAME) THAT IT'S YOUR TURN TO PICK THE GAME. YOU CAN PICK ANY ACTIVITY. KEEP HIM/HER PLAYING WITH YOU ACCORDING TO YOUR RULES.

(12) Code caregiver and child in PDI for 5 minutes. 


\section{FIRST CDI COACHING SESSION OUTLINE/INTEGRITY CHECKLIST (Continued)}

(13) Coach parent with child for about 30 minutes.

a) Have caregiver tell child the rules of special playtime.

"Today we are going to have special playtime. You can play with any of the toys on the table, and I will play with you. There are two rules. You have to play gently with the toys and you have to stay in your chair. If you play roughly or get out of your chair, I will turn around like this and play all by myself. Then, when you play nicely or sit down, I will turn back around and play with you. You're playing nicely now, so we can play with anything on this table that you want to play with."

b) Give caregiver labeled praises for the best skills demonstrated during coding.

c) Focus coaching primarily on behavioral descriptions

d) Give only positive feedback today; don't point out mistakes.

** See detailed coaching guidelines for this session attached.

\section{Review}

(14) Review coding sheets with caregiver for about 5 minutes. Focus on their strengths and reassure them that they are doing fine.

\section{Wrap up}

(15) Give new homework sheets and encourage caregiver to focus especially on decreasing questions and increasing reflections during their home practice. (Unless these skills are already at criterion and another skill needs more emphasis).

(16) Confirm next appointment time with parents. Write it down.

(17) File integrity checklist(s), coding sheet(s), homework sheet, and ECBI in participant's file and return file to clinic. 
Table 1

Dependent Variables, Measures, and Assessment Points

\begin{tabular}{|c|c|c|}
\hline Dependent Variable & Measure & Assessment Point(s) \\
\hline Caregiver positive behavior & DPICS-II CDI observation & $\begin{array}{l}\text { Pre-treatment } \\
\text { Prior to each session } \\
\text { Post-treatment } \\
\text { Follow up }\end{array}$ \\
\hline Caregiver negative behavior & DPICS-II CDI observation & $\begin{array}{l}\text { Pre-treatment } \\
\text { Prior to each session } \\
\text { Post-treatment } \\
\text { Follow up }\end{array}$ \\
\hline $\begin{array}{l}\text { Caregiver proportion of direct } \\
\text { commands }\end{array}$ & DPICS-II PDI observation & $\begin{array}{l}\text { Pre-treatment } \\
\text { Prior to each session } \\
\text { Post-treatment } \\
\text { Follow up }\end{array}$ \\
\hline Caregiver contingent praise & DPICS-II PDI observation & $\begin{array}{l}\text { Pre-treatment } \\
\text { Prior to each session } \\
\text { Post-treatment } \\
\text { Follow up }\end{array}$ \\
\hline
\end{tabular}


Table 1 (continued)

\begin{tabular}{|c|c|c|}
\hline Dependent Variable & Measure & Assessment Point(s) \\
\hline Child compliance & DPICS-II PDI observations & $\begin{array}{l}\text { Pre-treatment } \\
\text { Prior to each session } \\
\text { Post-treatment } \\
\text { Follow up }\end{array}$ \\
\hline $\begin{array}{l}\text { Diagnostic criteria for disruptive } \\
\text { behavior disorders }\end{array}$ & $\begin{array}{l}\text { DSM-IV Structured Interview for } \\
\text { Disruptive Behavior Disorders }\end{array}$ & $\begin{array}{l}\text { Pre-treatment } \\
\text { Post-treatment } \\
\text { Follow up }\end{array}$ \\
\hline $\begin{array}{l}\text { Caregiver report of child } \\
\text { behavior problems }\end{array}$ & Eyberg Child Behavior Inventory & $\begin{array}{l}\text { Pre-treatment } \\
\text { Prior to each session } \\
\text { Post-treatment } \\
\text { Follow up }\end{array}$ \\
\hline Parenting stress & Parenting Stress Index - Short Form & $\begin{array}{l}\text { Pre-treatment } \\
\text { Post-treatment } \\
\text { Follow up }\end{array}$ \\
\hline Consumer satisfaction & Therapy Attitude Inventory & $\begin{array}{l}\text { Post-treatment } \\
\text { Follow up }\end{array}$ \\
\hline
\end{tabular}


Table 2

Definitions of DPICS-II Codes

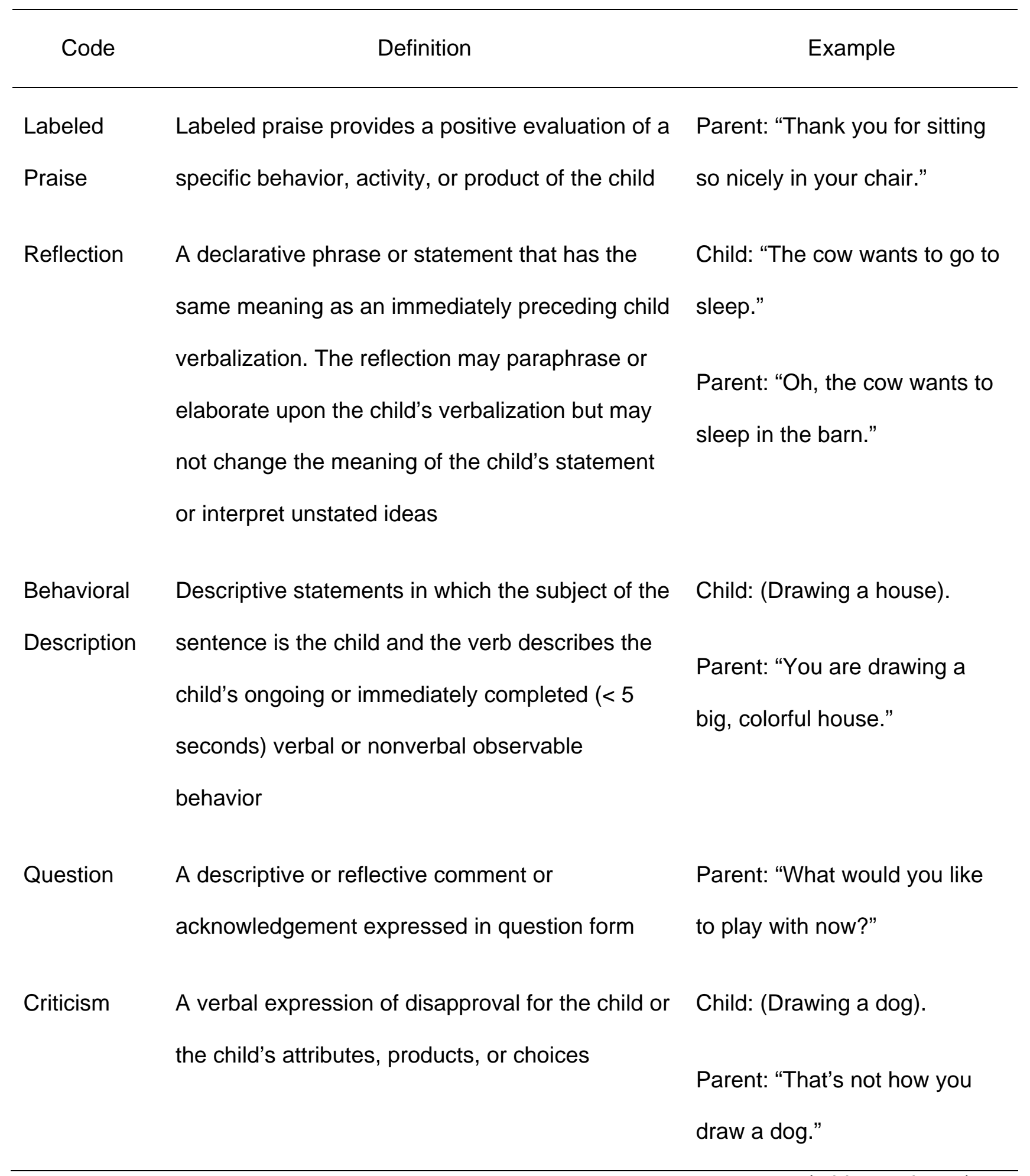

(table continues) 
Table 2 (continued)

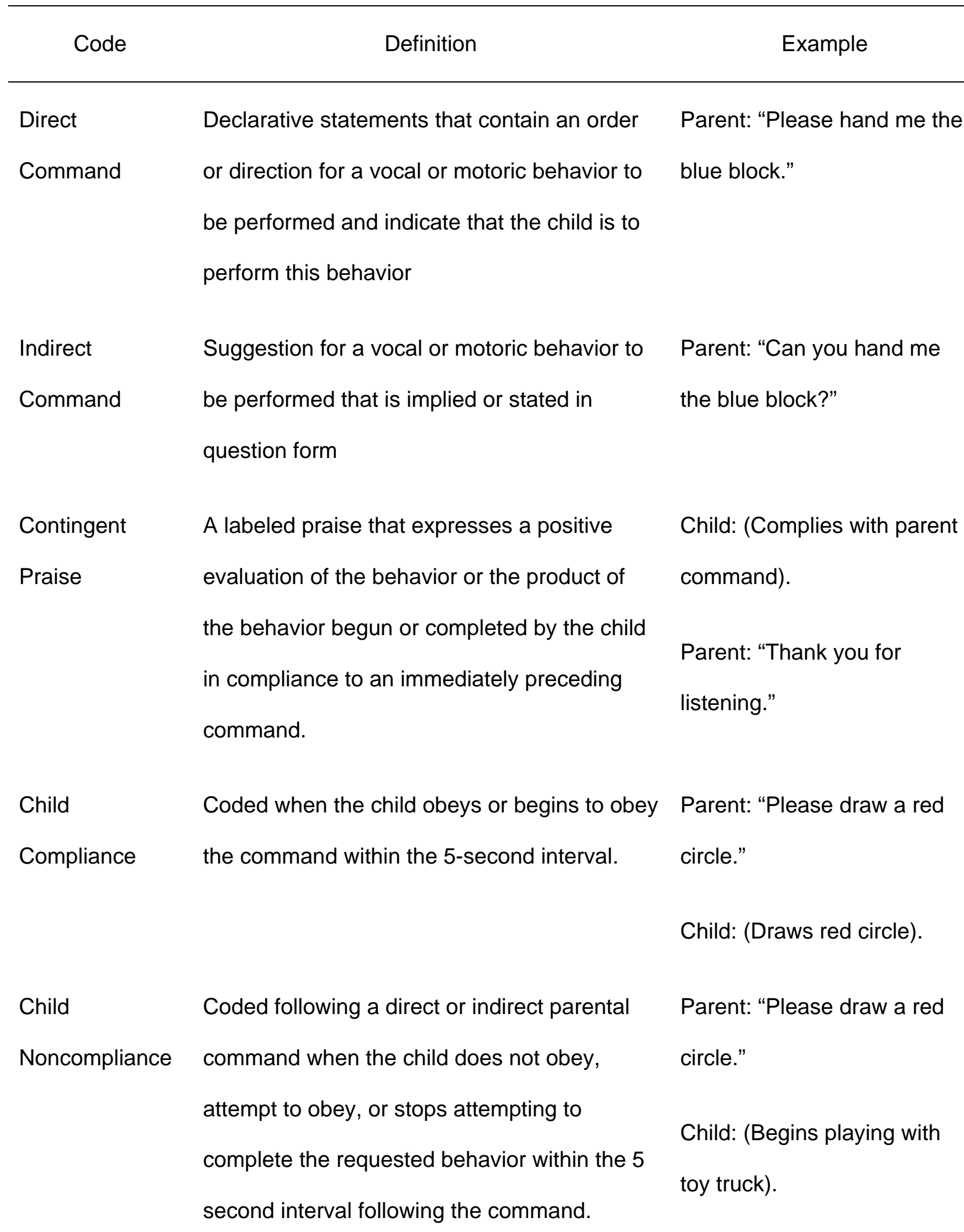


Table 2 (continued)

\begin{tabular}{lll}
\multicolumn{1}{c}{ Code } & \multicolumn{1}{c}{ Definition } & \multicolumn{1}{c}{ Example } \\
\hline Child No & Coded when the child is not given an & Parent: "Please put the \\
Opportunity for & adequate chance to comply with a command. & blocks away." (Parent is \\
Compliance & & holding container out of the \\
& & child's reach) \\
\hline Cther & Coded when none of the other categories are & Parent: "I'm drawing a yellow \\
& applicable. & sun." \\
\hline
\end{tabular}


Table 3

Assessment Procedures

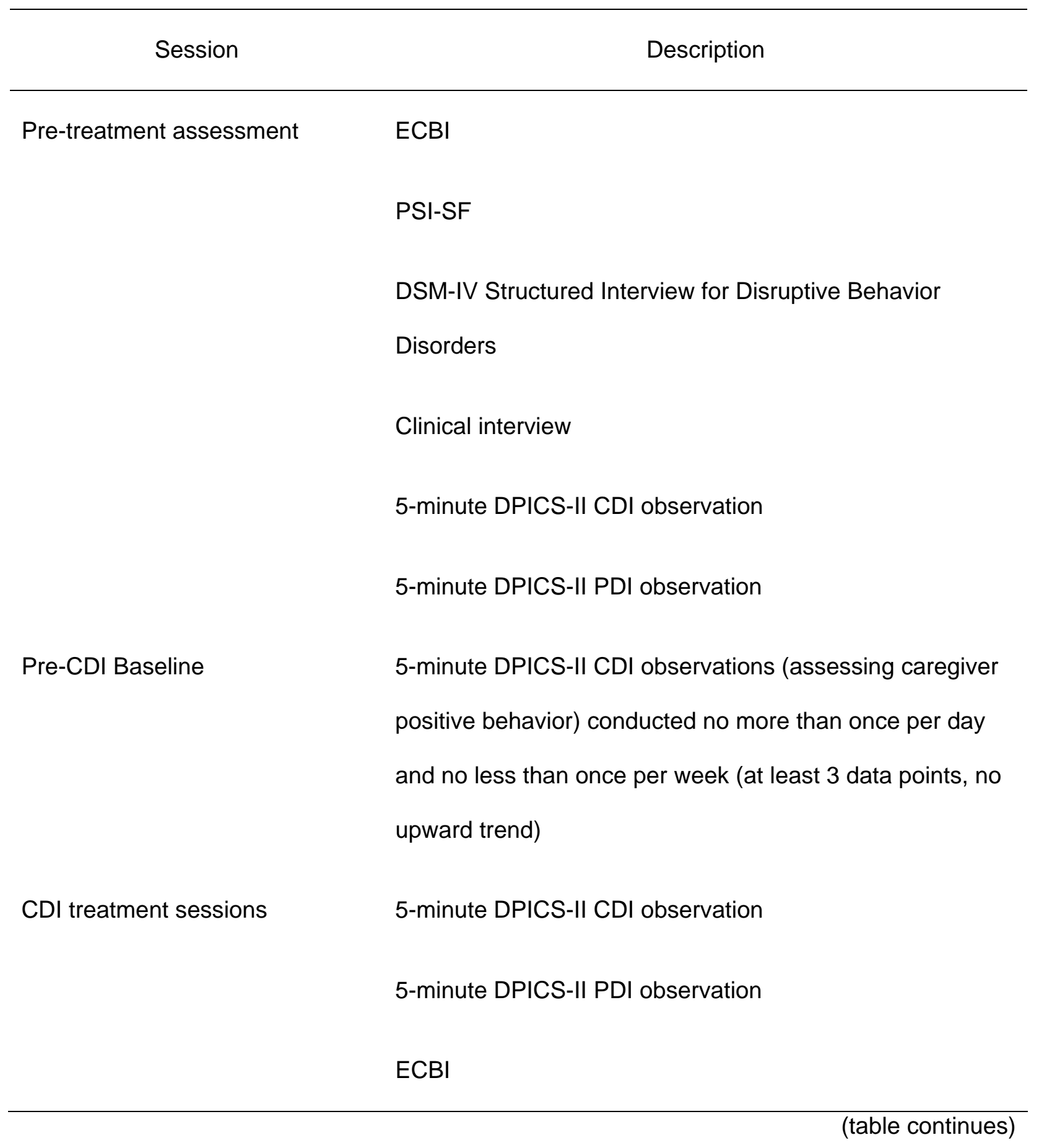


Table 3 (continued)

\begin{tabular}{|c|c|}
\hline Session & Description \\
\hline Pre-PDI Baseline & $\begin{array}{l}\text { 5-minute DPICS-II PDI observations (assessing caregiver } \\
\text { proportion of direct commands) conducted no more than } \\
\text { once per day and no less than once per week (at least } 3 \\
\text { data points, no upward trend) }\end{array}$ \\
\hline \multirow[t]{3}{*}{ PDI treatment sessions } & 5-minute DPICS-II CDI observation \\
\hline & 5-minute DPICS-II PDI observation \\
\hline & ECBI \\
\hline \multirow[t]{7}{*}{ Post-treatment assessment } & ECBI \\
\hline & PSI-SF \\
\hline & TAl \\
\hline & DSM-IV Structured Interview for Disruptive Behavior \\
\hline & Disorders \\
\hline & 5-minute DPICS-II CDI observation \\
\hline & 5-minute DPICS-II PDI observation \\
\hline
\end{tabular}


Table 3 (continued)

Session

Description

\begin{tabular}{|c|c|}
\hline \multirow[t]{7}{*}{ Follow up } & $\mathrm{ECBI}$ \\
\hline & PSI-SF \\
\hline & TAl \\
\hline & DSM-IV Structured Interview for Disruptive Behavior \\
\hline & Disorders \\
\hline & 5-minute DPICS-II CDI observation \\
\hline & 5-minute DPICS-II PDI observation \\
\hline
\end{tabular}


Table 4

Diagnoses of Participants Based on Caregiver Report on the DSM-IV Structured Interview for Disruptive Behavior Disorders

DSM-IV Structured Interview for Disruptive Behavior Disorders

\begin{tabular}{llll}
\hline Child & Pre treatment & Post treatment & Follow up \\
\hline Alex & ODD & ADHD-Impulsive & ADHD-Impulsive Type \\
& ADHD- Combined Type & Type & \\
Noah & ODD & None & None \\
& ADHD- Impulsive Type & & None \\
\hline Tami & ODD & None & Unavailable \\
\hline Rachel & ODD & Unavailable & \\
\hline David & ODD & & Unavailable \\
\hline
\end{tabular}

Note. DSM-IV = Diagnostic and Statistical Manual - Fourth Edition; ODD = Oppositional Defiant Disorder; ADHD = Attention Deficit/Hyperactivity Disorder. 
Table 5

Comparison of ECBI Intensity scores to previous PCIT studies

ECBI Intensity scores

\begin{tabular}{lccc}
\hline & Pre treatment & Post treatment & Follow up \\
Study & M (SD) & M (SD) & M (SD) \\
\hline Ware et al., 2006 & $157.67(34.82)$ & $89.33(12.90)$ & $71.67(8.14)$ \\
\hline Nixon et al., 2003 & $166.59(18.93)$ & $125.24(21.67)$ & $117.47(31.69)$ \\
\hline Schuhmann et al., 1998 & $172.9(28.80)$ & $131.6(40.60)$ & $126.3(42.1)$ \\
\hline Eisenstadt et al., 1993 & $169.3(25.90)$ & $112.0(20.10)$ & Not reported \\
\hline McNeil et al., 1991 & $180.7(28.20)$ & $105.9(29.20)$ & Not conducted \\
\hline
\end{tabular}

Note. $\mathrm{ECBI}=$ Eyberg Child Behavior Inventory; PCIT = Parent-Child Interaction Therapy. 
Table 6

Comparison of Child Compliance rates to previous PCIT studies

\section{Percent Child Compliance}

\begin{tabular}{lccc}
\hline Study & Pre treatment & Post treatment & Follow up \\
& M (SD) & M (SD) & M (SD) \\
\hline Ware et al., 2006 & $21.79(25.61)$ & $100.0(0.0)$ & $97.92(.03)$ \\
\hline Nixon et al., 2003 & $64(24)$ & $81(22)$ & Not reported \\
\hline Schuhmann et al., 1998 & 23 & 47 & Not reported \\
\hline Eisenstadt et al., 1993 & $47.0(15.9)$ & $73.1(19.9)$ & Not conducted \\
\hline
\end{tabular}

Note. PCIT $=$ Parent-Child Interaction Therapy . 


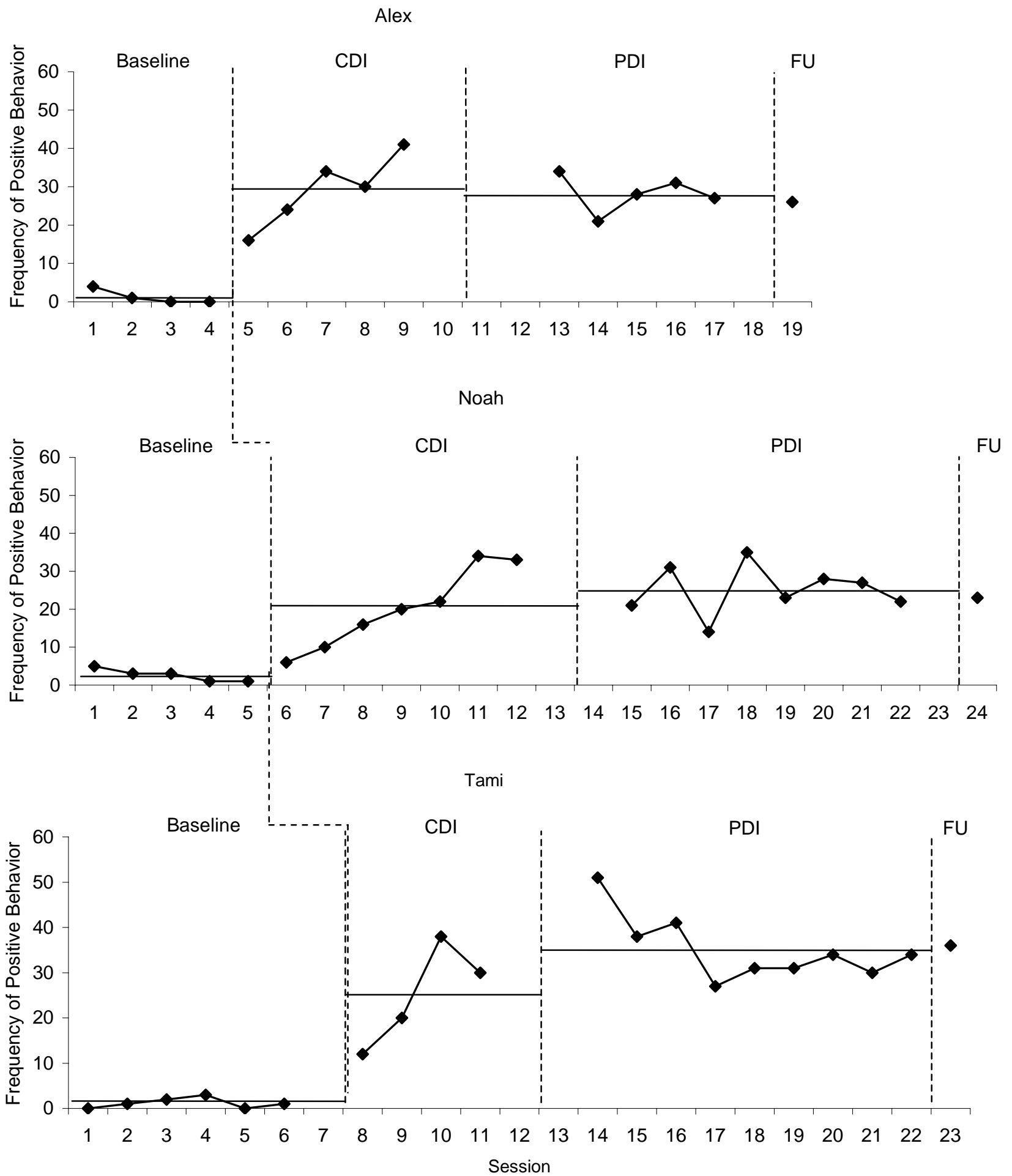

Figure 1. Caregiver positive behavior exhibited by caregivers who completed treatment with horizontal lines indicating means for each phase. 
Alex
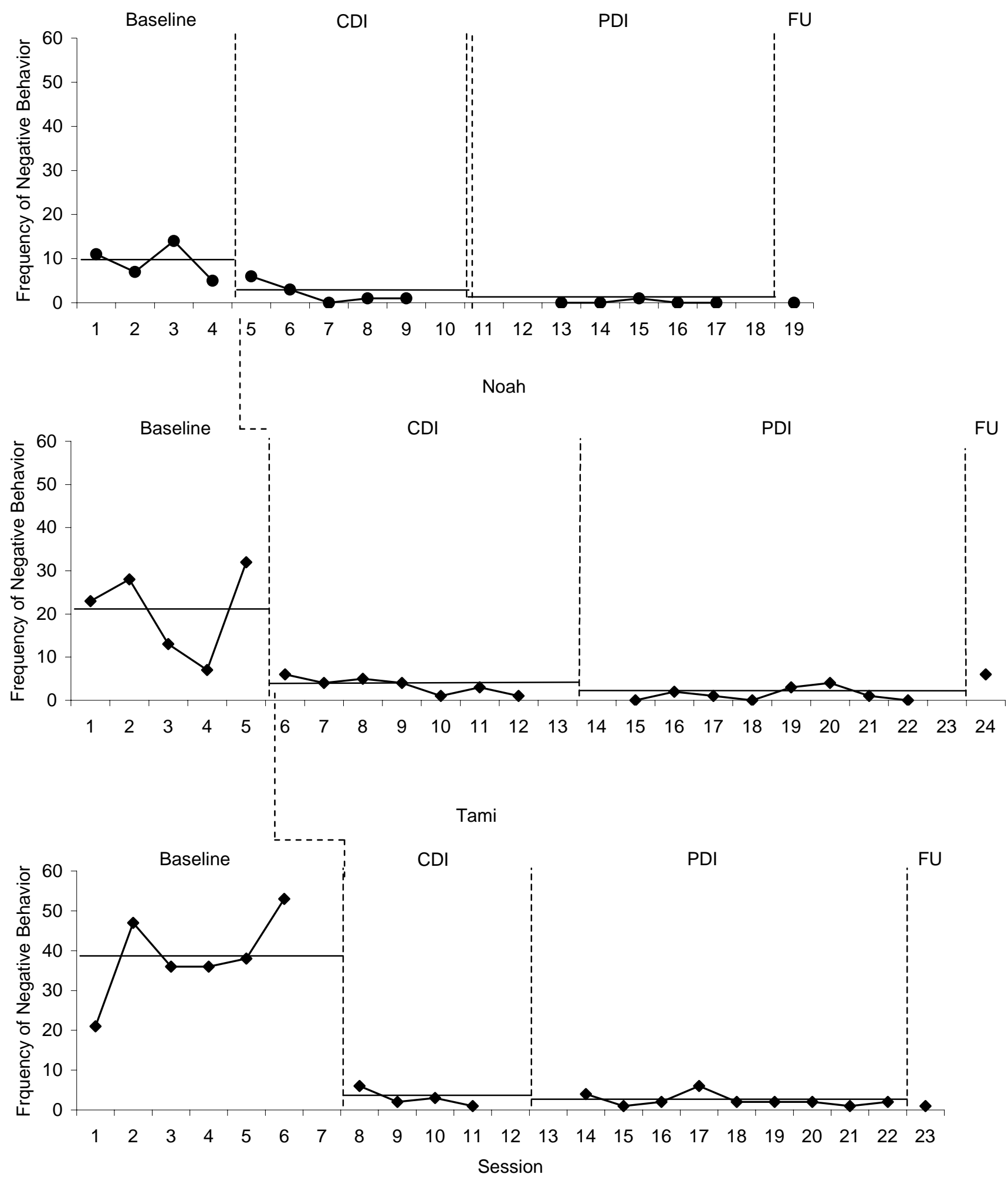

Figure 2. Caregiver negative behavior exhibited by caregivers who completed treatment with horizontal lines indicating means for each phase. 

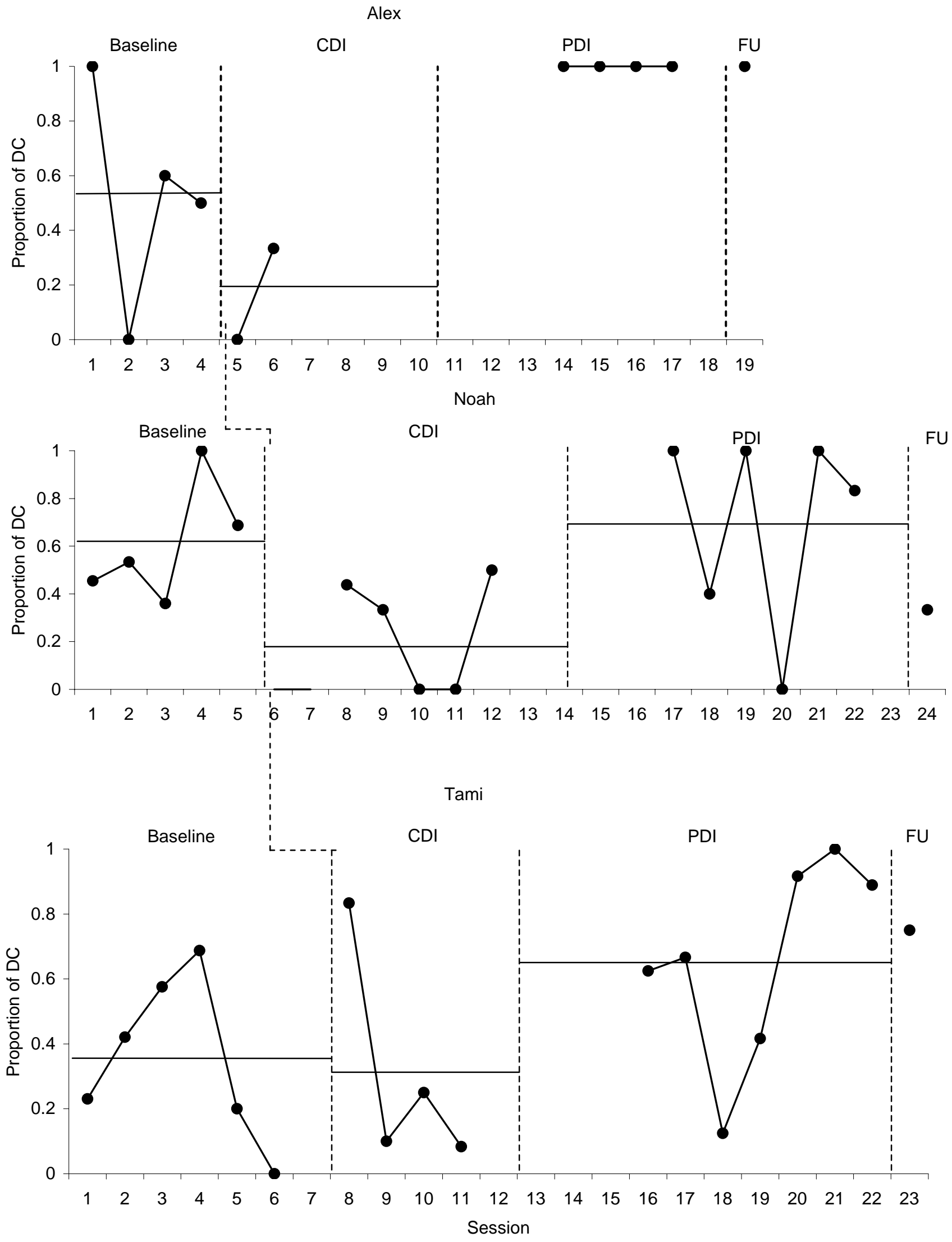

Figure 3. Proportion of direct commands exhibited by caregivers who completed treatment with horizontal lines indicating means for each phase. 

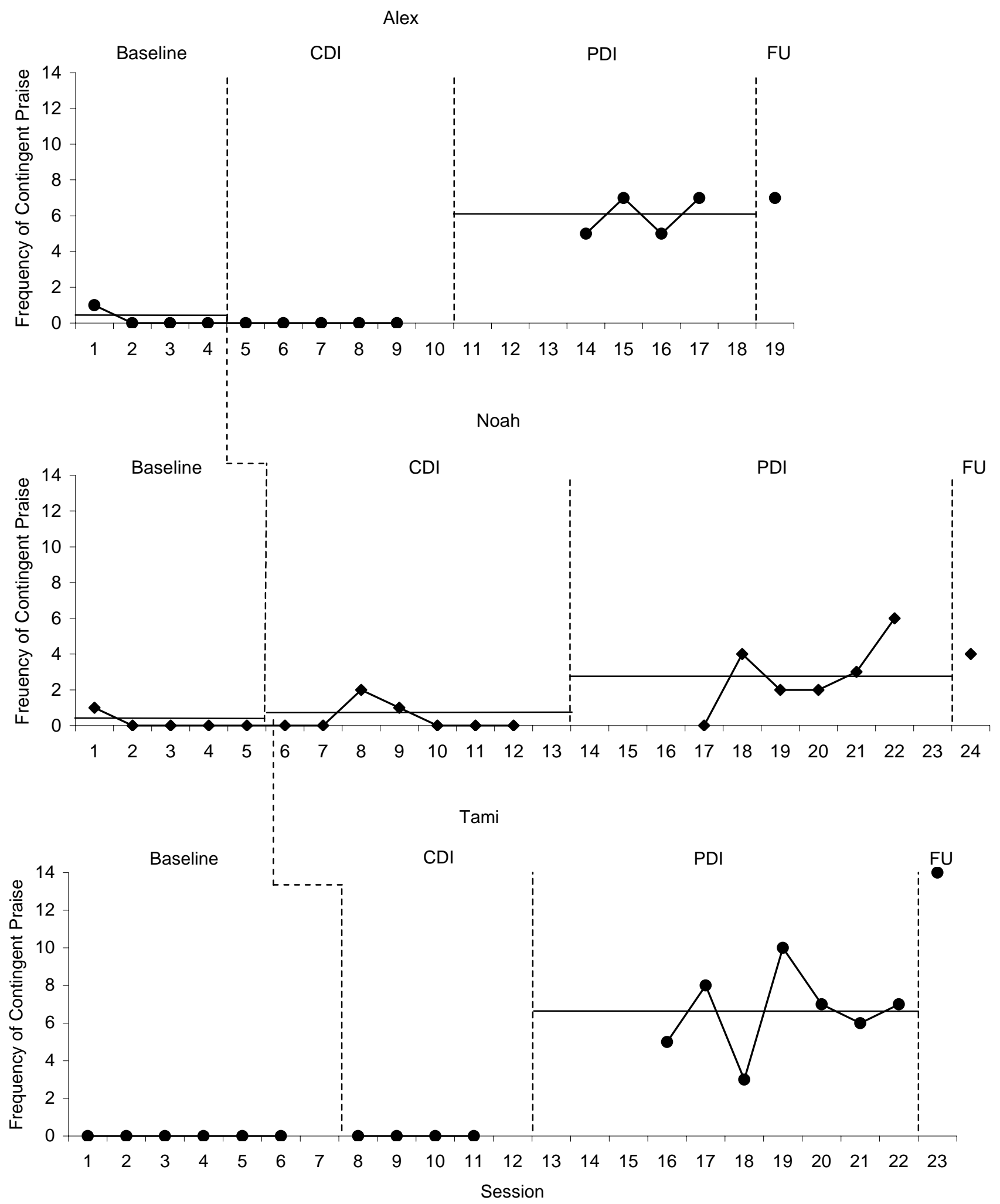

Figure 4. Contingent praise exhibited by caregivers who completed treatment with horizontal lines indicating means for each phase. 
Alex
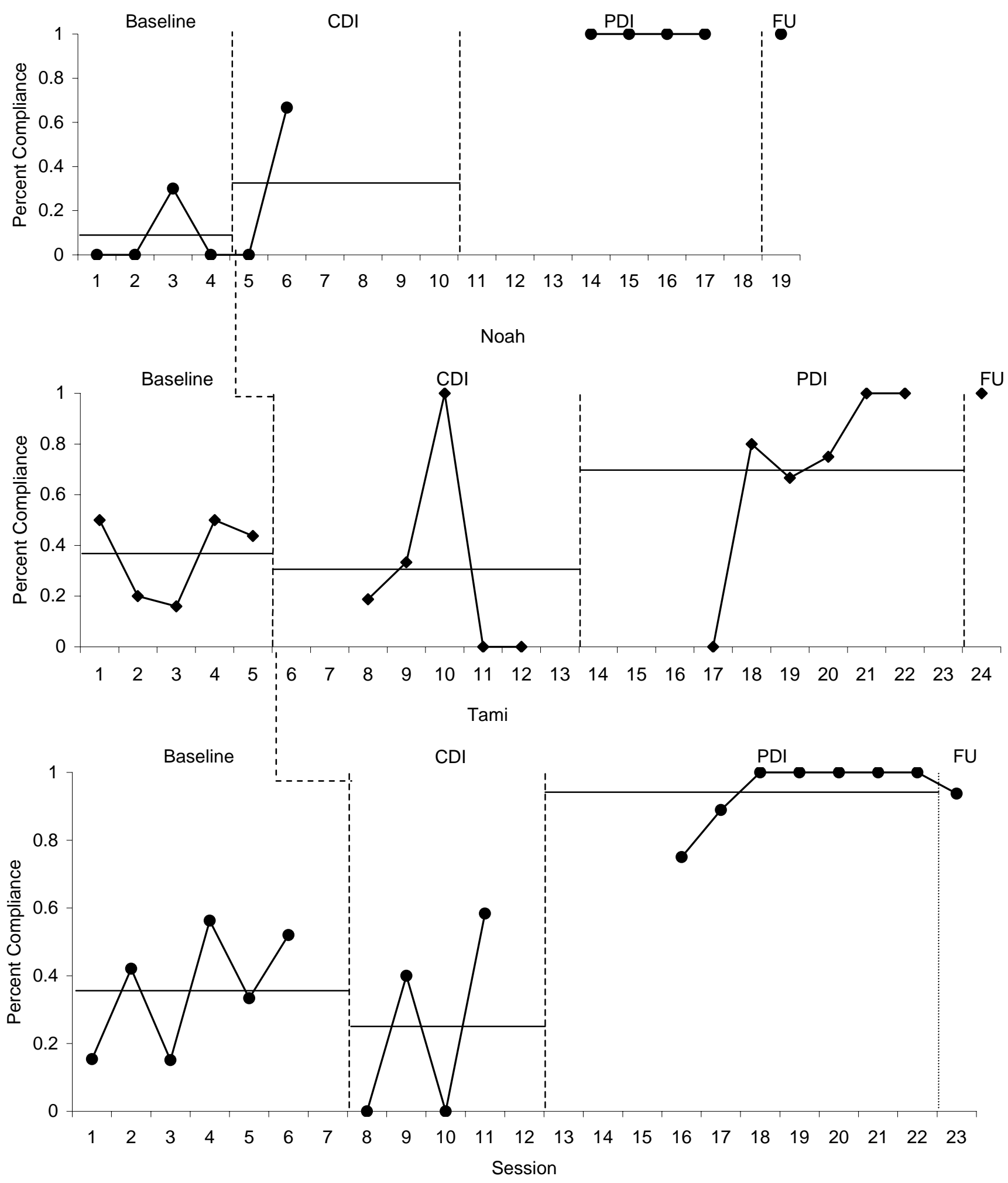

Figure 5. Child compliance rates exhibited by children who completed treatment with horizontal lines indicating means for each phase. 
Alex
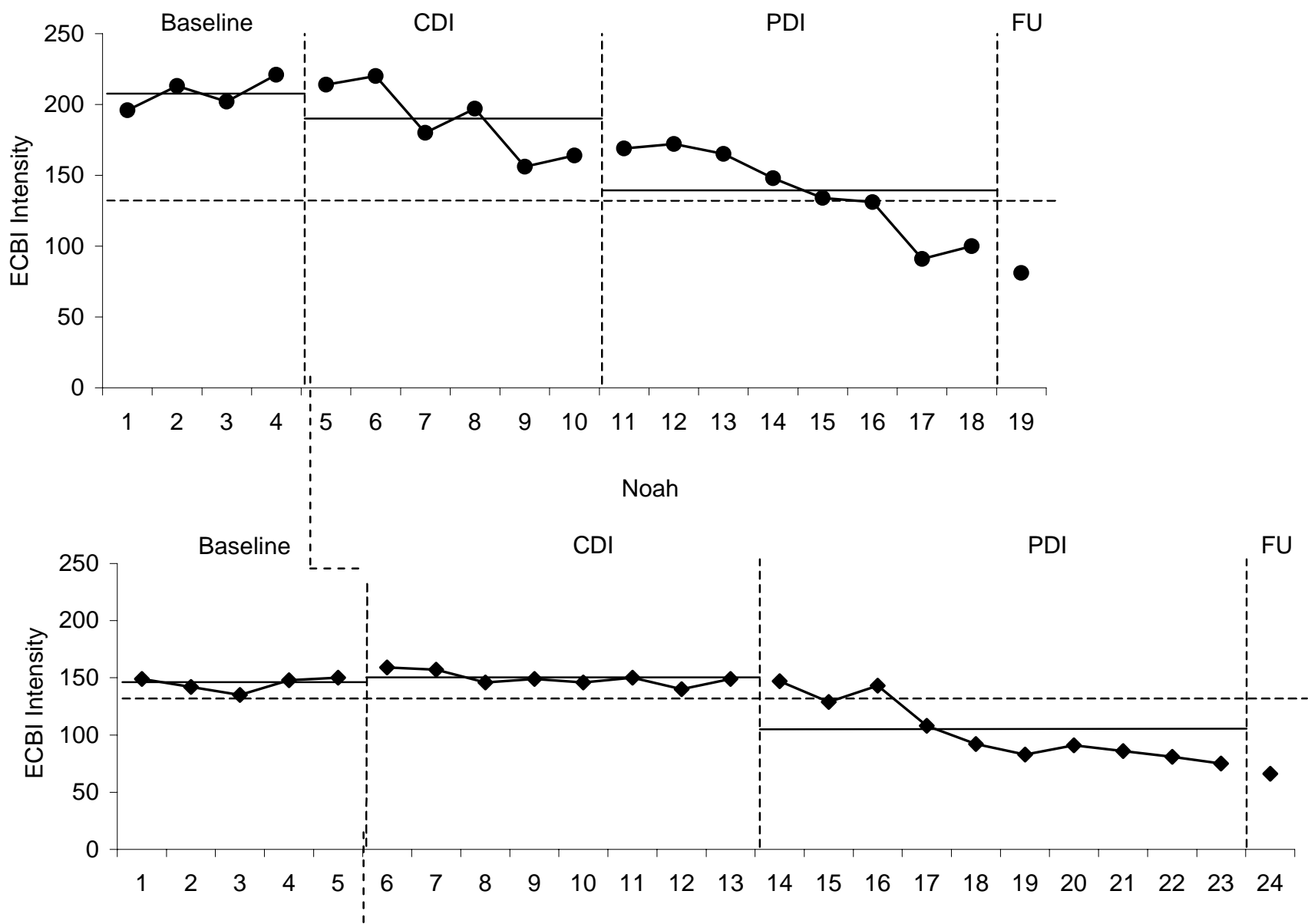

Tami

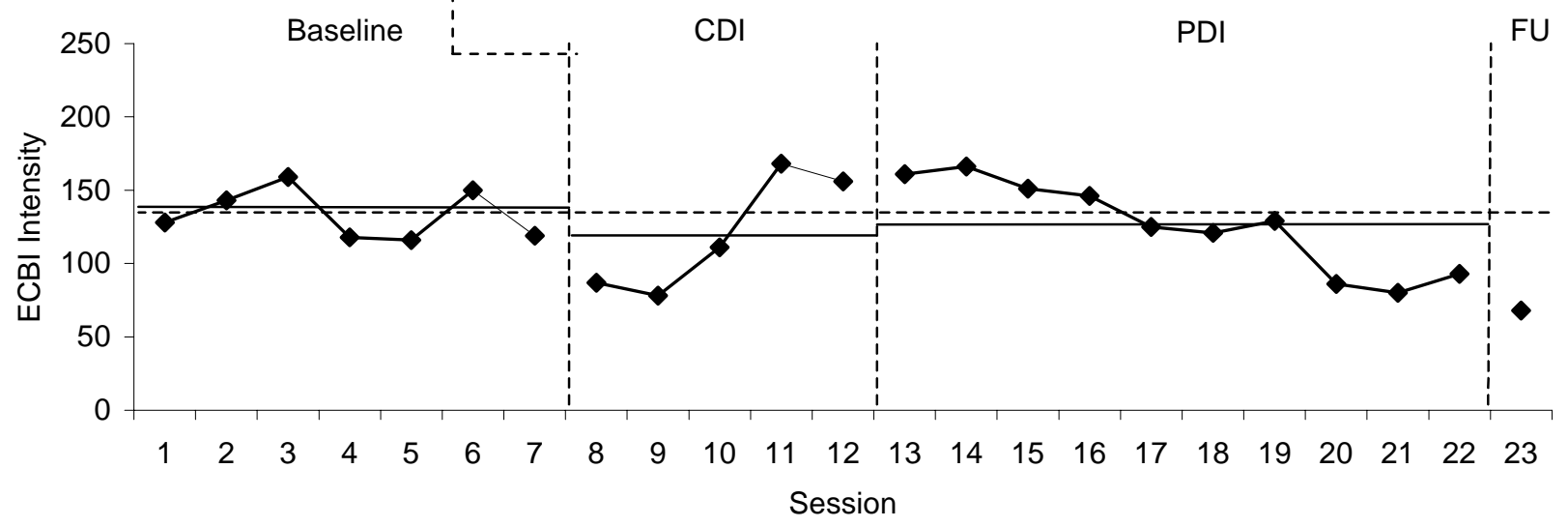

Figure 6 . ECBI Intensity scores reported by caregivers who completed treatment with horizontal lines indicating means for each phase and dashed horizontal line indicating the cutoff for clinical significance. 


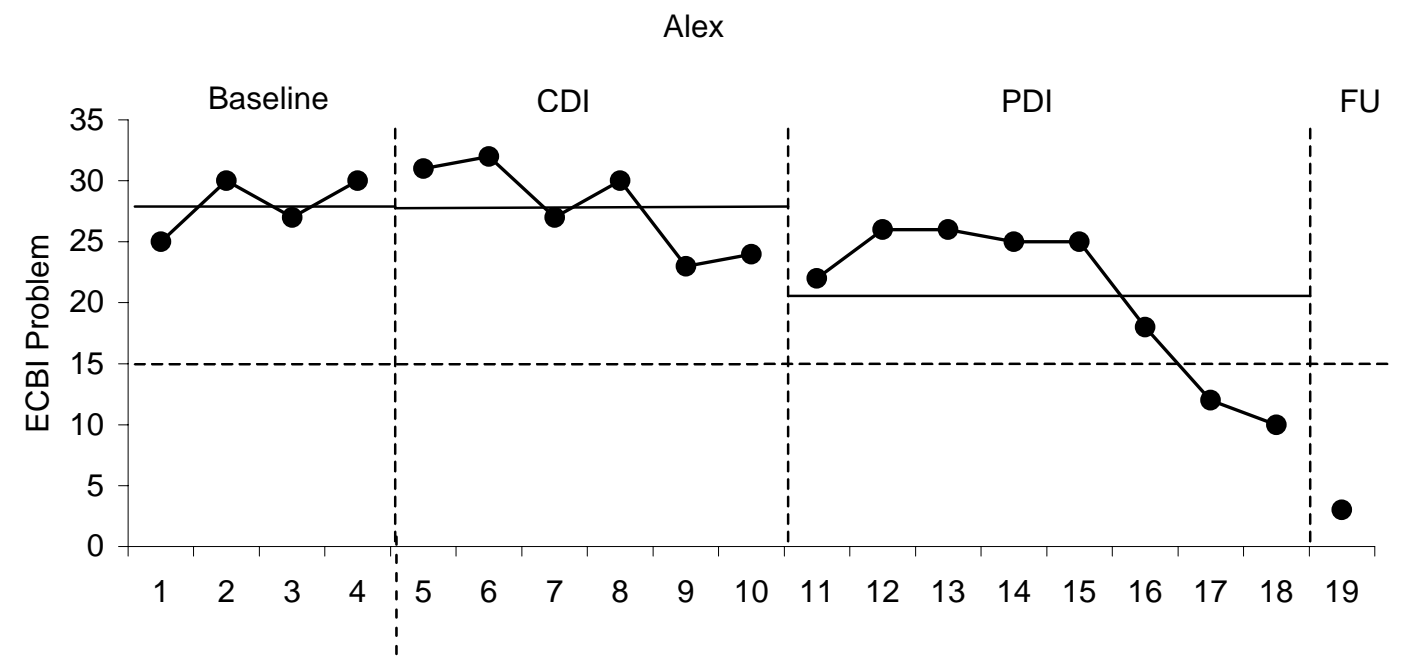

Noah
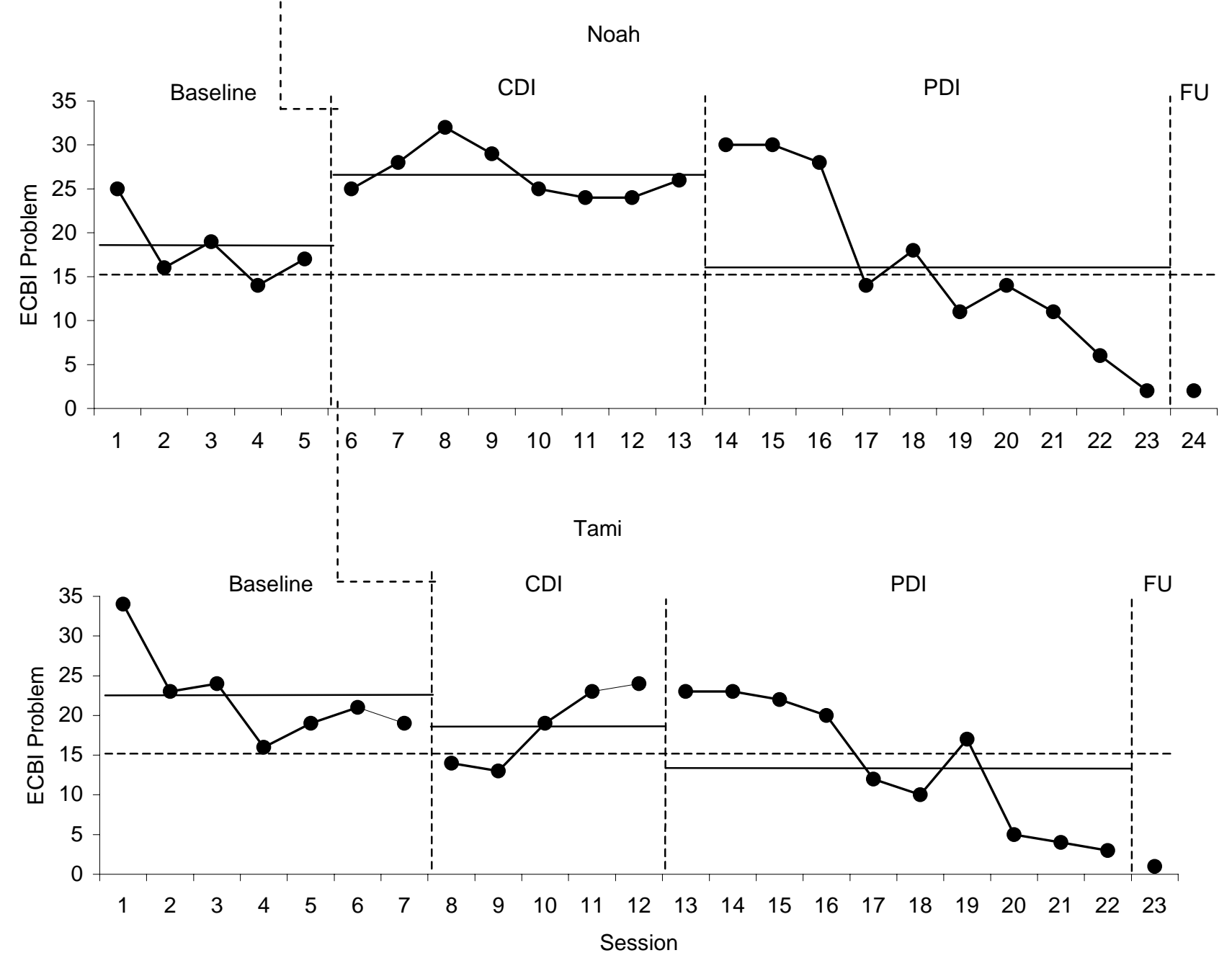

Figure 7. ECBI Problem scores reported by caregivers who completed treatment with horizontal lines indicating means for each phase and dashed horizontal line indicating the cutoff for clinical significance. 


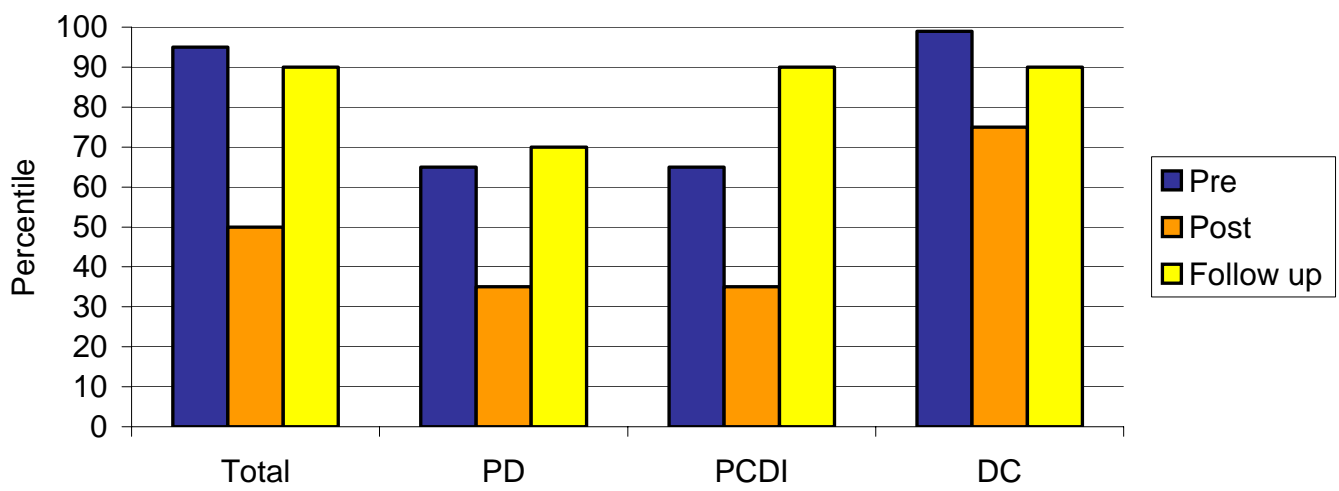

Noah

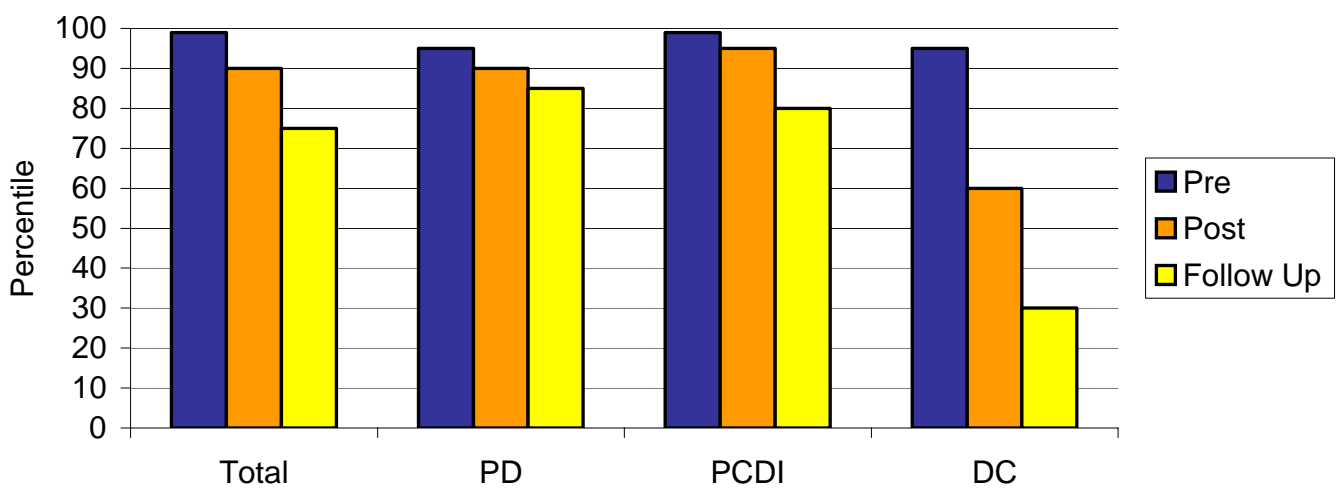

Tami

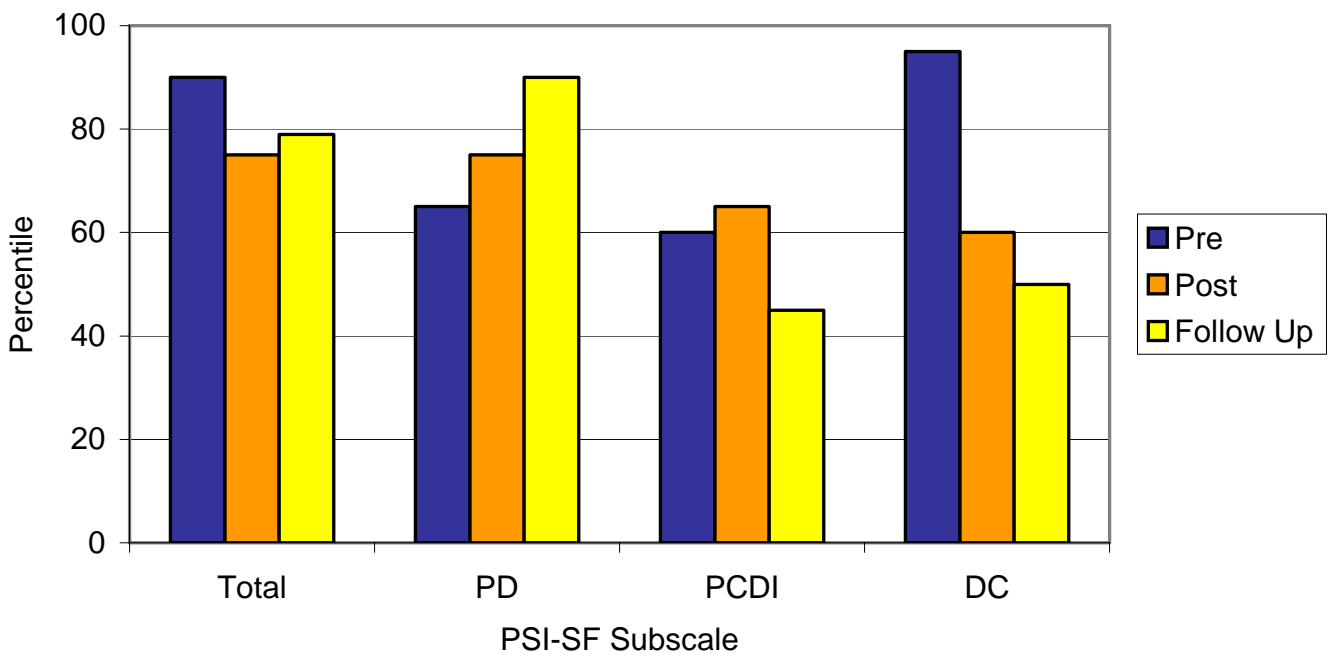

Figure 8. Bar graph of PSI-SF scores reported by caregivers who completed treatment. 
David

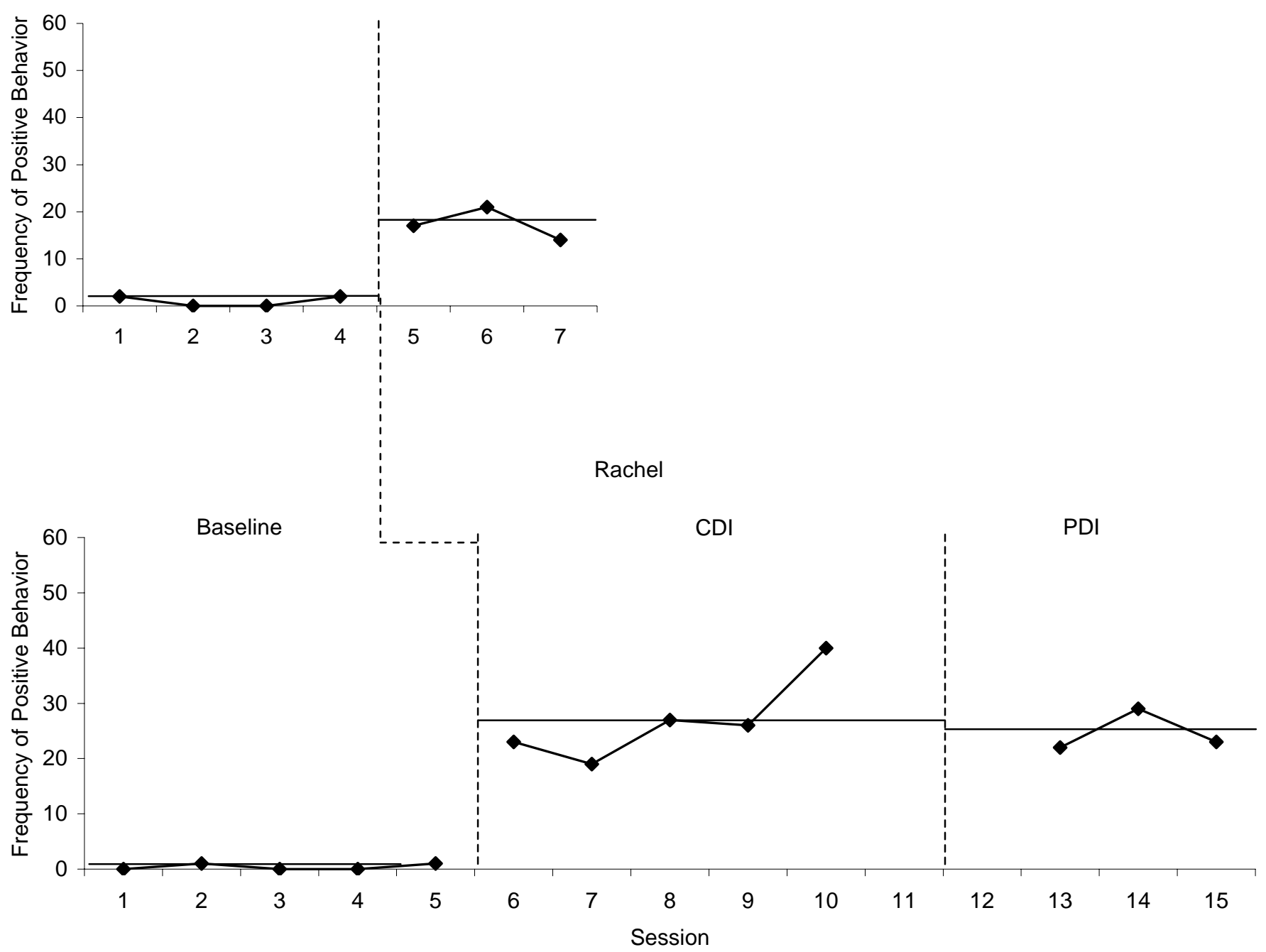

Figure 9. Caregiver positive behavior exhibited by caregivers who terminated treatment prematurely with horizontal lines indicating means for each phase. 


\section{David}

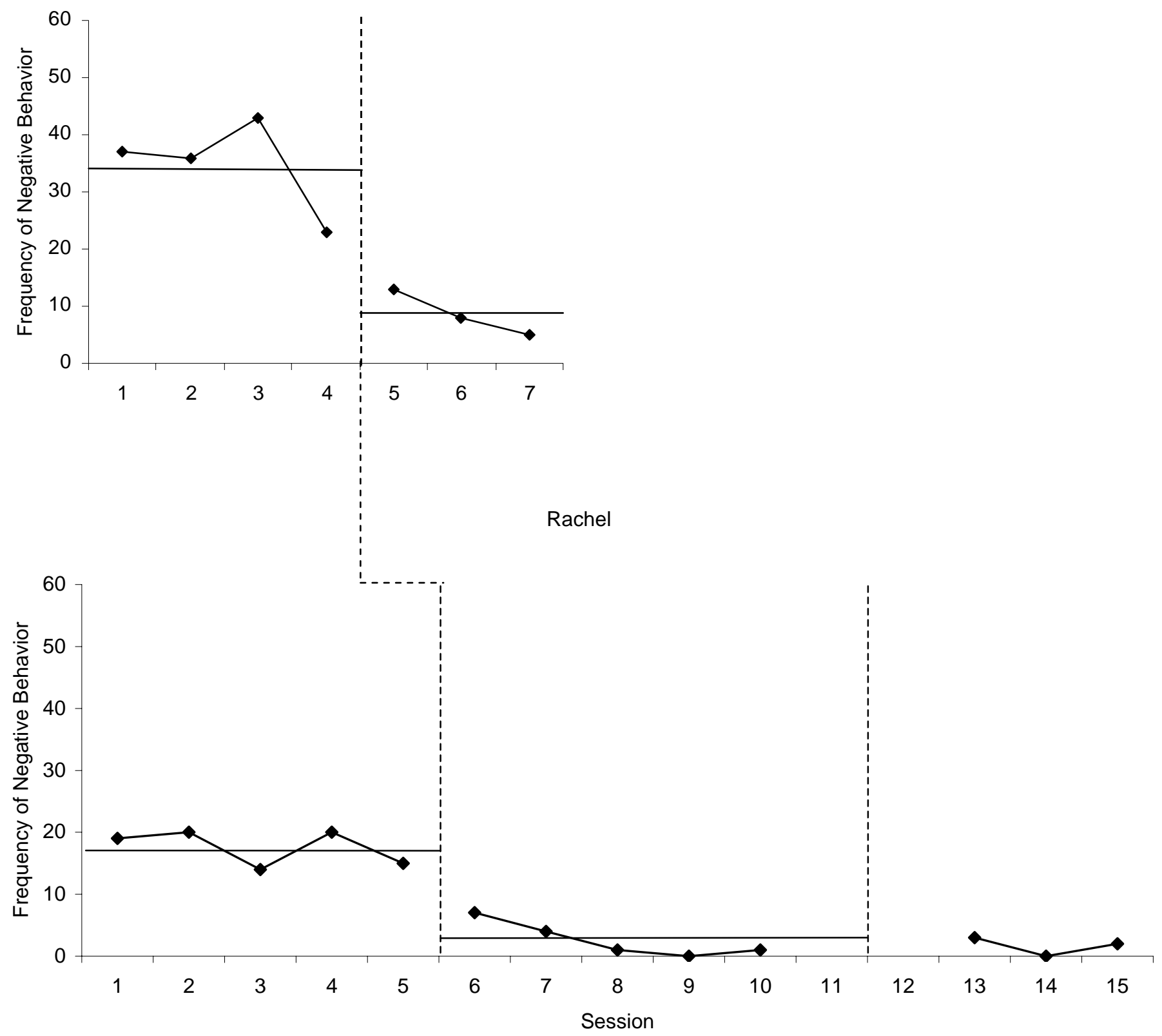

Figure 10. Caregiver negative behavior exhibited by caregivers who terminated treatment prematurely with horizontal lines indicating means for each phase. 


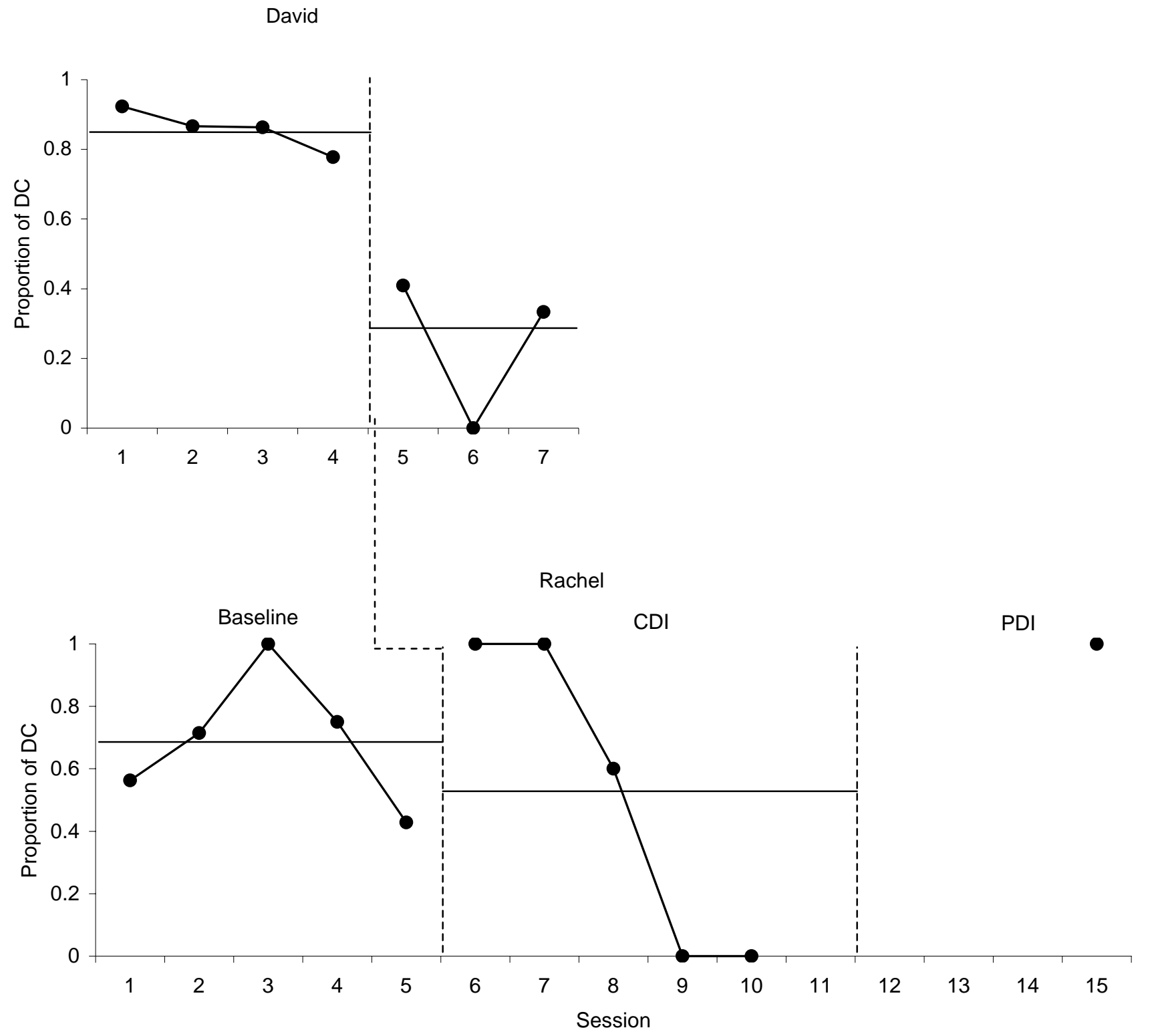

Figure 11. Proportion of direct commands exhibited by caregivers who terminated treatment prematurely with horizontal lines indicating means for each phase. 


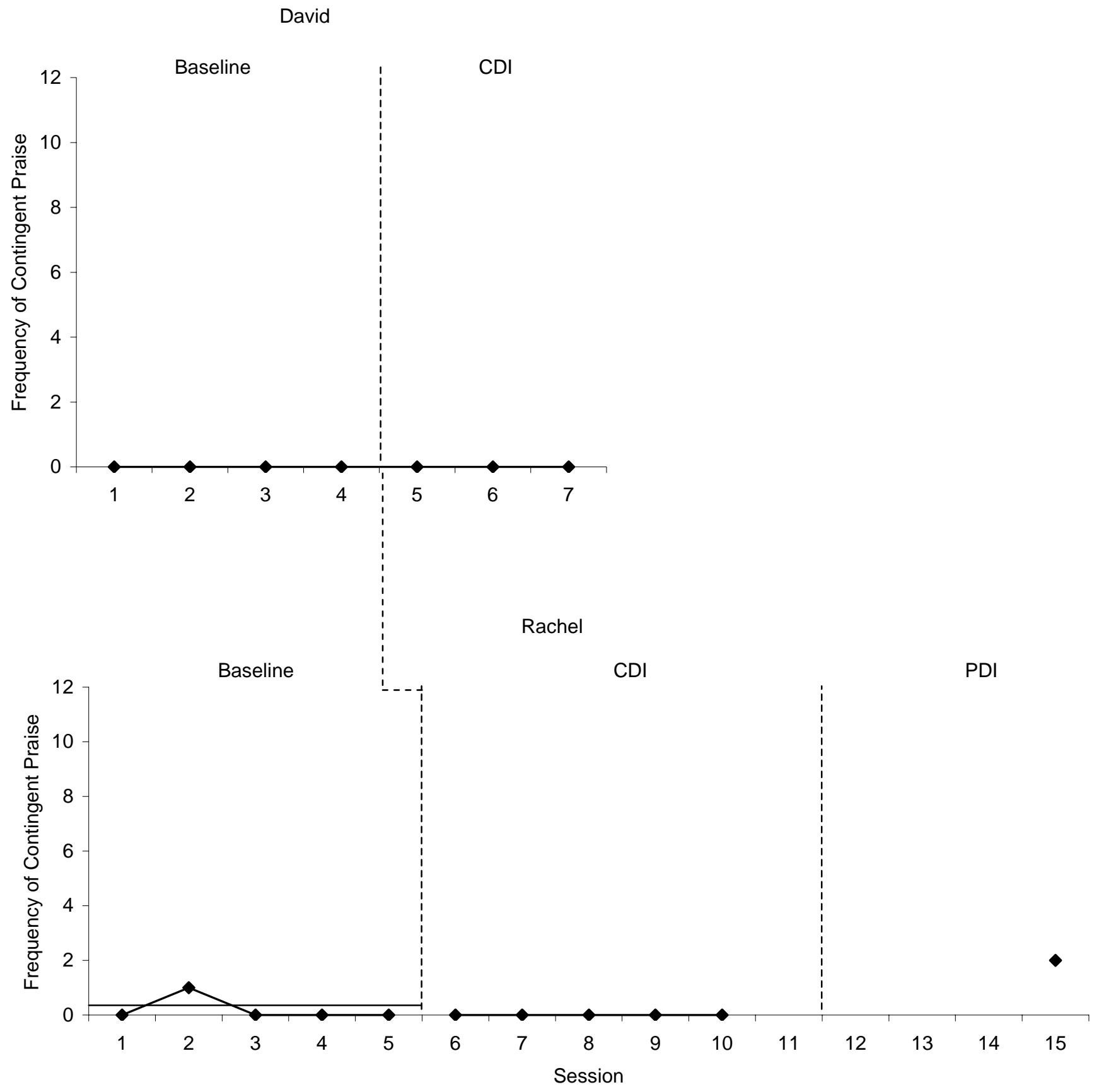

Figure 12. Contingent praise exhibited by caregivers who terminated treatment prematurely with horizontal lines indicating means for each phase. 


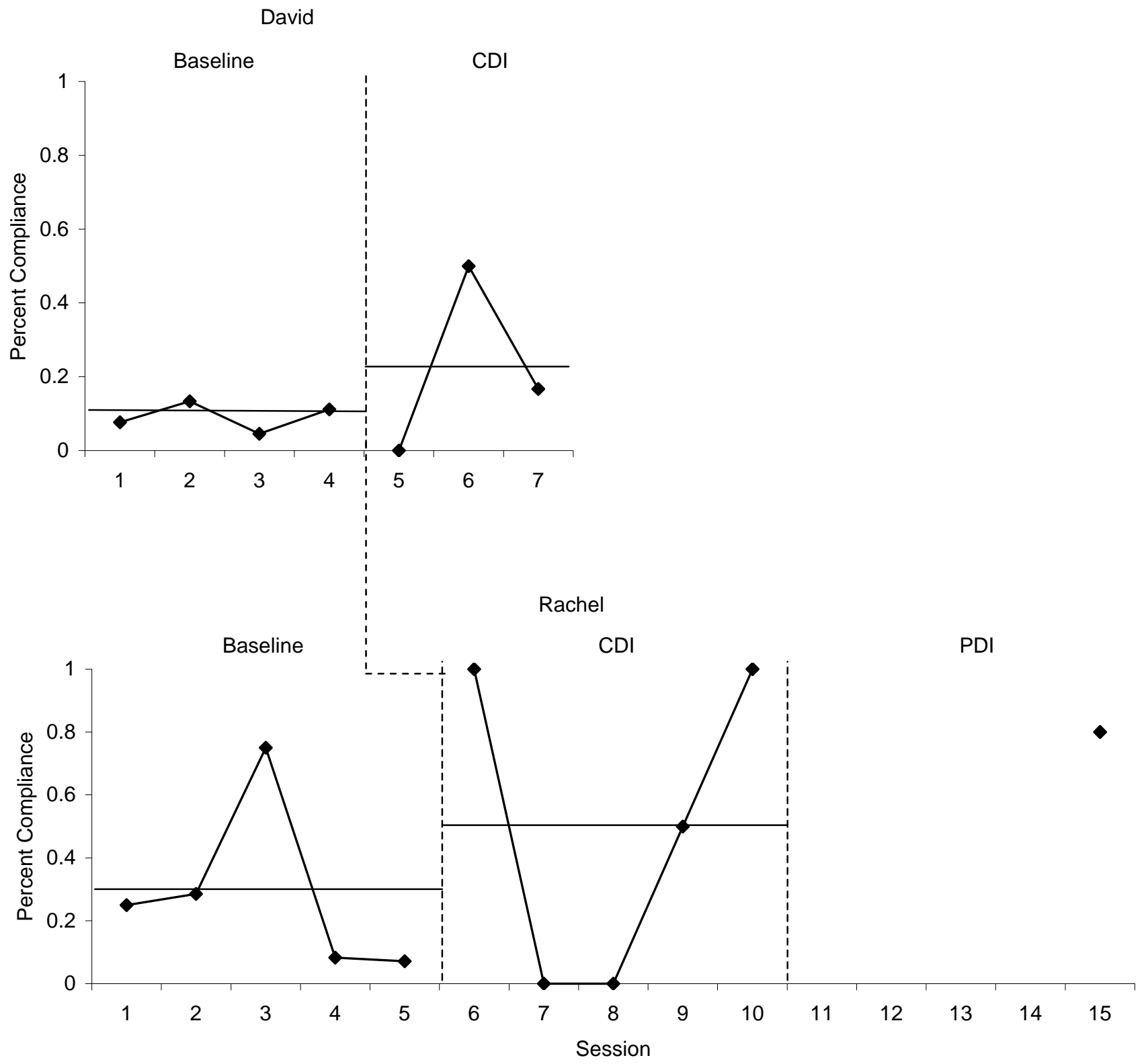

Figure 13. Child compliance rates exhibited by children who terminated treatment prematurely with horizontal lines indicating means for each phase. 


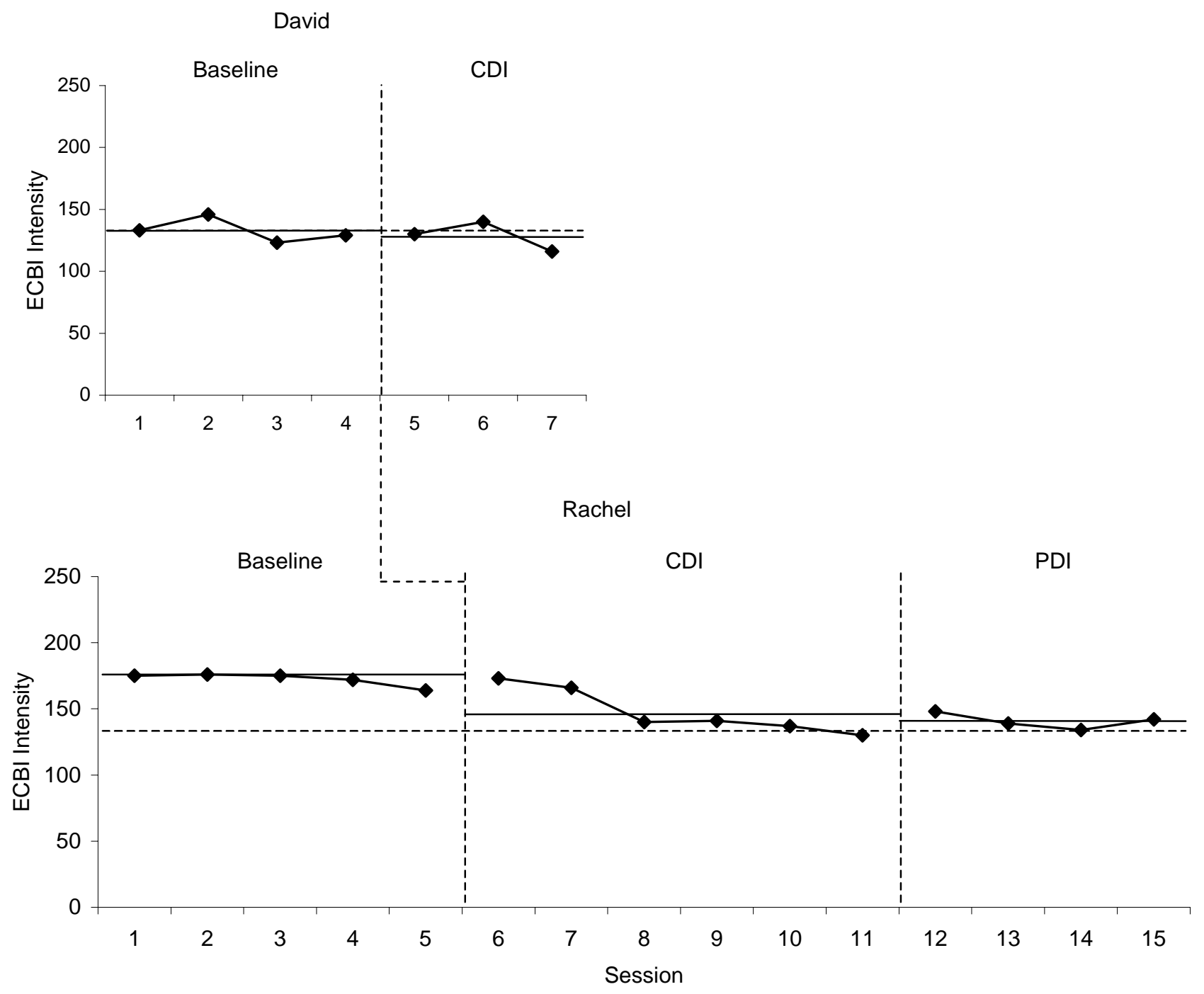

Figure 14. ECBI Intensity scores reported caregivers who terminated treatment prematurely with horizontal lines indicating means for each phase and dashed horizontal line indicating the cutoff for clinical significance. 


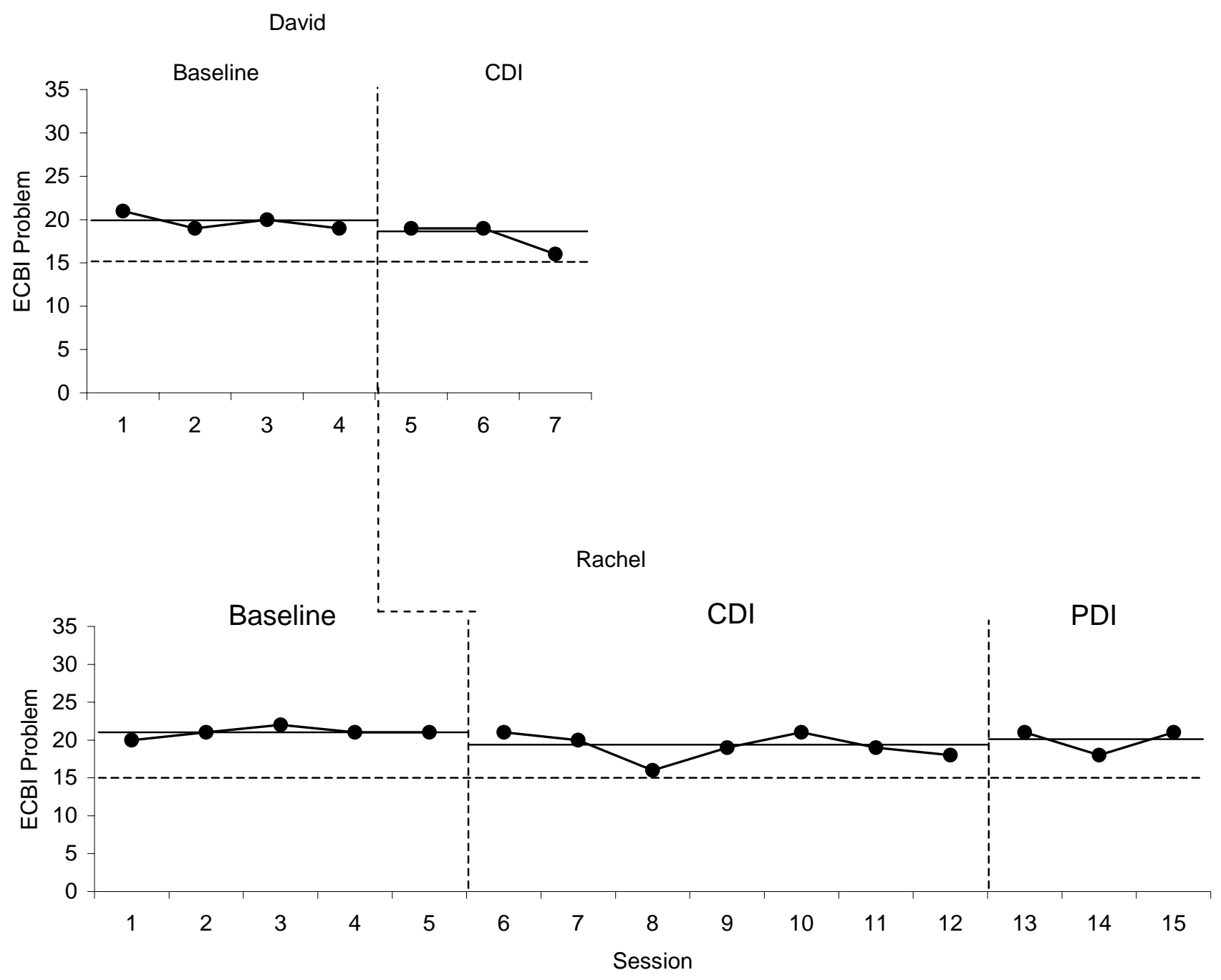

Figure 15. ECBI Problem scores reported by caregivers who terminated treatment prematurely with horizontal lines indicating means for each phase and dashed horizontal line indicating the cutoff for clinical significance. 
David

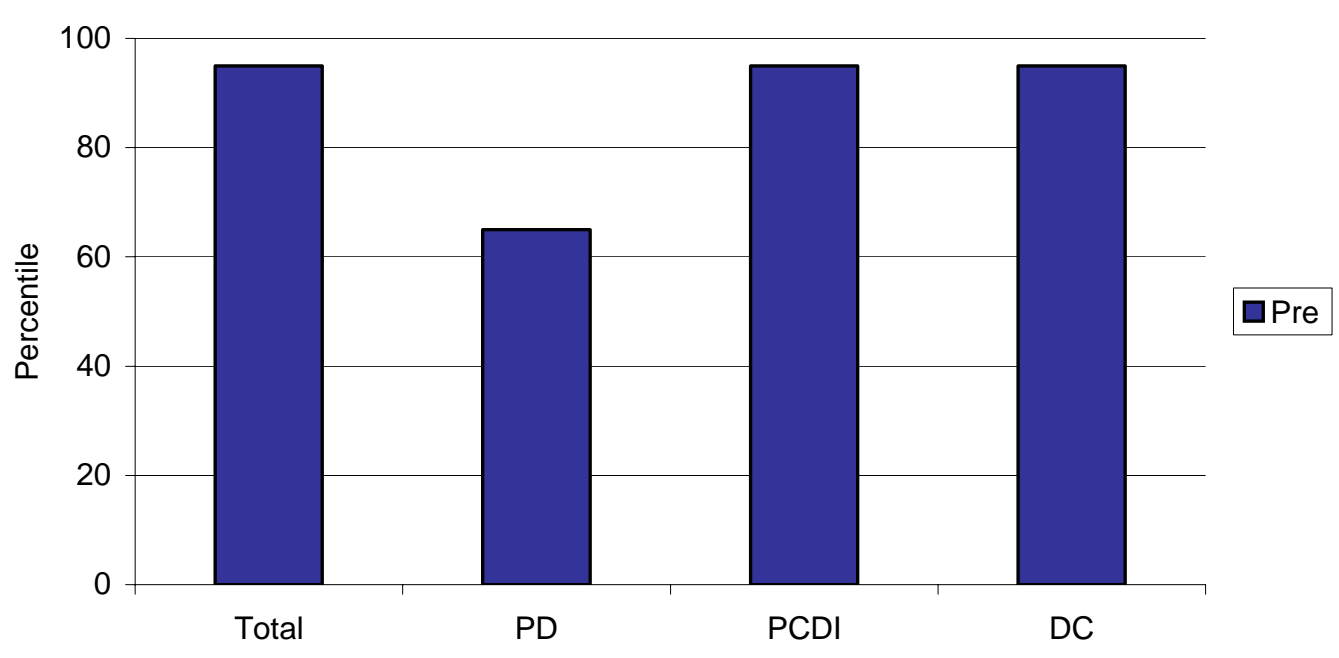

Rachel

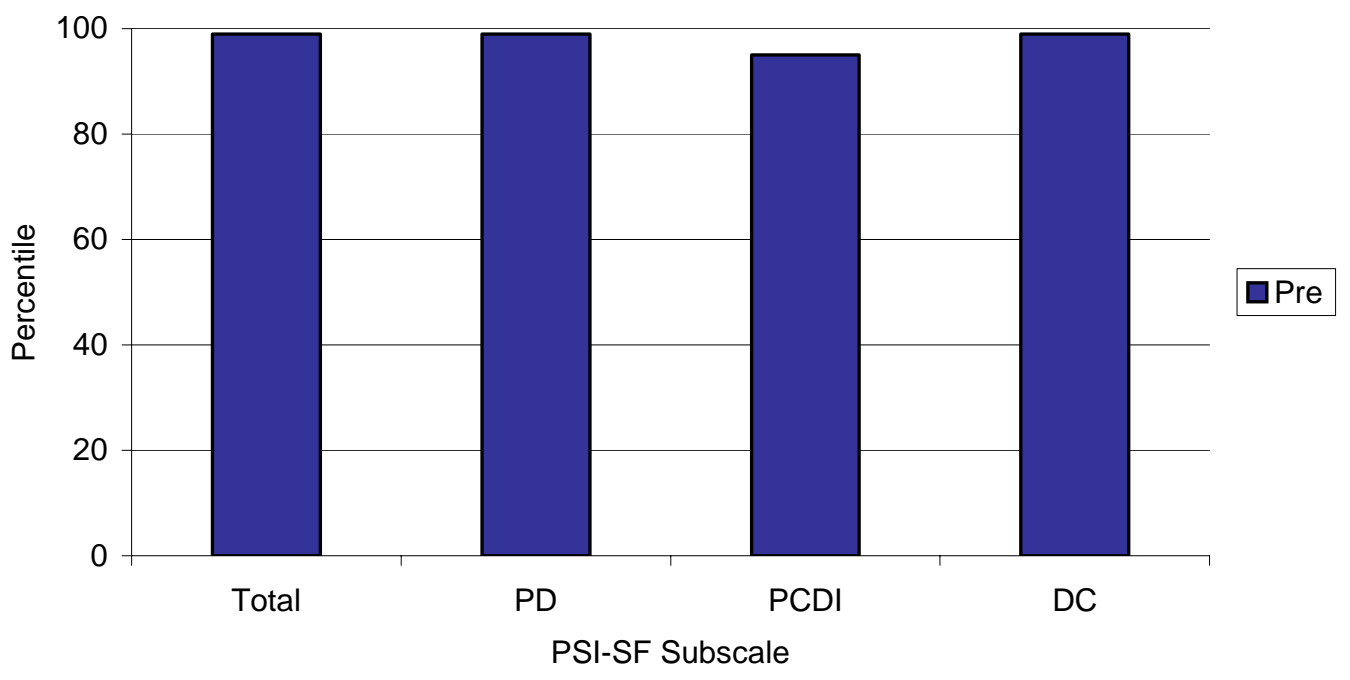

Figure 16. Bar graph of PSI-SF scores reported by caregivers who terminated treatment prematurely. 


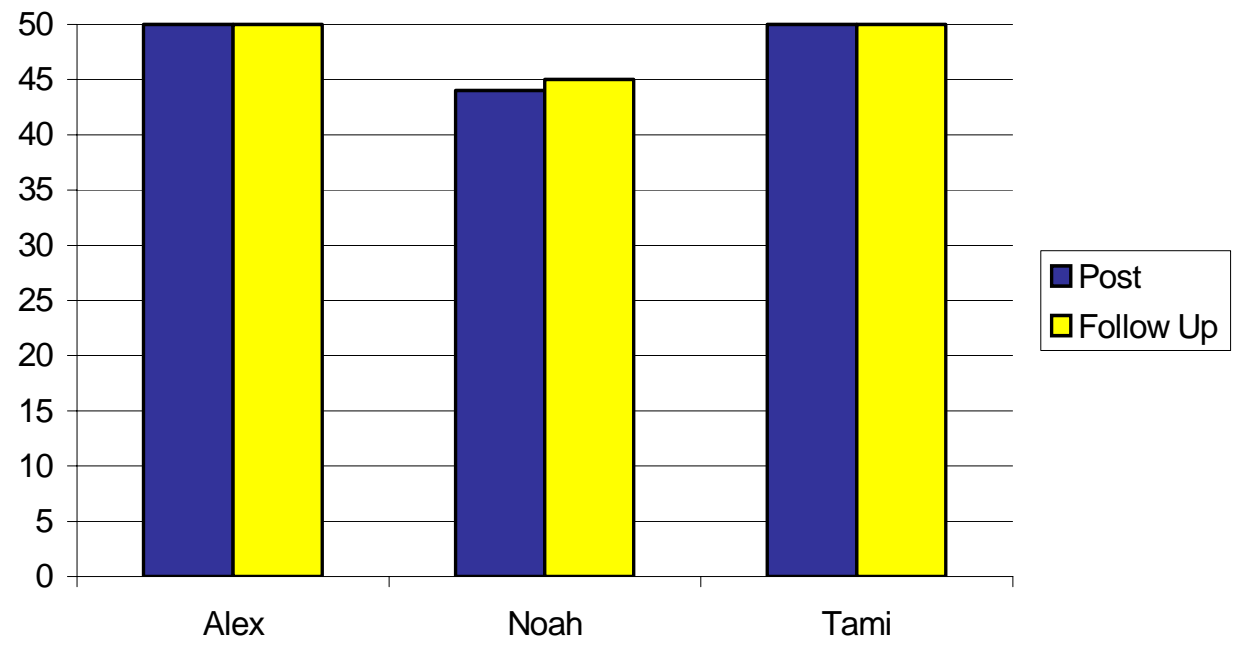

Figure 17. TAI scores reported by caregivers who completed treatment. 


\section{CURRICULUM VITA \\ Lisa M. Ware}

May 10, 2006

PERSONAL INFORMATION

Business Address

CAARE Diagnostic \& Treatment Center

UC Davis Children's Hospital

3300 Stockton Blvd.

Sacramento, CA 95820

Phone: (916) 734-4209

E-mail: lisa.ware@ucdmc.ucdavis.edu

\section{EDUCATION}

Doctorate - May 2006

West Virginia University, Morgantown, WV

Clinical Psychology

Title: Efficacy of In-Home Parent-Child Interaction Therapy

Committee Chair: Cheryl B. McNeil, Ph.D.

Master of Arts - May 2003

West Virginia University, Morgantown, WV

Clinical Psychology

Thesis: Predictors of Physical Abuse History and Abuse Potential: An Observation of Parenting Style in Mother-child Dyads Referred for Child Disruptive Behavior Problems

Committee Chair: Cheryl B. McNeil, Ph.D.

Bachelor of Arts- June 1999

University of California, Davis

Major: Psychology

Bachelor of Science- June 1999

University of California, Davis

Major: Human Development 
2003

2005

June 1999

Spring 1998

Fall 1995

RESEARCH
West Virginia University Psychology Department Alumni Fund Award for Independent Research

Recipient, Outstanding Senior at UC Davis

Dean's List, University of California, Davis
10/2004-

$06 / 2005$

$08 / 2000-$ $06 / 2003$

07/2001$06 / 2003$

08/2002$06 / 2003$

\section{Assistant Community Health Program Representative}

UC Davis Children's Hospital, CAARE Diagnostic \& Treatment Center Sacramento, California

Activities: Assist in the implementation of a research study examining the effectiveness of an in-home adjunct to Parent-Child Interaction Therapy. Conduct treatment integrity checks and assist in entering data and analyzing/interpreting data.

Supervisor: Susan Timmer, Ph.D.

\section{Graduate Research Assistant}

West Virginia University

Morgantown, West Virginia

Activities: Attended weekly research lab meetings. Reviewed current literature in the area of child behavior disorders. Assisted in the development of various research studies including the implementation of behavior modification programs in Pennsylvania Head Start classrooms.

Supervisor: Cheryl B. McNeil, Ph.D.

\section{Graduate Research Assistant}

West Virginia University

Morgantown, West Virginia

Activities: Attended weekly lab meetings. Reviewed literature in the area of malingering. Conducted study examining perceptions of hate crimes among jurors and attorneys. Conducted two studies examining the susceptibility of malingering instruments to the effects of coached malingering strategies.

Supervisor: William Fremouw, Ph.D.

\section{Graduate Research Assistant}

West Virginia University

Morgantown, West Virginia

Activities: Attended weekly lab meetings. Reviewed literature in the area of social phobia. Conducted study examining the role of risk and protective factors in predicting adult outcomes related to child maltreatment.

Supervisor: Tracy L. Morris, Ph.D. 
06/2002$08 / 2002$

08/2001$05 / 2002$

06/199809/1999

07/2005Present

10/2004$06 / 2005$

CLINICAL
Graduate Research Assistant

West Virginia University

Morgantown, West Virginia

Activities: Recruited participants for participation in a NIH grant examining social anxiety and family relationships; conducted research participant sessions which included administration and scoring of various psychosocial measures as well as videotaping a series of parent-child interactions; assisted in the development of database and conducted data entry using SPSS.

Supervisor: Tracy L. Morris, Ph.D.

Graduate Research Assistant

West Virginia University

Morgantown, West Virginia

Activities: Attended weekly lab meetings. Reviewed literature in the area of applied behavior analysis. Attended consultation meetings for parents of children with autism and developmental disabilities.

Supervisor: Cynthia Anderson, Ph.D.

Head Research Assistant, Child Protection Center, University of California, Davis Medical Center

Sacramento, California

Activities: Coded parent-child videotaped interactions using the Dyadic Parent-Child Interaction Coding System (DPICS-II); assisted in analyzing coded interactions based on sequential analysis; administered and scored various psychological measures; supervised research assistants; data entry using SPSS; conducted literature reviews; coordinated meetings; assisted in development of control group.

Supervisor: Anthony J. Urquiza, Ph.D.

Pre-Doctoral Psychology Intern

UC Davis Children's Hospital, CAARE Diagnostic \& Treatment Center Sacramento, California

Activities: Conduct intake assessments, individual therapy (including Trauma-Focused CBT), group therapy, Parent-Child Interaction Therapy, comprehensive psychological evaluations, and child welfare evaluations. Attended clinical didactics for all of the above-mentioned programs. Received clinical supervision including live supervision of clinical sessions.

Supervisors: Forrest Talley, Ph.D., Jayanthi Kasiraj, Ph.D., Georganna Sedlar, Ph.D., Kim Lundquist, LCSW, Blake Carmichael, Ph.D., Dawn Blacker, Ph.D., Nancy Zevell, Ph.D.

Assistant Community Health Program Representative UC Davis Children's Hospital, CAARE Diagnostic \& Treatment Center Sacramento, California 
Activities: Conduct in-home Parent-Child Interaction Therapy and support services consistent with a research protocol examining the effectiveness of in-home adjuncts to Parent-Child Interaction Therapy.

Supervisor: Nancy Zebell, Ph.D.

07/2002$06 / 2003$

08/2001$06 / 2003$

03/2002$12 / 2002$

08/2001$07 / 2002$

08/2000$07 / 2001$

$08 / 2000-$ $05 / 2001$
Psychological Associate

Greene County Children and Youth Services

Waynesburg, Pennsylvania

Activities: Conducted psychological evaluations, intellectual/achievement testing, and individual and family therapy, collaborated with caseworkers.

Supervisor: John Damm, Ed.D.

\section{Graduate Student Therapist}

West Virginia University

Morgantown, WV

Activities: Conducted therapy with fellow graduate students in the area of parent training related to child behavior problems.

Supervisor: Lindsey L. Cohen, Ph.D.

\section{Graduate Student Therapist}

West Virginia University

Morgantown, WV

Activities: Assisted in the development of a program for maltreating parents including the creation of a therapist manual and adjunct parent manual.

Parenting classes provided through Department of Health and Human

Resources of Morgantown, WV.

Supervisors: Lindsey L. Cohen, Ph.D. and William Fremouw, Ph.D.

\section{Graduate Student Therapist}

West Virginia University

Morgantown, WV

Activities: Conducted implosive therapy with client presenting with severe trauma history.

Supervisor: Joseph Scotti, Ph.D.

\section{Quin Curtis Center Staff Member}

West Virginia University

Morgantown, West Virginia

Activities: Assisted in administrative duties in the departmental psychology clinic for service, training, and research. Included assisting in training students in various procedures within the clinic (e.g., emergency procedures). Supervisor: Jeannie A. Sperry, Ph.D.

\section{Graduate Student Therapist}

Quin Curtis Center

West Virginia University

Morgantown, West Virginia

Activities: Participated in weekly team meetings, conducted Parent-Child Interaction Therapy with children and their families, provided psychological and educational evaluations. 
Supervisor: Cheryl B. McNeil, Ph.D.

09/1999-

$07 / 2000$

1998-1999

1997-1999

Fall 2002

Spring 2002-

Spring 2003

TEACHING
Program Assistant

University of California, Davis Medical Center, Child Protection Center Sacramento, California

Activities: Obtained information from caregivers regarding family history and prior social service intervention; transmitted information regarding case status to social workers and other professionals; scheduled appointments with children and their caregivers; completed various EPSDT contract-related forms; worked collaboratively with other Child Protection Center medical and psychology staff, foster parents, parents, county social workers and other professionals involved in child maltreatment cases.

Supervisor: Sherri Y. Terao, Ed.D.

\section{Teaching Assistant}

University of California at Davis, Center for Child and Family Studies

Davis, California

Activities: Worked in preschool program with children ages 2-4; created and implemented curriculum for preschool program; worked individually with focal child including floor time and sand tray.

Supervisor: Lynn Arner-Cross, M.A.

Crisis Line Counselor/ Teaching Assistant

Suicide Prevention Crisis Line

Sacramento, California

Activities: Trained new counselors; provided counseling and referrals based on crisis intervention model.

Supervisor: Robin Van Skike
Graduate Teaching Assistant

Abnormal Psychology (Undergraduate Course)

West Virginia University

Morgantown, West Virginia

Activities: Assisted in preparation of course syllabus; prepared lectures.

Supervisor: Cheryl B. McNeil, Ph.D.

\section{Graduate Teaching Assistant}

Behavioral and Psychological Assessment II (Graduate Course)

West Virginia University

Morgantown, West Virginia

Activities: Graded protocols for assessments administered; graded written reports; assisted in the development of assignments.

Supervisor: Lindsey L. Cohen, Ph.D. 
Activities: Delivered lectures using multimedia presentation format; supervised undergraduate tutors; monitored computer-based instructional activities and weekly quizzes; maintained grading records using SPSS.

Supervisors: Christina Adams, Ph.D., Cynthia Anderson, Ph.D., Joseph Scotti, Ph.D.

\section{Spring $2000 \quad$ Graduate Teaching Assistant}

Exceptional Children (Undergraduate Course)

West Virginia University

Morgantown, West Virginia

Activities: Delivered guest lecture; graded writing exercises, papers, and exams.

Supervisor: Cheryl B. McNeil, Ph.D.

\section{GUEST LECTURES}

$\begin{array}{ll}\mathbf{1 1 / 2 0 0 2} & \begin{array}{l}\text { Sexual Disorders and Gender Identity Disorder - Abnormal Psychology } \\ \text { (Undergraduate Course) }\end{array} \\ \mathbf{1 0 / 2 0 0 2} & \begin{array}{l}\text { Personality Disorders - Abnormal Psychology (Undergraduate Course) } \\ \text { 09/2002 }\end{array} \\ \begin{array}{l}\text { Obsessive-Compulsive Disorder - Abnormal Psychology (Undergraduate } \\ \text { Course) }\end{array} \\ \mathbf{0 8 / 2 0 0 2} & \text { The Research Endeavor - Abnormal Psychology (Undergraduate Course) } \\ \mathbf{0 4 / 2 0 0 2} & \begin{array}{l}\text { Personality Assessment Inventory - Behavioral and Psychological } \\ \text { Assessment II (Graduate Course) }\end{array} \\ \mathbf{0 2 / 2 0 0 2} & \text { Culture - Behavioral and Psychological Assessment II (Graduate Course) } \\ \mathbf{0 4 / 2 0 0 1} & \text { Gifted Children- Exceptional Children (Undergraduate Course) } \\ & \text { Mental Disorders- Introduction to Psychology (Undergraduate Course) }\end{array}$

\section{PUBLICATIONS}

Ware, L. M., Timmer, S. G., \& Urquiza, A. J. (2006). The Effectiveness of Parent Child Interaction Therapy For Victims of Interparental Violence. Submitted for publication to Journal of Family Violence.

Guriel, J., Yañez, Y. T., Fremouw, W. Shreve-Neiger, A., Ware, L., Filcheck, J., \& Farr, C. (2004). Susceptibility of the MFAST and TSI to coached malingering of post-traumatic stress disorder. Journal of Forensic Psychology Practice, 4(2), 37-56.

Ware, L.M., Fortson, B. L., \& McNeil, C. B. (2003). Parent-child Interaction Therapy: A promising intervention for abusive families. Behavior Analyst Today, 3, 375-382.

Ware, L. M., \& McNeil, C. B. (2003). Adoption. In T. H. Ollendick \& C. S. Schroeder (Eds.), The Encyclopedia of Pediatric and Child Psychology. Norwell, MA: Kluwer Academic/Plenum. 
McNeil, C. B., \& Ware, L. M. (2003). Parent training. In T. H. Ollendick \& C. S. Schroeder (Eds.), The Encyclopedia of Pediatric and Child Psychology. Norwell, MA: Kluwer Academic/Plenum.

Filcheck, H. A., McNeil, C. B., Greco, L. A., Ware, L. M., \& Bernard, R. S. (2001). Parent-Child Interaction Therapy: Can a manualized treatment be functional? Behavior Analyst Today, 2, 106-114.

\section{MANUSCRIPTS IN PREPARATION}

Blacker, D.M., Ware, L.M., Morello, A. T., \& Urquiza, A.J. (in preparation). Parental Stress Factors in Physically Abusive, Nonabusive High Risk, and Nonabusive Low Risk Parents.

Ware, L. M., Barnes, J. M., McNeil, C.B., \& Urquiza, A. J. (in preparation). The importance of parenting behaviors in the development of language: An examination of abusive and non-abusive families.

Ware, L. M., McNeil, C. B., Urquiza, A. J., Timmer, S. A., \& Filcheck, H. A. (in preparation). Observed parenting style in abusive, nonabusive high-risk, and nonabusive low-risk mothers of children with behavior problems.

\section{PRESENTATIONS}

Ware, L. M., Masse, J., Stevens, S., \& McNeil, C. B. (2006). Promise and Pitfalls of In-home Parent-child Interaction Therapy. Symposium presented at the 6th Annual Parent-Child Interaction Therapy Conference, Gainesville, FL.

Ware, L. M., Timmer, S. G., \& Urquiza, A. J. (2006). Parent-Child Interaction Therapy with Victims of Interparental Violence. Poster presented at the 6th Annual Parent-Child Interaction Therapy Conference, Gainesville, FL.

Bailey, K. A., Fortson, B. L., Tiano, J. D., Ware, L. M., \& Morris, T. L. (2005). Internalizing symptoms and substance use: Does social anxiety follow a different trend? Poster presented at the Association for Behavioral and Cognitive Therapies Annual Convention, Washington, DC.

Tiano, J. D., Humphreys, L. A., Ware, L. M., \& McNeil, C. B. (2004, November). Managing Child Disruptive Behavior in Head Start Classrooms. Poster presented at the Association for Advancement of Behavior Therapy Annual Convention, New Orleans, LA.

Bailey, K. A., Morris, T. L., Fortson, B. L., Chen, Y., Chrystan, J. A., Rork, K. E., \& Ware, L. M. (2004, November). Relationships Among Attachment, Depression, Anxiety, and Social Anxiety. Poster presented at the Association for Advancement of Behavior Therapy Annual Convention, New Orleans, LA. 
Ware, L. M., Humphreys, L. A., McNeil, C. B., Shontz, L., McCourt, G., Filcheck, H. A., Urquiza, A. J., \& Timmer, S. A. (November, 2003). Predicting Physical Abuse Status and Abuse Potential: An Observation of Maternal Behavior in a Sample Referred for Child Disruptive Behavior Problems. Poster presented at the Association for Advancement of Behavior Therapy Annual Convention, Boston, MA.

Guriel, J., Yañez, Y. T., Shreve-Neiger, A., Ware, L., Sharp, T., Farr, C., \& Fremouw, W. (2003, August). Detection of Internet-based coached malingering of schizophrenia and PTSD on the MFAST. Symposium presented at American Psychological Association annual convention, Toronto, Canada.

Ware, L. M., \& McNeil, C. B. (2003, March). Reactive Attachment Disorder and PCIT? Presented at the Quin Curtis Center Clinical Case Conference, Morgantown, WV.

Ware, L. M., Yanez, T., Tiano, J. D., VanDoran, K. E., O'Hearn-Bristol, T. (2003, February). Helpful and effective lessons in parenting. Presented at the Quin Curtis Center Clinical Case Conference, Morgantown, WV.

Barnes, J. M., Ware, L. M., Slavey, N. R., Humphreys, L. A., McNeil, C. B., Urquiza, A. J., \& Timmer, S. A. (2002, November). An Analysis of Parenting Behaviors and Child Language in Abusive and Nonabusive Families. Poster presented at the Association for Advancement of Behavior Therapy Annual Convention, Reno, NV.

Tiano, J. D., McCourt, V. M. R., Shontz, L. E., Humphreys, L. A., Fortson, B. L., Ware, L. M., \& McNeil, C. B. (November, 2002). United or divided: Sibling adoptive placements. Poster presented at the Association for Advancement of Behavior Therapy Annual Convention, Reno, NV.

Ware, L. M., \& Fortson, B. L. (2002, July). Difficulties facing school children: What can be done? An invited 2-hour continuing education workshop presented at Monongalia County School District, Morgantown, WV.

McNeil, C. B., Ware, L. M., Tiano, J. D., \& Fortson, B. L. (2002, June). Reactive Attachment Disorder and PCIT? Keynote address presented at the Parent-Child Interaction Therapy Conference, Sacramento, CA.

Ware, L. M., Barnes, J. M., Filcheck, H. A., Huphreys, L. A., Slavey, N. R., McNeil, C. B., Urquiza, A. J., \& Timmer, S. A. (2002, June). Observation of parenting behaviors in abusive and nonabusive mothers of children with behavior problems. Poster presented at the Parent-Child Interaction Therapy Conference, Sacramento, CA.

Barnes, J. M., Ware, L. M., Humphreys, L. A., Slavey, N. R., McNeil, C. B., \& Urquiza, A. J. (2002, January). The importance of parenting behaviors in the development of language: An examination of abusive and non-abusive families. Poster presented at the Eberly College of Arts and Sciences Research Horizons conference, Morgantown, WV.

Barnes, J. M., Ware, L. M., McNeil, C. B., \& Urquiza, A. J. (2001, November). The importance of parenting behaviors in the development of language: An examination of abusive and non-abusive families. Poster presented at the Association for Advancement of Behavior Therapy Annual Convention, Philadelphia, PA. 
Ware, L. M. (2001, October). Psychology: Science for the $21^{\text {st }}$ century. Presented as part of the American Psychological Association's Exploring Behavior Week, Westwood Middle School, Morgantown, WV.

Ware, L. M., McClellan, C. B., \& McNeil, C. B. (2001, October). Modifications in Parent-Child Interaction Therapy: A less than typical case presentation. Presented at the Quin Curtis Center Clinical Case Conference, Morgantown, WV.

Ware, L. M., McClellan, C. B., \& McNeil, C. B. (2001, June). Munchausen Syndrome by Proxy: A literature review and clinical case presentation of a mother's intentional production of her child's psychiatric illness. Poster presented at the meeting of the American Professional Society on the Abuse of Children, Washington, DC.

Filcheck, H. A., McNeil, C. B., Greco, L. A., Ware, L. M., \& Bernard, R. S. (2001, June). Parent-Child Interaction Therapy: Can a manualized treatment be functional? Poster presented at the Parent-Child Interaction Therapy Conference, Sacramento, CA.

McNeil, C. B., Vincent, J. D., \& Ware, L. M. (2001, June). Parent-Child Interaction Therapy: Masters video demonstration. Paper presented at the Parent-Child Interaction Therapy Conference, Sacramento, CA.

Ware, L. M., McClellan, C. B., Vincent, J. D., Triplett, H., \& McNeil, C. B. (2001, June). Assessment guiding treatment in Parent Child Interaction Therapy: A clinical case presentation of oppositional defiant disorder with pervasive developmental disorder not otherwise specified. Poster presented the 2nd Annual Parent-Child Interaction Therapy Conference, Sacramento, CA.

Lee, K., Herschell, A., Blacker, D., Dobbins, C., Ghosh Ippen, C., Linscomb, M., Ware, L., \& Zebell, N. (2001, June). Clever clinical explanations for PCIT concepts: A collaboration between CARE Santa Rosa and CAARE Sacramento. Poster presented at the ParentChild Interaction Therapy conference, Sacramento, CA.

Vincent, J. D., Filcheck, H. A., Ware, L. M. (2001, April). A PCIT-based approach to behavior management in preschool settings. A two-hour workshop presented to Head Start staff in Howesville, WV.

McNeil, C. B., Filcheck, H. A., Herschell, A. D., \& Ware, L. M. (July 24-28, 2000). Parent-Child Interaction Therapy: A 5-day workshop presented for the Department of Child and Adolescent Psychiatry, Columbia University, New York City, NY.

Blacker, D. M., Ware, L. M., Morello, A. T., Singh, S. K., Borrego, Jr., J., \& Urquiza, A. J. (2000, April). Physically abusive, nonabusive high-risk and nonabusive low-risk parents: $A$ comparison of distress, depression, and social isolation. Poster presented at the 80th Annual Convention of the Western Psychological Association, Portland, OR.

Blacker, D. M., Whitney, L. M., Morello, A., Reed, K., \& Urquiza, A. J. (1999, June). Depression, Distress, and Social Isolation in Physically Abusive and Nonabusive Parents. Poster presented at the $7^{\text {th }}$ Annual Colloquium for the American Professional Society on the Abuse of Children, San Antonio, TX. 
Borrego, Jr., J., Whitney, L. M., \& Urquiza, A. J. (1999, June). A sequential analysis of abusive parents' negative behaviors in response to child noncompliance. Poster presented at the $7^{\text {th }}$ Annual Colloquium for the American Professional Society on the Abuse of Children, San Antonio, TX.

Borrego, Jr., J., Whitney, L. M., \& Urquiza, A. J. (1999, June). Patterns of reinforcement between high- and low- abuse potential mothers. Poster presented at the $7^{\text {th }}$ Annual Colloquium for the American Professional Society on the Abuse of Children, San Antonio, TX.

Borrego Jr., J., Vargas, E.C., Cervantes, G., Flores, E.A., Whitney, L. M., \& Urquiza, A.J. (1999, June). Parent-child Interaction Therapy with a Hispanic family. Poster presented at the $7^{\text {th }}$ Annual Colloquium for the American Professional Society on the Abuse of Children, San Antonio, TX.

Terao, S. Y., \& Whitney, L. M. (1999, June). Methodological issues related to violence in the community. In A. J. Urquiza and J. Borrego Jr.'s Violence, Parenting, and Treatment: Differentiating Cultural Characteristics. Paper presented at the $7^{\text {th }}$ Annual Colloquium for the American Professional Society on the Abuse of Children, San Antonio, TX.

Borrego, Jr., J., Whitney, L. M., Golladay, B., Flores, E. A., \& Scott, K. (1999, May). In J. Borrego Jr., (Chairperson), Preparing and Training Undergraduate Research Assistants for Graduate School. Panel discussion presented at the $79^{\text {th }}$ Annual Convention of the Western Psychological Association, Irvine, CA.

Borrego, Jr., J., Whitney, L. M., Golladay, B., Morello, A., Reed, K., \& Urquiza, A. J. (1999, May). Compliance $\rightarrow$ Reinforcement Patterns Between High- and Low- Abuse Potential Mothers. Poster presented at the $79^{\text {th }}$ Annual Convention of the Western Psychological Association, Irvine, CA.

Borrego, Jr., J., Whitney, L. M., Golladay, B., \& Urquiza, A. J. (1999, May). Physically Abusive Parents' Negative Responses to Child Noncompliance. Poster presented at the $79^{\text {th }}$ Annual Convention of the Western Psychological Association, Irvine, CA.

\section{GRADUATE ACADEMIC HONORS AND AWARDS}

HERF Award (\$2000 awarded during first year)

Scholarship award for $7^{\text {th }}$ International Family Violence Research Conference in Portsmouth, $\mathrm{NH}(\$ 150)$

\section{GRANT WRITING}

Submitted Title: Childhood Obesity Prevention in Rural West Virginia: Evaluation of a program targeting dietary intake and physical activity to: Claude Worthington Benedum Foundation

Amount of funding requested: $\$ 71,206$

Status: Not funded

Principal Investigator: Jeannie A. Sperry, Ph.D.

Grant Writers: Jeannie Sperry, Ph.D., Rebecca Bernard, Kevin Del Ben, Cara O'Connell, Lisa Ware, John Spiker 


\section{DEPARTMENTAL COMMITTEE MEMBERSHIP}

2000-2001 Student Representative, Quin Curtis Center Steering Committee

2001-2002 Student Representative, Faculty Evaluation Committee

2001-2002 Student Representative, Alumni Newsletter Committee

2002-2003 Student Representative, Child Clinical Training Committee

\section{SUPERVISION ACTIVITIES}

Undergraduate Honors Thesis Students

Jill A. Barnes (Spring 2000, Fall 2001)

Undergraduate Research Assistants

Jill Barnes (Fall 2000, Spring 2001, Fall 2001, Spring 2002)

Shannon Bond (Fall 2001)

Mariya Borodonskaya (Winter 2004, Spring 2005)

Lisa Humphreys (Fall 2001, Spring 2002, Fall 2002, Spring 2003)

Chris Luzier (Fall 2000, Spring 2001)

Gini McCourt (Fall 2002)

Lauren Shontz (Fall 2002, Spring 2003)

Nicole Slavey (Fall 2001, Spring 2002)

Helena Triplett (Fall 2000, Spring 2001)

Andrea Valenti (Fall 2000, Spring 2001)

Undergraduate Teaching Assistants

Jill A. Barnes (Spring, 2001)

Lisa A. Humphreys (Fall, 2002)

ACADEMIC REVIEWING

2001, 2002 Abstract review for American Psychological Association Division 12 convention program

2002 Article review for Journal of Clinical Child and Adolescent Psychology

$2002 \quad$ Article review for Education and Treatment of Children

$2003 \quad$ Article review for Cognitive and Behavioral Practice

$2003 \quad$ Article review for Journal of Consulting and Clinical Psychology

2005 Article review for Child Abuse and Neglect

PROFESSIONAL AFFILIATIONS

Association for Behavioral and Cognitive Therapies, student member

Child Maltreatment and Interpersonal Violence Special Interest Group (SIG)

Parenting and Families SIG 
American Psychological Association, student member

APAGS Member

Division 37 - Child, Youth, and Family Services

Section 1 - Section on Child Maltreatment

Division 53 - Society of Clinical Child and Adolescent Psychology

American Professional Society on the Abuse of Children, student member

\section{REFERENCES}

Cheryl B. McNeil, Ph.D.

West Virginia University

Department of Psychology

PO Box 6040

Morgantown, WV 26506-6040

(304) 293-2001, extension 31677 (phone)

(304) 293-6606 (fax)

cmcneil@wvu.edu (email)
Forrest Talley, Ph.D.

UC Davis Children's Hospital

CAARE Center

3300 Stockton Blvd.

Sacramento, CA 95820

(916) 734-3185 (phone)

(916) 734-6652 (fax)

forrest.talley@ucdmc.ucdavis.edu (email)

Georganna Sedlar, Ph.D.

UC Davis Children's Hospital

CAARE Center

3300 Stockton Blvd.

Sacramento, CA 95820

(916) 734-6626 (phone)

(916) 734-6652 (fax)

georganna.sedlar@ucdmc.ucdavis.edu (email) 